\title{
Environmental counter-narratives of Mapuche and Māori primary school children
}

\section{Katia Ximena Guiloff Titiun}

A thesis submitted to Victoria University of Wellington in fulfilment of requirements for the degree of

Master of Environmental Studies

School of Geography, Environment and Earth Sciences

Victoria University of Wellington

2018 


\begin{abstract}
Scholars working from decolonial perspectives examine how processes of colonisation have marginalised local and contextualised knowledges in favour of dominant, usually Western, monological claims to 'Truth'. These monological truths are characterised by binaries of separation such as nature/culture, adult/child and human/environment which subjugate non-binary ways of knowing. Around the world, children's, and particularly indigenous children's, environmental knowledges are rendered incomplete and non-scientific within processes of State-sanctioned monocultural formal education. Decolonial scholars argue that this subjugation lies at the heart of humans' destructive ecological practices and the current crisis of sustainability.

In this thesis I explore the environmental narratives of two groups of indigenous primary school children in Chile and Aotearoa New Zealand in an effort to contribute to decolonial research and explore counter-narratives. I use a Critical Pedagogies of Place analytical lens to understand how concepts of cultural decolonisation and ecological reinhabitation were represented within the children's audio-visual environmental narratives and consider how these counter-narratives may help us to practice more creative and inclusive 'border thinking' to address environmental problems.
\end{abstract}

\title{
Keywords
}

Environment, narratives, indigenous, decolonial, decolonisng, critical pedagogies of place, Mapuche, Māori 


\section{Acknowledgements}

My deepest gratitude goes to the children who participated in this research project. The eight of you generously shared your time, knowledges and imagination and taught me about the importance of being a poyenche (a warm and loving person) and of nurturing whanaungatanga (connectedness). Chageltumay and ngā mihi mahana ki a koutou.

To Roberto, Bianca and the parents who opened their doors to this project and often to sharing meaningful conversations, mate and tea with me, thank you. I am especially grateful to the Contreras-Calfuqueo family in Llaguepulli who took me into their home, suffered through my strange vegetarian cooking and provided so many opportunities to learn and laugh. Also to Nadia, for the time shared in the ruka, her help with Mapuche words and concepts and her hospitality and friendship. I am looking forward to visiting Llaguepulli again and going for sunset walks with many dogs by the lake.

To my supervisors, Drs. Sara Kindon and Hiria McRae, for your enduring faith and trust in me and this project, for your patient and attentive feedback and your compassion. I could not have finished this without your support.

To my mother Fanny, I am very grateful for your continuous interest in a topic that is somewhat foreign to you and for your encouragement through this journey.

I am grateful to my flatmates for providing nurturing meals and for being patient with my days of frustration. Also to my friends and my Chilean whānau here in Wellington who have provided advice and spaces to talk about this project and spaces to disconnect from it and re-connect with other joys of life. Especially to my friend Marcela, thank you for your support, interest and compassion, and for opening so many doors to new relationships which have made this research possible. Also thank you for always knocking on my door and checking in, I consider myself lucky to have had such a luminous being beside me over the last couple of years iGracias mil!

Finally to my partner Jamie, for the never-ending availability of oats in the morning and for the persistent lightness and good humour you bring into my life. Especially for 
your openness to exploring new ideas and ways of being in the world with me, and for your openness to embarking on this exciting new adventure of being parents together. Ngā mihi nunui ki a koe tāku tane mahana, ka nui tāku aroha mōu ki a koe.

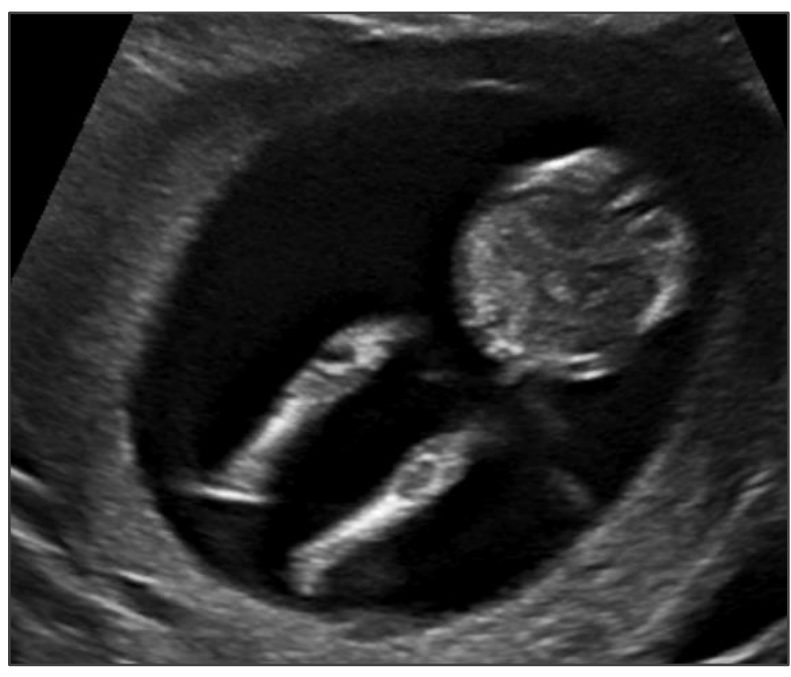

Last but not least, to the littlest one of them all, this baby who has been growing inside and with me over the last eight months. You have already taught me so much patience and brought in such a clear perspective of what is important and valuable.

I hope this research is one more seed for a world in which you can keep on growing through caring relationships. I am looking forward to holding you in my arms. 


\section{Contents}

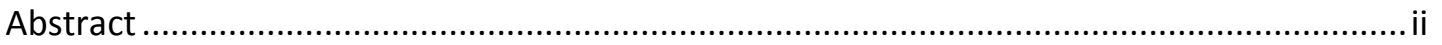

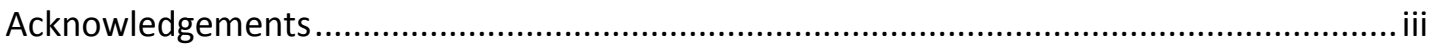

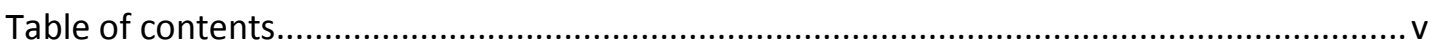

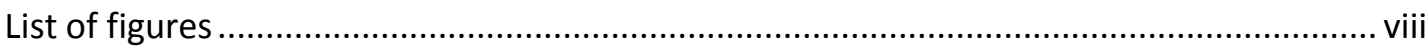

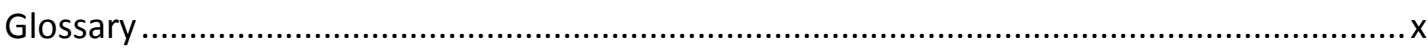

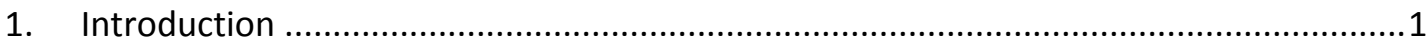

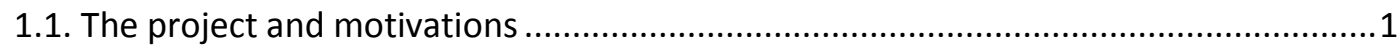

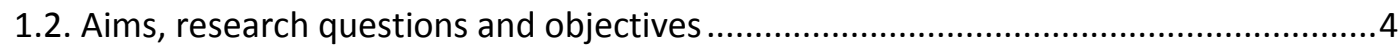

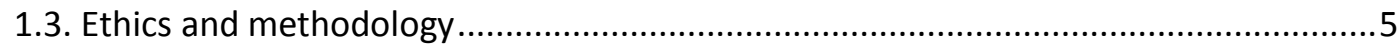

1.4. The places of research: Llaguepulli and Takapuwahia ..............................................6

1.4.1. Llaguepulli and the 'Kom pu Lof ñi Kimeltuwe' School ........................................6

1.4.2. Takapuwahia and the 'Te Puna Matauranga' programme ....................................9

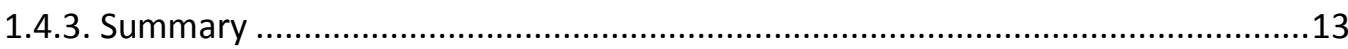

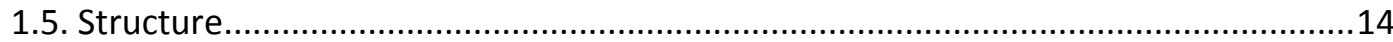

1.6. Notes on terminology, translation and voice..........................................................

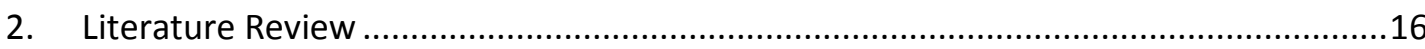

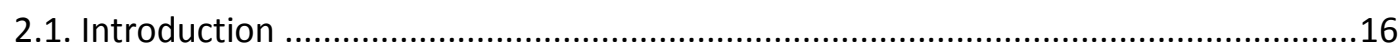

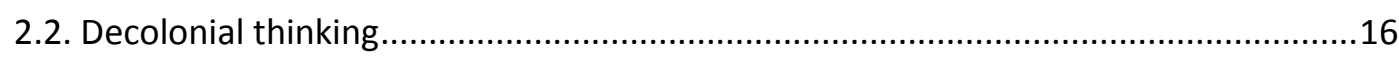

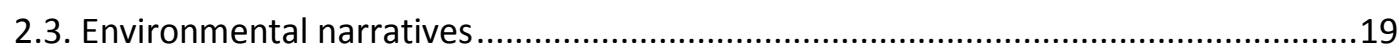

2.4. Children's knowledges with and about the environment........................................20

2.5. Mapuche and Māori children's environmental knowledges within formal education24

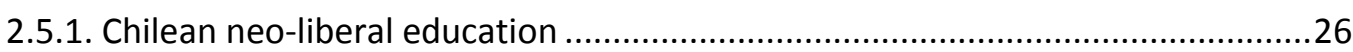

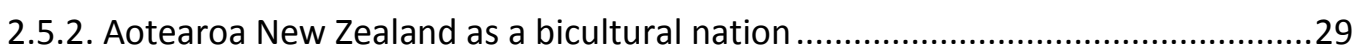

2.5.3. Mapuche and Māori children's environmental knowledges ...............................32

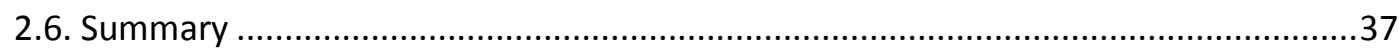

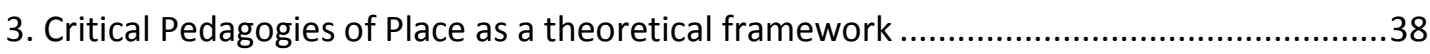

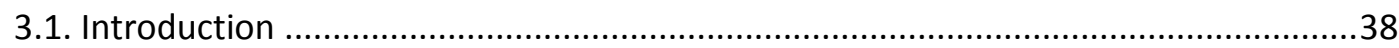

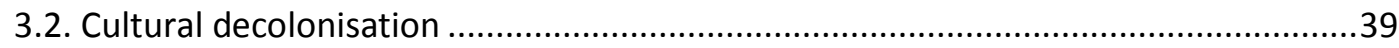

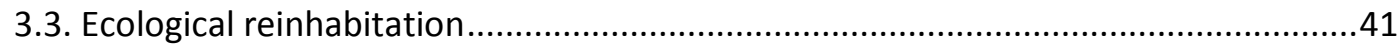

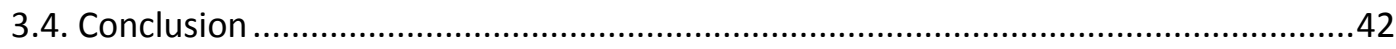

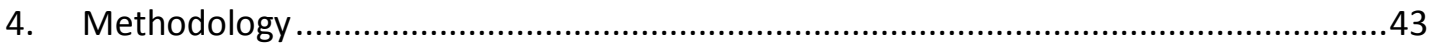

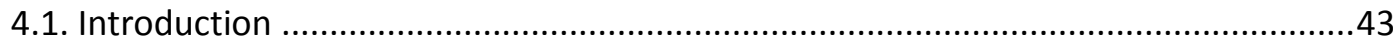




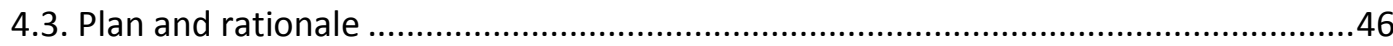

4.3.1. A knowledge exchange with appropriate methods ......................................46

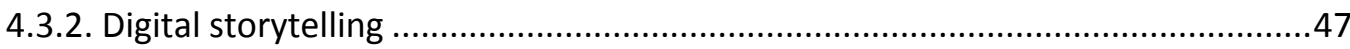

4.3.3. Reflexive participant observation ..........................................................49

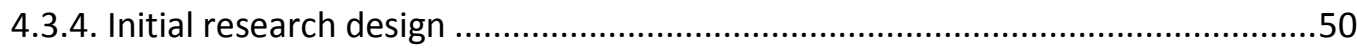

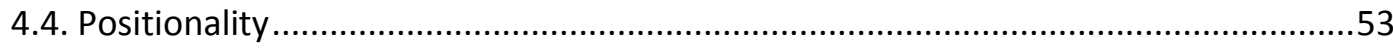

4.5. Establishing connections (or failing to do so) ................................................54

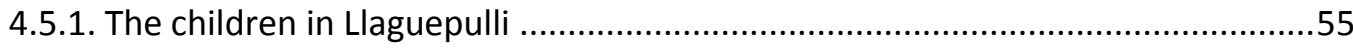

4.5.2. The children in Takapuwahia ............................................................ 58

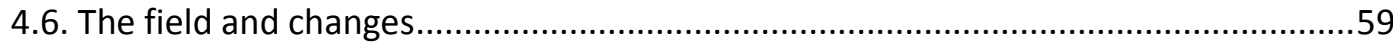

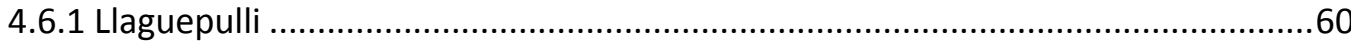

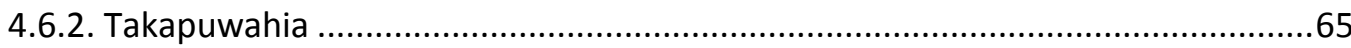

4.6.3 Summary of changes and final research design.......................................69

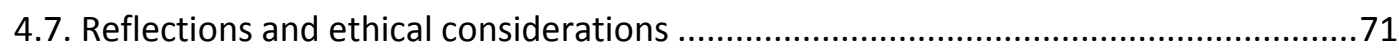

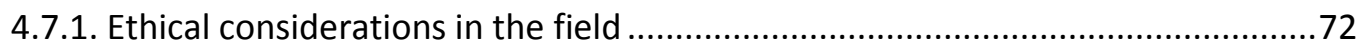

4.7.2. Ethical considerations for the analysis .................................................. 75

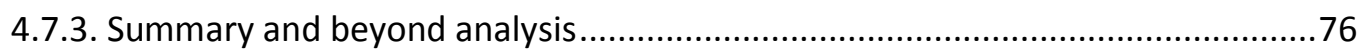

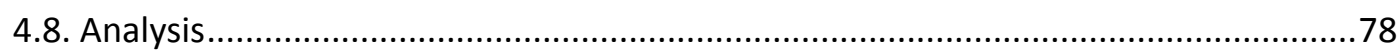

4.8.1 Organising and visualising collected data: Four areas of focus ..........................78

4.8.2. Applying Grounded Theory and planes of analysis ........................................8

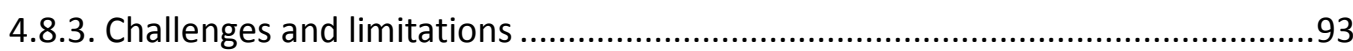

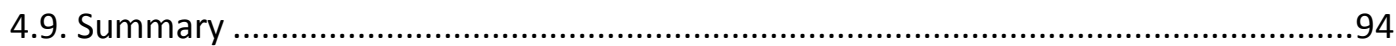

5. AL's narrative: Entanglements of Culture Territory and Personal Identity..................96

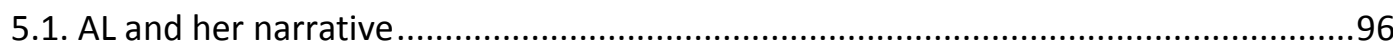

5.2. Entanglements of territory, culture and self-conception in the other narratives ....101

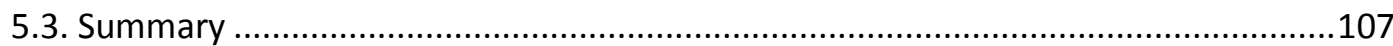

6. K's narrative: Inhabitation through personal and ancestral experience....................109

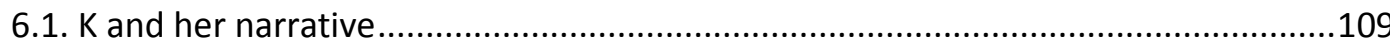

6.2. Inhabitation through personal and ancestral experience in other children's narratives

6.3. Summary ........................................................................................... 120

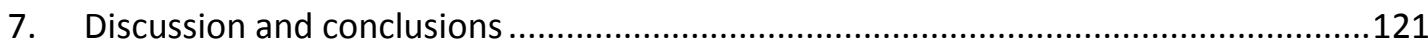

7.1. Imbrications of Territory, Culture and Self-Conception ......................................121

7.2. Ecological Reinhabitation and Cultural Decolonisation .......................................122

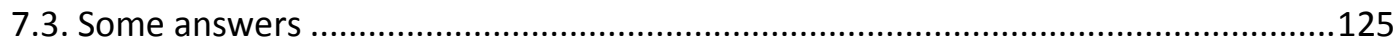


7.4. Contributions to the field 127

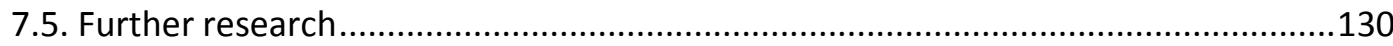

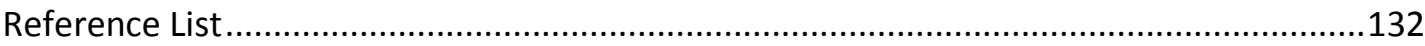

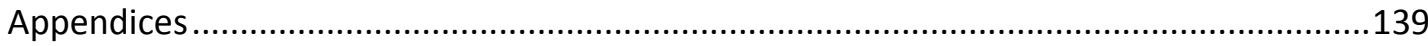

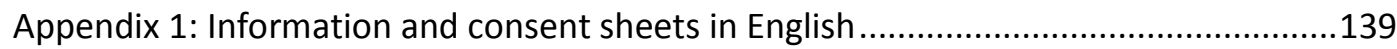

Appendix 2: Information and consent sheets in Spanish ................................................145

Appendix 3: Memorandum from Human Ethics Committee .........................................152

Appendix 4: Power points used for presentations.......................................................153 


\section{List of figures}

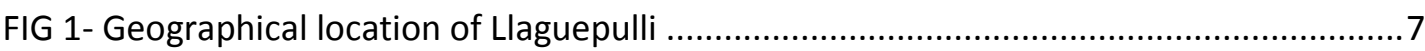

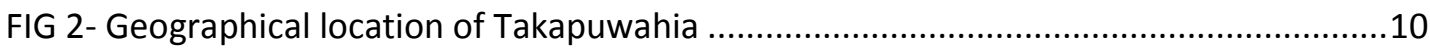

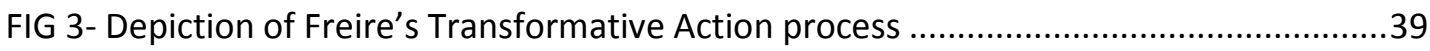

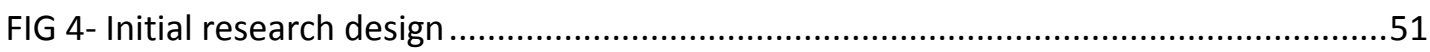

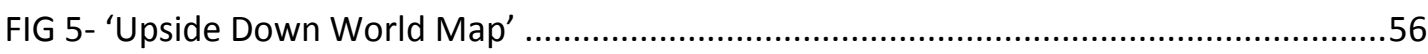

FIG 6- Timer photo taken at the end of the first workshop in Llaguepulli ..............................57

FIG 7- Photo taken by me during the first workshop in Llaguepulli.....................................57

FIG 8- Photo taken by me after our final workshop in Takapuwahia ..................................59

FIG 9- Photo taken by me of the house I stayed in in Llaguepulli .........................................61

FIG 10- Photo taken by me of the 'ruka' beside the house ..................................................61

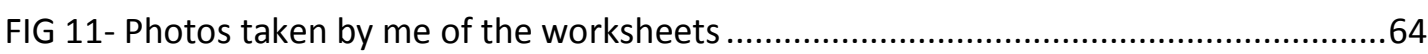

FIG 12- Photo taken by me at the harbour in Takapuwahia ................................................6

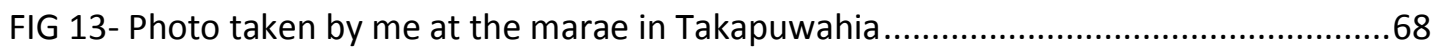

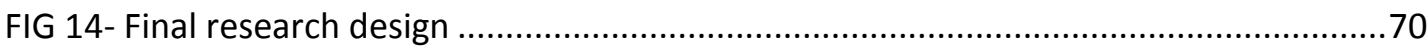

FIG 15- Kaupapa Maori educational research framework, (Bishop, Denzin, \& Lincoln, 2005)72

FIG 16- Table of 'Areas of focus' based on Freeman and Mathison, 2009 ...........................80

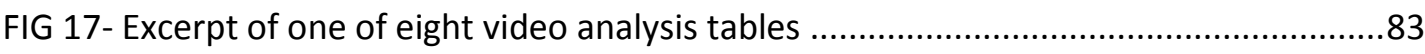

FIG 18- Three planes of analysis bases on Tzou et al. (2010).............................................85

FIG 19- Three planes of analysis applied to excerpt of video analysis table...........................86

FIG 20- Axial analysis of 'Cognitive Ecology' for the eight videos ........................................8

FIG 21- Axial analysis of 'Situated Activity Systems' for the eight videos .............................89

FIG 22- Axial analysis of 'Cultural Toolkits' for the eight videos ..........................................91

FIG 23- Main pattern of analysis: Territory, Culture and Self-Conception ............................92

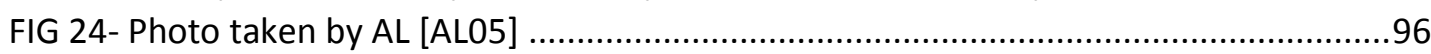

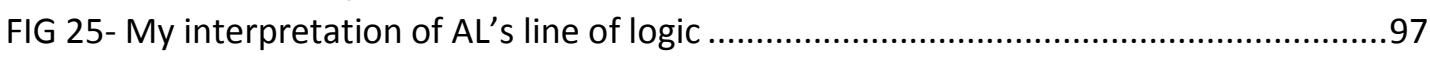

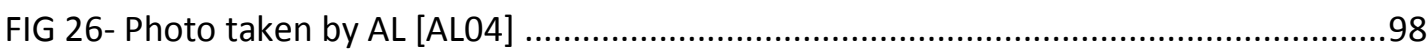

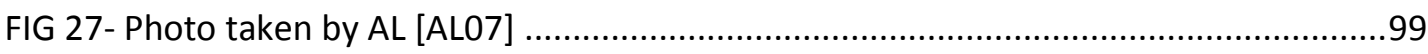

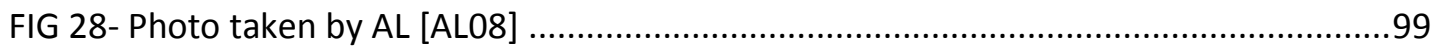

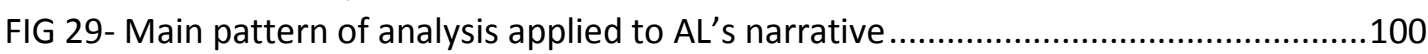

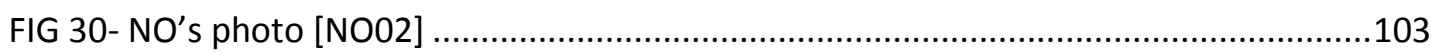

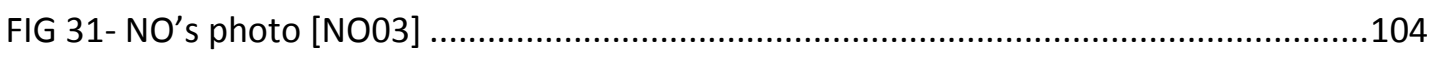

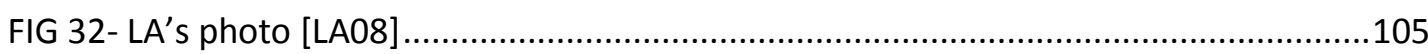

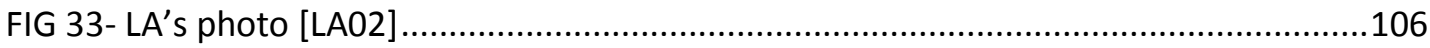

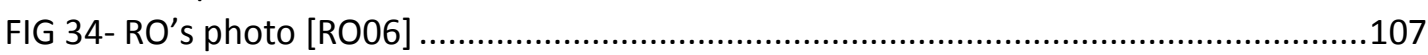

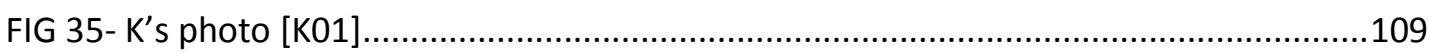

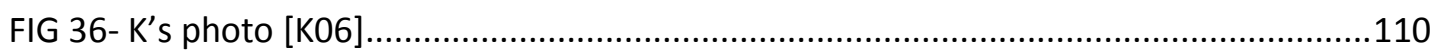

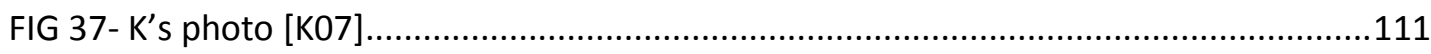

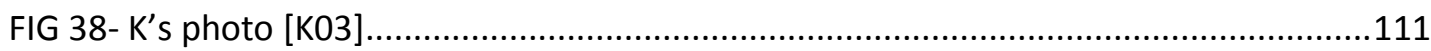

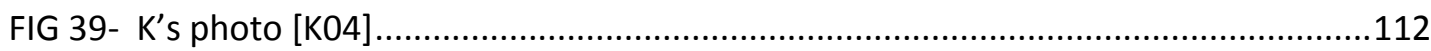

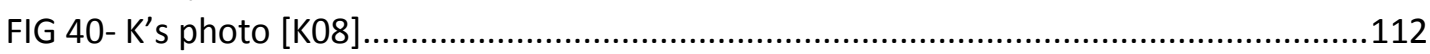

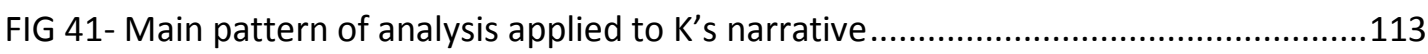

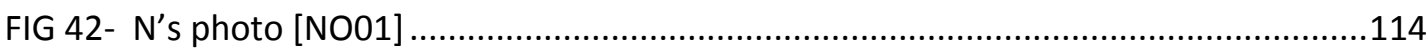

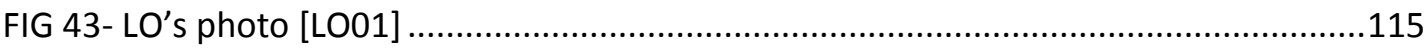

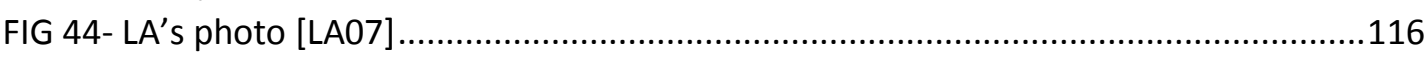


FIG 45- R's photo [RO05]

116

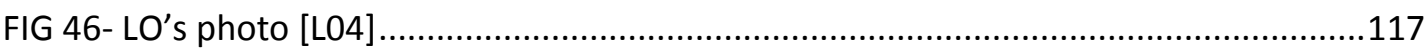

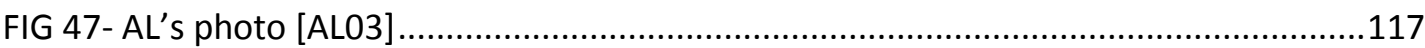

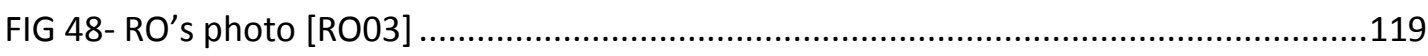

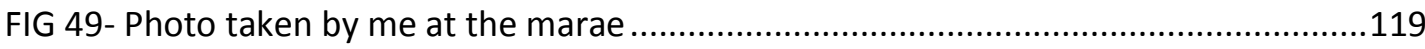

FIG 50- Smith's representation of 'transformative action' (GH Smith, 2003, p.13).............123 
Mapudungun ${ }^{1}-$ English

Chagueltumay: Thank you

Che: Person,people

Gen: Guardian, owner of a space

Itrofill: Everything

Itrofill mogen: Environment, biodiversity, all living beings

Kimün: Knowledge

Lafken: Sea, lake

Lawen: Medicine

Longko: Leader

Mapu: Land, territory

Mapu ñuke choyon iñchiñ: We are the sprouts of Mother Earth

Mapudungun: Mapuche language

Mari mari: Hello, greetings

Mogen: Life

Newen: Strength

Newenche: Strong person

Pentukun: Personal introduction in regards to territorial origin

Poyenche: Loving person

Rakizuam: Thought process

Ruka: Traditional Mapuche straw house

Trawün: Meeting

Wall Mapu: Mapuche territory

Wingka: White person

\footnotetext{
${ }^{1}$ For the purposes of this research I have used the 'Alfabeto Mapuche Unificado' (Unified Mapuche Alphabet) which is one of three different alphabets that are available for the written Mapuche language. I have decided to use this one because of its simplicity and because my Mapudungun advisor recommended it. Nevertheless it is important to acknowledge that through this research I met several people who do not support this particular alphabet and that the issue of a Mapuche written alphabet is very much a relevant political affair. For more on this see Cruz (2017).
} 
Te reo Māori - English

Aotearoa: Māori name for New Zealand

Haka: Traditional Māori dance

Hangi: Earth oven, food cooked in an earth oven

Hui: Meeting, gathering

Iwi: Tribe

Kaimoana: Seafood

Kaitiaki: Guardian, steward

Kaitiakitanga: Guardianship, stewardship

Kaupapa: Plan, topic, matter for discussion

Kawa: Ceremony

Kāwanatanga: Governorship

Koro: Grandfather

Kotahitanga: Unity

Kura Kapuapa Māori: Māori immersion medium schools

Mana: Authority

Manaakitanga: Hospitality, kindness

Marae: Māori meeting house

Mātauranga: Knowledge, wisdom

Pākehā: English, foreign

Papatuanuku: Mother Earth

Pepeha: Form of introduction that establishes identity and territory

Pōwhiri: Welcoming ritual

Puna: Well, fountain

Pūtaiao: Science

Rangatira: Chief

Rangatiratanga: Ownership, chiefly autonomy

Ranginui: Father Sky

Rohe: Territory, area

Tāne-Mahuta: God of the forests and birds

Tāngata: People 
Tangi: Funeral

Taonga: Treasure

Te Ao Māori: The Māori world

Te Kohanga Reo: The language nest

Te Marautanga o Aotearoa: The Curriculum of Aotearoa

Te Puna Matauranga: The well of knowledge

Te reo: The language

Te Tiriti o Waitangi: The Waitangi Treaty

Tikanga: Protocol

Tino rangatiratanga: Self-determination, sovereignty

Wairua: Spirit

Whakapapa: Genealogy

Whānau: Family group

Whanaungatanga: Kinship, sense of family connection

Whare Wānanga: Māori tertiary education

Whenua: Land 


\section{Introduction}

This research explores Mapuche and Māori children's environmental counternarratives. It does so as a way of nurturing spaces, within academia and environmental discourses, for marginalised, embodied and embedded voices which bring other knowledges to the forefront.

The stories which brought me to this research also brought me to decolonial thought as a way of understanding those relationships between coloniality and environmental knowledges. I will now expand on these stories and relationships.

\subsection{The project and motivations}

The project from which this research emerged started with a journey to Chile, was informed by insights and thought processes within my Masters courses and finally came together in another journey in Aotearoa New Zealand. The journey to Chile in 2015 was one in which I learnt more about Mapuche ${ }^{2}$ history, culture and struggle than I had learnt in over fifteen years immersed in the Chilean education system while growing up. I became aware of the ongoing political, physical and spiritual oppression that Mapuche people have been subjected to under the Chilean government. Amongst the initiatives and places I visited, one in particular stood out for me and it was the Mapuche community of Llaguepulli ${ }^{3}$. This community has strong core values focused on the revitalisation of their culture and language; values that could be seen in the 'Kom pu Lof ñi Kimeltuwe' ('henceforth 'Kom pu Lof') project, which literally means 'place of learning for all communities'. 'Kom pu Lof' is the local primary school and the first autonomous Mapuche school in the

\footnotetext{
${ }^{2}$ Mapuche are the largest indigenous group in Chile. They represent $87.31 \%$ of the total indigenous population of the country, which is $4.6 \%$ of the total (Chile, 2002). 'Mapu' translates as 'territory' and 'che' as people, so Mapuche can be understood as 'people of the land' (Marimán, Caniuqueo, Millalén, \& Levil, 2006, pp. 28-32). The colonisation of Mapuche territory or Wall Mapu by the Spanish begun in 1541 though it was not until 1883 that the territory was fully included within the Chilean nation (Ibid, pp. 81-126). I will expand further on Mapuche history in sections 1.5.1. and 2.5. ${ }^{3}$ Llaguepulli is a Mapuche community composed of ninety families and located in the Lake Budi basin. This area was declared an 'Indigenous Development Area' in 1997 as a government initiative to focus government action to benefit indigenous development (Fajardo Garrido, 2013, p. 19). I will expand further on Llaguepulli in section 1.5.1.
} 
country. The community's longko (leader), who is also the school's principal, describes it as an example of "resistance through education" (Rosas 2013, p.23).

Returning to Aotearoa New Zealand and starting my Masters courses, I also started learning more about indigenous Māori ${ }^{4}$ education. One of my courses took place inside a marae (traditional Māori meeting house), respecting the tīkanga (practices) of that sacred place. This course focused on 'Critical Pedagogies of Place' (henceforth $\mathrm{CPOP}$ ), a pedagogical theory which focuses on cultural decolonisation and ecological reinhabitation (Gruenewald, 2003a, 2008). According to Gruenewald (2003 \& 2008), cultural decolonisation refers to the awareness and confrontation of dominant ideologies, and ecological reinhabitation relates to inhabiting a place which has been ecologically disrupted. These concepts, together with the readings and conversations my classmates and I had at the marae, allowed us to sense the relevance of place and territory to learning and establishing relationships with, and within the environment.

Alongside these insights, I started learning about colonisation and its ongoing effects, and I became particularly interested in the relationship between the processes of colonisation and indigenous environmental knowledges ${ }^{5}$. This interest led me to decolonial thought as presented by the Modernity Coloniality Programme in Latin America (henceforth 'MC' as used by Escobar, 2007) and to decolonising methodologies as presented by Māori scholar Linda Tuhiwai Smith. Decolonial thought underscores a strong link between coloniality and environmental and social justice, as it understands the world's current environmental sustainability crisis as a crisis of thought, narrative and ontology (Leff, 2003; Mikulak, 2008). Escobar (2007) explains the origins of this crisis through the marginalisation of non-capitalist knowledges, in particular those knowledges which enact a continuity, instead of a

\footnotetext{
${ }^{4}$ Māori, the tangata whenua (tangata translates to 'people' and whenua to 'land', meaning 'people of the land) of Aotearoa/New Zealand, are the only indigenous group who was inhabiting this land when the English settlers arrived in 1769 (King, 2003). Māori currently represent $14.9 \%$ of the total Aotearoa/New Zealand population (Zealand, 2013). Since the 1980s, indigenous Māori education in Aotearoa/New Zealand has developed a fully immersive educational path - from early childhood to tertiary - which is managed by Māori for Māori. I will expand further on Māori history and formal education pathways in section 2.5 .

${ }^{5}$ The MC uses this plural form (Escobar, 2007) to evidence the multiplicity of different knowledges, and I will continue to do so throughout this thesis.
} 
separation "between the natural, human and supernatural worlds" (p.197). The relationships established by decolonial thought between environmental sustainability and processes of coloniality resonated strongly with what I had seen throughout my journey in Chile and what I was learning about Māori in Aotearoa New Zealand.

Finally, in 2016 I participated as translator and driver in a two-week cultural exchange where a Mapuche delegation visited New Zealand to learn with and from Māori tourism and education initiatives, a Hui/Trawün (Mapuche and Māori words for gathering). This delegation of three came from the community of Llaguepulli, and one of their main goals was to "establish bonds of support between the Māori people and the Mapuche Lafkenche territory of Lake Budi in the educational space" (email exchange, August, 2016, own translation). Together with my colleague and friend Dr. Marcela Palomino-Schalscha, we travelled for ten days and visited at least twelve different tourism and education initiatives. During this time we slowly started to know each other, to carefully unravel the many layers which separate us. This happened between and through us and between and through our encounters with the different peoples and places we visited.

These two journeys, which connected Mapuche and Māori education initiatives and what I had learnt about Māori education, CPoP and decolonial thought, highlighted for me the issue of the marginalisation of Mapuche and Māori children's environmental knowledges. In both Aotearoa New Zealand and Chile, the formal education system advances Western scientific knowledge as the dominant truth (in different degrees in each country), a dominant truth which constraints the space for what the MC calls 'other' ways of thinking to be a part of conversations with, and about the environment.

I was inspired by Smith's (1999) call for indigenous people to 'research back' through the telling of their own stories and Walsh's idea of "locating oneself and one's praxis within the cracks and crevices of the modern/colonial order" (Walsh, 2014 , p. N/A). This inspiration led me to talk to Roberto, a teacher from 'Kom pu Lof' who was part of the visiting delegation to Aotearoa New Zealand. We talked 
about generating a space for environmental dialogue between Mapuche and Māori children. In this space, my idea was that children from each country, who were immersed in a formal indigenous education system which stems from their own culture and territory, would share their environmental narratives with an 'other' and listen to the other's narrative in an open dialogue. Roberto agreed with this idea which I continued to develop into the current thesis.

I perceived that this cross-cultural encounter through dialogue could provoke surprise, challenge and change (D. B. Rose, 1999) for the children involved, through the exploration of each other's local and embodied environmental knowledges.

\subsection{Aims, research questions and objectives}

The central aim of this research has been to facilitate the generation of Māori and Mapuche children's environmental narratives as a means to advance 'critical border thinking' (Escobar 2007, p.191) and offer alternatives or counter-narratives to those imposed by dominant Western epistemologies.

Specifically, the project sought to enable children involved to:

- Reflect on their relationships with their environments stemming from their own conceptions of territory and culture;

- Learn about another culture which shares similar histories and perspectives, thus generating inter-cultural and inter-national support networks and empathy; and

- Share their voices and thoughts on environmental issues within their communities and to speak back to wider and global environmental narratives. 
Based on the above objectives my research questions were:

1. How do Mapuche and Maori children represent relationships with and within the environment?

2. In what ways do the children's narratives enact cultural decolonisation and ecological reinhabitation?

3. What are the implications of this process for the development of critical border thinking and the world's current environmental sustainability crisis?

\subsection{Ethics and methodology}

In order to answer the research questions outlined above, I wanted to design a research project aligned to decolonising methodologies which would encourage the participants to tell their own stories and share their own knowledges with, and within the environment.

This goal presented several ethical issues, the main one being my own position as a non-indigenous adult researcher working with indigenous children. Smith (1999), contends that research, especially research with indigenous peoples, is one of the most powerful vehicles for the realisation and regulation of the code of imperialism and colonialism (p.7). She makes a call for researchers to ask themselves: Whose research is it? Who owns it? Whose interests does it serve? (p.10).

These questions are also relevant when doing research with children. Several authors explore the ethical issues which pervade adult-children relationships within research. Some of the main issues are the power imbalances between adult researchers and child subjects (Morrow, 1999); the notion that adults cannot access children's subjectivities, which leads to research being an adult representation of children's knowledge (Hill, 1997; Punch, 2002); and the ethics of informed consent and confidentiality (Lewis \& Lindsay, 1999; Morrow \& Richards, 1996; Stanley \& Sieber, 1992). 
As a final reflection, it is relevant to mention that using these methodologies called for establishing relationships with the children, their teachers and sometimes the children's parents too. These relationships often required me to introduce the other group (Mapuche to Māori and Māori to Mapuche). Even though the narratives created by the children spoke by themselves to those who viewed, they were actually framed in my representations of the other group as well. I'll go into further details about the ethics of this research project in section 4.6.

\subsection{The places of research: Llaguepulli and Takapuwahia}

This research took place at two sites, Llaguepulli in the South of Chile and Takapuwahia in the lower North island of Aotearoa New Zealand. In the next couple of sections I will situate Llaguepulli and Takapuwahia geographically and historically. I will also describe the education initiatives which were the main contexts of connection to the groups of children who participated in the project.

\subsubsection{Llaguepulli and the 'Kom pu Lof ñi Kimeltuwe' School}

The Llaguepulli community sits at the edge of Lake Budi, the only saline lake in South America, which is located in Chile's Araucanía ${ }^{6}$ region or the Wall Mapu (name of the ancestral Mapuche territory) (FIG. 1).

\footnotetext{
${ }^{6}$ Wall Mapu/Araucania is the $15^{\text {th }}$ region of Chile and also the region where the 'frontier' used to exist between Spanish colonisers and Mapuche. It is currently the poorest region and the one with the highest proportion of Mapuche people in the country (INE, 2002).
} 


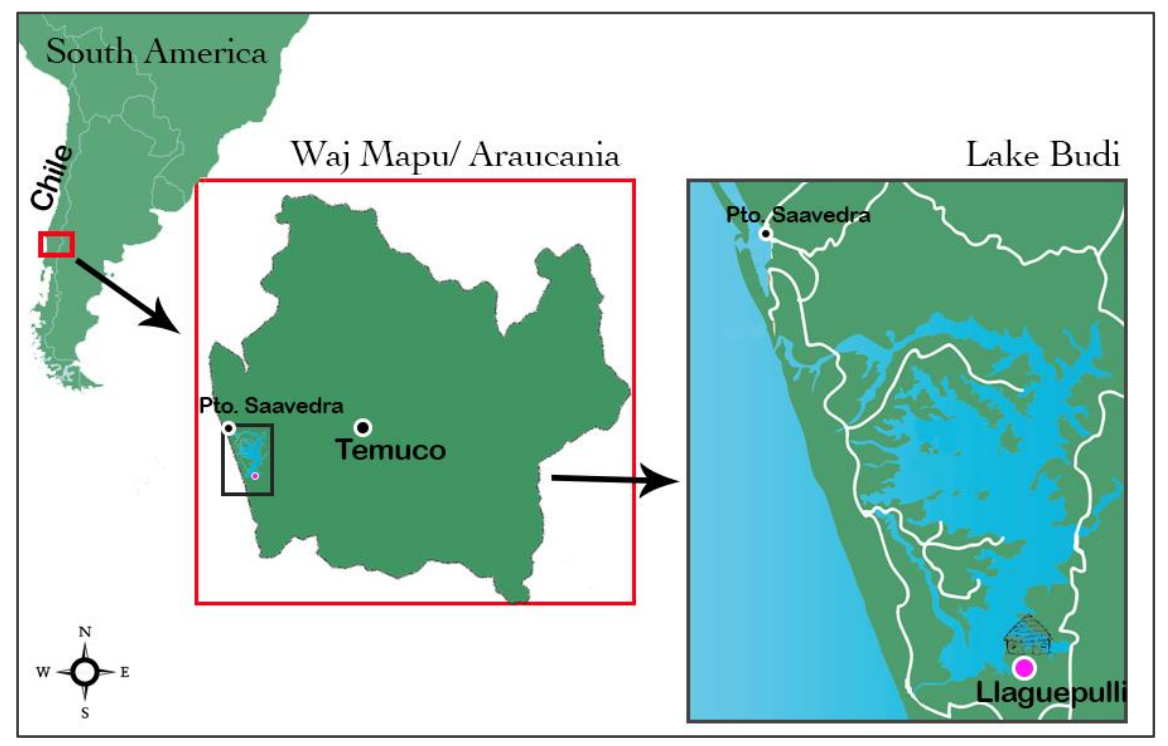

FIG 1-Geographical location of Llaguepulli

This is a historically contested territory very close to the area that used to be called 'the frontier' up until 1883 when, after years of military encounters between Chilean and Mapuche people, this land was taken as part of the Chilean state (Marimán, Caniuqueo, Millalén, \& Levil, 2006). Llaguepulli, a rural community inhabited by approximately ninety families (Fajardo Garrido, 2013), is one hundred percent Mapuche-Lafkenche people; Mapu can be translated as 'Earth', Che as 'Man' and Lafken as 'Sea', so Mapuche-Lafkenche can be understood as the 'people of the land of the coast'. It is also an environmentally contested territory, as after occupation by wingkas (white people) and by Capuchins (missionaries), Mapuche Lafkenche people were relegated to small plots and were geographically and culturally controlled by the Capuchin Religious Order until 1990 (Pinto Contreras, 2013). This move into smaller plots turned traditional communal management and use of land into divisions characterised by intense cattle and agricultural use, which resulted in severe erosion and forest depletion (Bengoa, 2000; Fajardo Garrido, 2013).

Llaguepulli is characterised by a tightly knit community which is very active in terms of participating in and generating projects related to the revitalisation of language and culture. Some examples of these are its tourist initiatives, micro-financing programmes and revitalisation of agricultural practices geared to reforestation and 
generation of jobs. One of this projects is 'Kom pu Lof ', the autonomous primary school of Llaguepulli.

The Llaguepulli school was managed by the Catholic Church until 2006, when community families who were dissatisfied with the religious pedagogy taught at the school, and the way it presented Mapuche culture as folklore, started gathering signatures and lobbying to take over the management. They achieved this transition to community management and have been successful in terms of school growth, new teachers and score improvements measured by national standards (Rosas, 2013). For Mauricio Painefil, the community's longko (leader), this is one of the most powerful acts of resistance by the community (Rosas, 2013). Currently 'Kom pu Lof' has approximately 50 students (from my own experience) and seven teachers who are all actively involved in the re-shaping and re-claiming of Mapuche education. As I saw during my time in Llaguepulli, this involvement is a continuous commitment which includes actions such as: visiting other Mapuche schools to help them re-connect to their culture, nurturing spaces for ancestral practices within the school routine and, in some cases, donating a sizeable portion of a very low salary in order to cover costs such as transport and infrastructure.

In 2011, the Llaguepulli community and Chilean academics came together in a UNESCO funded project for the creation of an emergent curriculum, the first of its kind in Chile (Pinto Contreras, 2013). This is an ongoing project which was handed in to the National Education Council at the end of last year and has very recently been accepted. The project acts as conscious resistance to the fact that Mapuche children are losing contact and awareness of their traditions in terms of culture and practices within their environment. So it becomes an "imperious need" to pass on ancestral wisdom about the "components of nature and spirituality in each of the elements... which don't have a place in formal education" (Leiva Sepúlveda \& Miranda Sandoval, 2015, p. 44, own translation). Its main goals are "the teaching and transmission of 'Kimun' (knowledge), from which their 'Rakizuam' (thought process), which has emerged from a dialectic relationship with the Lafkenche territory, which has articulated their worldview and language, both key in the maintenance and projection of the Mapuche-Lafkenche people." (Pinto Contreras, 
2013, p.28, own translation). The curriculum is grounded both in ancestral concepts and the Chilean educational guidelines. One of the most relevant areas within these concepts, both for the people involved in developing the curriculum and for this research is Itrofill Mogen, which can be roughly translated as environment or biodiversity. In the words of Painequeo: "Itrofill' can be translated as 'everything', it is the earth, the water, the air, the sun, the clouds, it is all. 'Mogen' is life. So Itrofill Mogen is all kinds of life." (Painequeo as cited in Leiva Sepúlveda \& Miranda Sandoval, 2015, pp. 49-50, own translation). It is a balanced coexistence with the Mapu (earth) from a natural, social and spiritual perspective (Pinto Contreras, 2013, p. 21 , own translation). It sees territory as a live unit where all members are legitimate and related. The relevance of this concept for education is that it instills respect for the natural, social and spiritual environment, allowing students to position themselves within biodiversity and to maintain their culture.

This curriculum arises in the midst of contentious times for the Chilean education system, where for years now students (ranging from highschool to university) have taken to the streets to protest and demand quality, free and non-commodified education. Within the wider issue of Chilean education, Mapuche scholars and activists have criticized the system as: monocultural, de-contextualized, colonising and overly-centralized (Quilaqueo, Quintriqueo, Torres, \& Muñoz, 2014). In this context, an emergent Mapuche-Lafkenche curriculum which focuses on the "strengthening and conservation of their culture, through the knowledge of their surrounding environment towards the internalization of their own worldviews" (Leiva Sepúlveda \& Miranda Sandoval, 2015, p.45, own translation), presents itself as what MC scholar Walsh (2014) would call a decolonial crack. This is a crack which may "weaken and fracture the hegemonic whole" and whose effects depend on "how the seeds planted, sprout, flourish, and grow" (Walsh, 2014, p. N/A).

\subsubsection{Takapuwahia and the 'Te Puna Matauranga' programme}

Takapuwahia is the oldest Māori settlement of Porirua city and is located by the shore of Te Awarua a Porirua (the Porirua harbour) in the lower North Island of Aotearoa New Zealand (FIG. 2). 


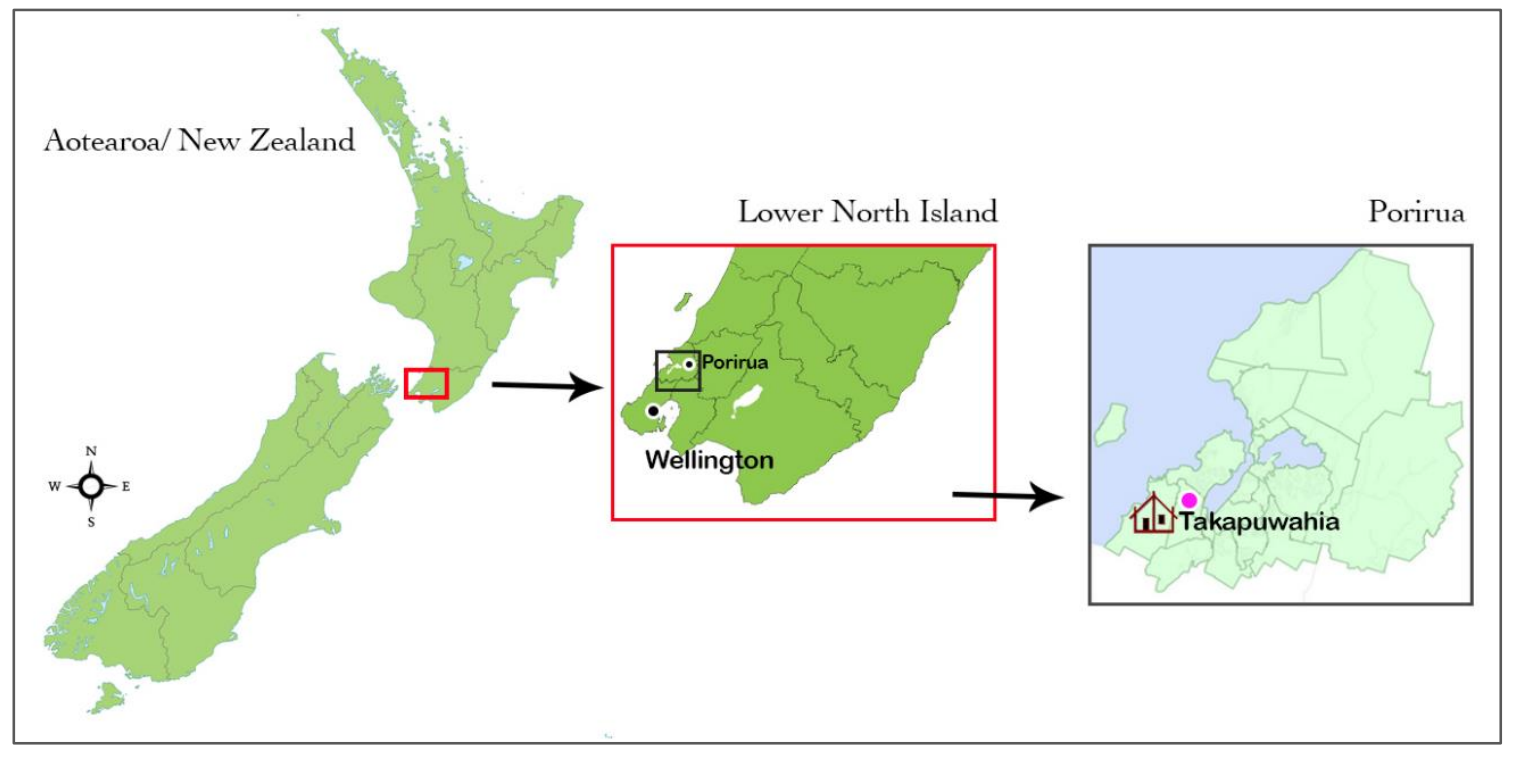

FIG 2- Geographical location of Takapuwahia

Takapuwahia is under the mana (authority) of Ngāti Toa Rangātira iwi (tribe, henceforth 'Ngāti Toa'), who migrated from the Waikato region in the 1820 s led by the ancestor Te Rauparaha. Takapuwahia has been Ngāti Toa's primary home since 1889 , following the imprisonment without trial of Te Rauparaha.

During the 1830s, Ngāti Toa came to control a large amount of territory both in the lower North and in the upper South islands. In 1840, together with over forty Māori rangatira (chiefs), Te Rauparaha signed Te Tiriti o Waitangi ${ }^{7}$ (The Waitangi Treaty). The signing of the Treaty and the large amount of English settlers arriving in Aotearoa New Zealand over the next couple of decades resulted in land disputes all over the country where, by 1963 , Māori had lost over 1.6 million hectares $^{8}$. This drastic reduction of land came hand in hand with radical environmental and demographic changes as, across the country, forests were cleared for timber and farming (Blaschke, Trustrum, \& DeRose, 1992; Fetzel, Gradwohl, \& Erb, 2014) and the European population increased as the Māori population decreased through infectious diseases and initiated an urban migration (Collette \& O'Malley, 1974;

\footnotetext{
${ }^{7}$ Te Tiriti o Waitangi is the founding document of Aotearoa/New Zealand as a bicultural nation. The Treaty was devised responding to the Crown's desire to formalise the colony in New Zealand (King, 2003). For Māori it was understood as having full sovereignty over their lands and treasures, and by English as a way to settle and buy land. I will expand on the Treaty's significance and repercussions in section 2.5 .

8 These lands were lost through land sales (King, p.182), through confrontations during the 'New Zealand Wars' (1845-1872) and confiscations under the 1963 New Zealand Settlements Act (Ministry for Culture and Heritage, 2016).
} 
King, 2003). For Ngāti Toa, this meant the loss of most of their lands, a grievance which was brought up to the Waitangi Tribunal ${ }^{9}$ for the first time in 1986, initiating a process of inquiries and agreements which resulted in the signing of a Deed of Settlement in 2012. This Deed of settlement redressed Ngāti Toa culturally by vesting the co-management of several places of significance, financially by granting over seventy million New Zealand dollars and commercially by opening opportunities for them to buy land at price (New Zealand Government, 2012). In the 2012 Deed of Settlement, Ngāti Toa's relationship with the environment is framed as essential for their identity and cultural integrity:

"To Ngāti Toa Rangatira, the lands, lakes, rivers and harbours within their rohe [territory] were taonga [treasures]. Their history and relationship with these resources is still one of the foundations of their identity, cultural integrity, wairua [spirit], tikanga [protocols] and kawa [ceremony]. "

(Rangatira, Trust, \& Crown, 2012, section 1.31, p.10, my translations between brackets) The cited paragraph relates to the concept of kaitiakitanga (guardianship). Ngāti Toa consider themselves as the guardians of the Porirua harbour and declare that limitations on them performing their role as kaitiaki (guardians) "due to impacts created through development and political change have been detrimental to the iwi" (Victoria University of Wellington, 2017, p. 7). This consideration is put in practice through the iwi's participation in resource management and through restoration and education projects (http://www.ngatitoa.iwi.nz).In Takapuwahia this becomes particularly relevant considering the radical environmental changes experienced by the harbour, especially during the 1950s and 60s when it experienced development pressure from "intensified land use, contamination, and siltation" (Victoria University of Wellington, 2017, p. 9) which resulted in the inability to harvest kaimoana (seafood) and the loss of almost a third of the harbour through reclamation of land.

${ }^{9}$ The Waitangi Tribunal is a government institution established in 1975 to address Waitangi Treaty breaches. 
Nowadays Takapuwahia is a close-knit community and the base of Ngāti Toa iwi is around the marae (meeting house). Ngāti Toa iwi actively invests in initiatives geared to care for the wellbeing of their community, especially in the areas of health, environment and education (http://www.ngatitoa.iwi.nz).One of these initiatives is 'Te Puna Matauranga' (henceforth 'Te Puna') which literally translates into 'the fountain of knowledge', the programme which the group of children who participated in this project attend. I will now describe its history and main principles.

'Te Puna' is a iwi-based education programme which offers after-school support for students and aims to improve Māori educational achievement (http://www.ngatitoa.iwi.nz). The programme was launched at the beginning of 2016 and most of my knowledge about its history comes from the fact that the programme co-ordinator, Bianca, was my classmate during one of the Education courses of my Master's degree. Throughout that course she developed some of the ideas which underlie the project and then, through a synergy of events related to funding, vacancies and interest from the Iwi, she was able to launch the programme.

According to the Programme Outline (sent to me by Bianca as an email exchange on December, 2017), "Puna Matauranga is centered on the principles of Whanaungatanga, Manaakitanga and Rangatiratanga". Manaakitanga (hospitality, kindness) relates to the "responsibility of the host to care for their visitor's emotional, spiritual, physical and mental well-being" (ero.govt.nz, as cited in the aforementioned document). Whanaungatanga (kinship, sense of family connection) "encompasses Māori collective identity and responsibility" (Otrel-Cass et al., 2009, as cited in the aforementioned document). Finally, rangatiratanga (sovereignty, autonomy) is about the capacity to "define one's own destiny [...] to define what that destiny will be and to define and pursue a means of attaining that destiny" (Bishop 2011, as cited in the aforementioned document). Following these principles, the programme supports Māori student's achievement by nurturing connections between families, students and school. It does this by engaging both the families and the teachers in an active commitment to participate and 
communicate about the children's needs and progress. This provides a supportive iwi based environment which, even though it still needs to demonstrate its results in qualitative terms measured by students' achievements, is based in Māori values and principles.

\subsubsection{Summary}

'Kom pu Lof' and 'Te Puna' are two very different educational initiatives and rooted in different histories and places. 'Kom pu Lof' is the first autonomous Mapuche primary school in Chile located in a small rural community, whereas 'Te Puna' is an after-school education initiative located in a highly urban neighbourhood. Furthermore, 'Kom pu Lof' is framed within a national legal framework which has not properly recognised indigenous Mapuche identities, whereas the legal framework which surrounds 'Te Puna' in Aotearoa New Zealand is based on a bicultural understanding which recognises indigenous Māori identities and their autonomous education initiatives.

Notwithstanding these differences, both of these initiatives are based on Mapuche and Māori notions which relate to a sense of kinship and interconnectedness, such as Itrofill Mogen (biodiversity- all that is alive) and whanaungatanga (kinship, sense of family connection). They are also both based in conceptions which position human beings as partly responsible for maintaining balance and well-being within the environment (see previously explained concepts of Itrofill Mogen and Kaitiakitanga). As such, I interpret them as subverting the dominant monological regime of Western scientific truth. Moreover, they are both located in areas which have been ecologically disrupted and are involved in projects which relate to the reinhabitation of those lands. 'Kom pu Lof', for example, has an active programme where children participate in a native tree nursery and learn about traditional agricultural practices. These characteristics lead me to view both of these educational initiatives as potential examples of a Critical Pedagogy of Place. I will further expand on this theory in chapter 3. 


\subsection{Structure}

Having presented the stories, theories and places that have shaped this research, I will now describe how it is structured.

Chapter two situates research in theory and place by providing a Literature Review and a description of both research sites. In the Literature review I will present decolonial thought and decolonising methodologies, and discuss how environmental narratives may present a decolonising methodology. Framed in decolonial thought, I will then explore the socio-spatial marginalisation of children and, in particular, the environmental narratives of Mapuche and Māori children within formal education.

In chapter three I present Critical Pedagogies of Place as a theoretical framework. I introduce in detail its main concepts of cultural decolonisation and ecological reinhabitation as ways of bringing together decolonising practices and embodied environmental knowledges.

Then I move to the Methodology, in chapter four, presenting relational constructionism as the underlying ontology for this research and the ways in which it relates to decolonial thought and research with children. In this chapter I explain my chosen methods and initial research design in relation to the project aims and the ways in which relationships were built during the process. Then I reflect on my positionality, before presenting the groups of children who participated in the project, their contexts and the relationships we built. From this I move on to reflections on the experiences of being in the field and how this resulted in changes to the original research design. Finally, I present some ethical considerations in regards to being in the field, working with children and analysing data before moving to the presentation of the ways in which data was finally analysed.

In chapters five and six I explore the main themes which emerged through the analysis, by presenting the children's images and narratives and weaving them with observations and reflections. These themes are: 'Entanglements of culture, territory 
and personal identity', and 'Inhabitation through personal and ancestral experience'.

Finally, in chapter seven I return to the research questions to present discussions and conclusions, and close by reflecting on the contributions this research may present and possible future areas of research.

\subsection{Notes on terminology, translation and voice}

Throughout the thesis I use te reo Māori (the Māori language) and Mapudungun (the Mapuche language) words by showing them in italics and providing a translation (between parenthesis). These translations come from my learning experiences, questions to experts and dictionaries. I have attempted to be as clear and respectful in these translations as possible, but recognise they will inevitably be simplifications of complex ideas. There is also a glossary of terms after the Table of Contents. I will also use bold to identify key theoretical phrases.

Finally, I have chosen to use a first person narrative voice, weaving in my personal experience with the events and the literature. This choice is, on the one hand, based on a relational constructionism ontology which legitimises doing research "through ongoing dialogues and reflexive practices" (Hosking, 2011, p. 61). On the other hand, it is simply something that has happened because as much as I wished to tame this thesis into a docile straight line, it's proven to be more of a slippery and ever-changing creature, like a rhizome which has "no beginning or end; it is always in the middle, between things, interbeing" (Deleuze, 1987, p. 27). 


\section{Literature Review}

\subsection{Introduction}

The following review explores the literature in order to introduce, clarify and better understand the concepts and topics which converge at this thesis. It starts by exploring decolonial thought and its relationship to environmental narratives, defining the main issues which will be explored throughout the research of monological truths, disembeddedness and marginalisation of knowledges. It then looks at how these issues take place in the experience and research with children, especially looking at what happens with Mapuche and Māori children's environmental narratives within formal education.

In the following section I introduce decolonial thinking; its origins, principles and proposals for research praxis. I will then show how environmental narratives relate to this line of thought and how they can be a path towards decolonising knowledges about and with the environment.

\subsection{Decolonial thinking}

According to Maldonado-Torres (2011), decolonial thinking has existed at least since the late fifteenth century but has been announced as a profound and globallyinterconnected project shifting away from modernisation since the end of the twentieth century. It is a "family of diverse positions that share a view of coloniality as a fundamental problem... and of decolonisation or decoloniality as a necessary task which remains unfinished" (p.2). Within this diverse lineage of perspectives, I have chosen to work particularly with those advanced by Māori scholar Linda Tuhiwai Smith and the Latin American Modernity-Coloniality Research Programme (MC). I will draw from these particular sources because they are grounded in the 
territories that this research explores: Aotearoa New Zealand and Abya Yala Latin America ${ }^{10}$.

In Aotearoa New Zealand, G.H. Smith (2003) looks at societal changes for Māori in the 1980 s and identifies a call to theory undertaken by Māori as a "strategic reinvestment in theoretical tools to assist their transformation" (p.4). One of the leading scholars in this movement is Linda Tuhiwai Smith. In her ovular work 'Decolonising Methodologies', L.T. Smith (1999) presents colonialism as a specific form of imperialism which still "frames the indigenous experience... still hurts, still destroys and is continuously being reformulated" (p.22). She describes this imperialism as a field of discursive knowledge which implies the subjugation of 'Others' (p.25). Within this view, research represents one of the "ways in which the underlying code of imperialism and colonialism is both regulated and realized" (p.7). This code is based on regimes of monological truths (Foucault, 1991), that is to say, political regimes which perpetuate systems of production and regulation of what is considered to be a single and correct 'truth'. In response, L.T. Smith proposes researching back as a way of fighting for self-determination $(1999$, p. 7). She argues that one of the most powerful tools to do this is "telling our own stories" (p.42), and I will return to this form of resistance when speaking about environmental narratives in the following section. L.T. Smith's theories have influenced those of the MC.

The MC, as defined by Escobar (2007), is "an other way of thinking that runs counter to the great modernist narratives... [and] locates its own inquiry in the very borders of systems of thought and reaches towards the possibility of noneurocentric modes of thinking" (pp. 179-180). It is composed of a group of Latin American and Latin Americanist scholars who forward the need to generate a new

\footnotetext{
${ }^{10}$ Arguably, Latin America is too wide a territorial definition, considering I'll be looking specifically at the Mapuche Lafkenche territory; however, through my research process I was not able to find Mapuche Lafkenche authors who were engaging with similar themes and were validated by the research participants of this project. This is an important gap and perhaps a pitfall of working from a distant colonial settler university. It might also reflect the wide division between academic literature and Mapuche culture which has been defined by Chihuailaf (1999) as a culture of 'oraliteurs' where the texts are oral and firmly grounded in the lived experience. In contrast, l've had a wider exposure to Māori academic writing while living and studying in Aotearoa New Zealand.
} 
understanding of modernity in order to address the "intertwined relation of modernity/coloniality and the subjectivities and epistemologies this relation has intentionally subalternized, ignored and displaced" (Walsh, 2012, p. 12). This understanding starts from the recognition that there is a Eurocentric mode of thinking (modernity) which continues to predominate in most places in the globe. This mode of thinking is characterised by disembeddedness or the separation of social life from local context, where the direct experience of place becomes secondary to relations between absent others. It is also concerned with the effects of subalternisation or marginalisation of knowledge, through the identification and advancement of European knowledge as the dominant and truthful one which pushes other knowledges to the margins (Escobar, 2007, p.182). The MC advocates for critical border thinking (p.191) which acknowledges the imposition of Western epistemologies through colonialism, but does this from the "subjectivities, histories, memories, and experiences that do not simply remain anchored in the colonial past, but that are (re) constructed in different ways within the local and global coloniality of the present" (Walsh, 2012, p. 14). These subjectivities represent 'an other' thinking which enables critical theorising from and through difference.

There are several resonances between L.T. Smith's line of thought and that of the $M C$, particularly in relation to the subalternisation of knowledge and subjugation of 'Others' by processes of colonisation. While most authors who work with these theories seem to use the words decoloniality and decolonisation interchangeably (Grosfoguel, 2007; Maldonado-Torres, 2011; Mignolo, 2012), Walsh draws a distinction between decoloniality as a continuous process aimed at constructing "radically distinct social imaginaries, conditions, and relations of power, knowledge", and decolonisation as a project which aims to "confront the vestiges of colonialism" (Walsh, 2012, p. 11). For the purposes of this thesis I will use the term decolonial thinking when speaking about a purposeful line of thought and decolonising when speaking about praxis. I will particularly draw from the concepts of the marginalisation or subalternisation of knowledges, that of monological truths and also disembeddedness, as defined above. I will now explore the notion of environmental narratives in the light of these concepts and as framed by 
decolonial thought. This will allow me to further understand how these narratives can subvert processes of colonisation by bringing local and experiential knowledges from the margins to the center.

\subsection{Environmental narratives}

According to Robertson, Nichols, Horwitz, Bradby, \& MacKintosh (2000), who explore environmental narratives as a pathway to restore degraded landscapes in Australia, 'environmental narratives' are "stories that are bounded by the narrator's particular experiences, observations, and attachment to place" (p. 120). Following on from this definition, it can be said that environmental narratives are inherently embedded and experiential, as they emerge through the relationship of a narrator with a particular environment.

The conceptualisation of coloniality, through the processes of marginalisation of knowledge and disembeddedness discussed above, have marginalised local and contextual environmental narratives in favour of dominant ones. According to Berkes (2010), when looking at the modern Western history of human beings' relationship to the environment, it can be characterised by separation and "the commodification of nature" (p. 14) which, in turn, has perpetuated binaries of nature/culture and human/environment. These binaries are perceived by the MC as lying at the heart of the "ecologically destructive practices of modernity" (Escobar, 2007, p. 197) and have often been ideologically enforced over local environmental narratives through processes of formal education and resource management policies. In Chile, for example, Mapuche environmental narratives which perceive "an indivisible unity between natural, super-natural and spiritual dimensions" (Quintriqueo \& Torres, 2013, p. 200, own translation) have been omitted or discriminated against in the formal state-sanctioned schooling context which prioritises Western scientific knowledge as a universal monological truth (Quintriqueo \& Torres, 2013; Rojas-Maturana \& Peña-Cortés, 2015). Environmental policies have also often enacted a subalternisation of local knowledges and 
practices, as is the case with the Law Decree 7011 in Chile, which consolidated massive pine forest plantations in the Araucanía region, disrupting the ecosystem and Mapuche agricultural practices (Peña-Cortés, Escalona-Ulloa, Rebolledo, Pincheira-Ulbrich, \& Torres-Álvarez, 2009).

The marginalisation of environmental narratives, in favour of a dominant and disembedded monological truth, has been argued as one of the main issues leading to the current state of environmental degradation. Mikulak (2008), theorising on the relationship between humans and the environment, calls this situation a 'crisis of narratives' (p. 68). In response, several authors have argued for a shift in perspectives: a "conceptual shift in the epistemological assumption of one objective truth" (p. 130) towards a position that legitimises multiple perspectives.

Furthermore, internationally this shift can be traced in recent environmental policies such as the declaration of legal personhood of the Whanganui river in New Zealand (Te Awa Tupua Bill, 2016) and the granting of legal rights to Pacha Mama (Mother Earth) in Bolivia (Ley de la Madre Tierra, 2010). These policies also reflect what Escobar (2007) calls 'novel environmental rationalities', or the rethinking of the ethics and culture of production framed within a dialogue of knowledges ( $p$. 198).

Coming back to L.T. Smith's (1999) conception of "telling our own stories" (p.42) as a way to resist regimes of monological truths, environmental narratives provide meaningful pathways towards decolonising and contesting monological conceptions of the relationships between humans and the environment. Through their situated and contextualised nature, environmental narratives open a space for dialogue between the dominant Western scientific knowledge and the local knowledges which transgress binary rationalities.

\subsection{Children's knowledges with and about the environment}

While the epistemological shifts and novel environmental rationalities mentioned above are to be welcomed, they also reflect adult agendas and knowledges which 
marginalise children. Matthews and Limb (1999), in their attempt to define an agenda for the geography of children, identify several ways in which children can be perceived "as a neglected social grouping undergoing various forms of sociospatial marginalization" (p.62). They describe this marginalisation often starting from the adult view that children are not capable of voicing and understanding their own needs and thus not able to participate in the decision-making processes which build their environments. This issue translates into environments being built for and not with children, a situation which relates to children being perceived as pre-political and lacking agency when shaping their places (Bartos, 2011). Several authors (Holloway \& Valentine, 2000; Matthews \& Limb, 1999) use the example of playgrounds to illustrate this point, as playgrounds are designed by adults as a space for children to spend energy and, at the same time, to contain them to a determined spatial practice which keeps them separate from the adult world.

Matthews and Limb's analysis, while helpful, mostly reflects on children's relationships with and within urban built environments in the UK, but it sheds a light on the conceptualisations of childhood which marginalise and/or contain their voices and their physical experiences. These authors raise the need "to investigate the environment as children 'see it'" (Matthews \& Limb, 1999, p. 66) moving away from the assumption that children know less than adults and towards the idea that "they may know 'something else'" (p. 68). Bartos (2011), in her work in Aotearoa New Zealand, built on this call to look at the meaning-making processes through which children develop an environmental awareness. She focused not only on how children saw the environment, but on how they embodied and sensed it. Other authors (Malone, 2016; Nairn \& Kraftl, 2016), also highlight the importance of being attentive to children's sensory and affective relationships in order to understand their relationships with, and within, the environment. They perceive children to have a "very strong affective sense of their everyday world" (Matthews \& Limb, 1999, p. 77) and a stronger relationship with 'natural' environments than adults (Chawla, 1988).

Such ideas stem from environmental psychology theories which suggest that when children spend time outside in 'natural' places they develop a stronger 
environmental consciousness (Kahn \& Keller, 2002; Louv, 2005). Thus children tend to be portrayed as the hope for the future, as having the capacity to bridge the gap between "the present and the future [...] being the materials from which the future will be made" (Lee 2013 as cited in Malone, 2016, p. 189). However, such perspectives can also contain children within adult-oriented environmental agendas. Both Bartos (2011) and Malone (2016) criticise this theorisation of children's human-nature relations, for instance, because it presents a romantic and reified perspective of both childhood and nature which portrays "a kind of Disneyfied childhood where nature [is] accessible to all" (Malone, 2016, pp. 190-191). This portrayal also fails to account for the complexities and entanglements of children, space and place, and doesn't take into account “children's agency when they do engage with their environment" (Bartos, 2011, p. 2). Furthermore, this portrayal of children as the hope for the wellbeing of our environmental future can have strong utilitarian outcomes. According to Sund and Öhman (2014), for example, who look at the universal values behind Environmental and Sustainability Education (ESE), these often embody a "homogenising tendency that promotes a neoliberal agenda" (p.642).

As such, even in approaches which seek to involve children in environmental knowledge and action, their knowledges and narratives become marginalised by the furthering of a dominant monological truth about the environment and the role that children play within it. This situation particularly affects children belonging to minority and oppressed groups. In the words of Tzou, Scalone and Bell (2010), Environmental Education (EE) does not necessarily address environmental justice "especially around issues of race, social class and power relations... [because it can] reinforce dominant societal values and marginalize those groups of students who are most impacted by pressing modern environmental issues" (p.105). This marginalisation frequently occurs because children and childhood are perceived as homogenous and universal categories which do not take into account differences in terms of gender, race, ethnicity, ability, health, age, culture and territorial location (Bartos, 2011; Holloway, 2014; Matthews \& Limb, 1999; Tzou et al., 2010). Holloway (2014), who explores the ongoing changes in the field of children's 
geographies, specifies that "Majority World children remain under-represented in children's geographies, much as research on the Global South is under-represented in human geography as a whole" (p.386). Based on her reflections on children's geographies, this lack of research doesn't only have consequences in terms of the lack of representation of marginalised children within academic texts, but also in terms of policy development and the opening of possibilities for these children to participate as social actors in their communities and nations.

Further, de Leeuw and Greenwood (2016) identify that there has been little attention to the role played by indigenous youth in the geographies of childhood and that there is a need to create spaces for engaging with indigenous children through research frameworks which "work to redress existing power imbalances" (p.61). These power imbalances emerge through the working of colonial power, through "historical constructions of land and childhood" (Nairn \& Kraftl, 2016, p. 10). An example of this situation can be seen in Williamson, Pérez, Modesto, Coilla, \& Raín's (2012) analysis of the ways in which Mapuche childhood and youth are under-represented in narratives about the Araucanía region. They speak generally about the "invisibility of indigenous childhood" in academic, scientific and intellectual pursuits (p.136, own translation).

This absence can be perhaps explained by the historical conceptualisation of children as human becomings rather than human beings (Holloway \& Valentine, 2000); a notion focused more on their socio-biological development than their actual subjectivities, experiences and ways of being in the world. However, during the 1980s the conception of children in the West shifted towards a constructivist view of them as meaning-producing and active agents in the world (Bartos, 2011; Holloway \& Valentine, 2000), resulting in what has been called the New Wave of childhood studies. The New Wave, like decolonial thought, sought to break binary notions associated with ideas of the social child versus the natural child (Ryan, 2011). This binary is perceived as limiting the understanding of the multiple imbrications of body, space and place in childhood (Bartos, 2011; Holloway, 2014; Nairn \& Kraftl, 2016; Ryan, 2011) and as perpetuating a dominant monological view of nature and culture. 
In addition, children came to be understood as embedded in particular definitions of gender, race, class and ethnicity (Bartos, 2011, p. 7). The New Studies of Childhood (NSCC), which focuses in the ways through which spatial discourses of childhood shape and inform socio-spatial practices and places (Holloway \& Valentine, 2000), has developed in parallel with indigenous calls to decolonise research. This focus has provided the impetus, in this thesis, for me to privilege the generation and sharing of indigenous children's environmental narratives.

Following on this impetus and the relationships I had already established with Mapuche and Māori communities, I sought to further understand how Mapuche and Māori children's environmental knowledges have been marginalised through processes of colonisation.

\subsection{Mapuche and Māori children's environmental knowledges within formal education}

According to Godoy (2009), formal schooling is one of the most successful mechanisms for the consolidation and diffusion of dominant colonial knowledge by "denying the previous culture and forwarding foreign theoretical knowledge" (p.2, own translation). This has been especially true for indigenous children who have been de-indigenised by schools as a way for "colonial nationhood... to maintain power and thwart strong self-determining indigenous subjects" (de Leeuw \& Greenwood, 2016, p. 57). Following from these assertions, I will focus this chapter on the histories of Mapuche and Māori formal education in order to further understand how Mapuche and Māori children's environmental narratives have been and are being marginalised.

Several Mapuche and Māori scholars argue that formal schooling has "mostly worked to reproduce the interests" of the dominant society (G. H. Smith, 2000, p. 64) and is founded in a "decontextualized curriculum which favours homogeneising models to maintain relationships of power and domination" (Quilaqueo, Quintriqueo, Torres, \& Muñoz, 2014, p. 272). The histories of colonisation of both 
cultures widely differ, in terms of amount of time (the Spanish arrived in 1540 to Chile, and the English in 1769 to New Zealand) and geographies, and there's also a huge diversity of experiences within both Mapuche and Māori groups in terms of the relationships they established with colonisers and processes of colonisation. Acknowledging these differences, I will attempt to bring together some of the common elements and then branch out in order to describe Mapuche and Māori histories of formal education.

During the early and mid-nineteenth century, in both Chile and Aotearoa New Zealand, missionary and native schools ${ }^{11}$ were established with the purpose of introducing indigenous children to "the habits and customs of the civilised life" (Blest Gana as cited in Flores Chávez \& Azócar Avendaño, 2006, p. 79, own translation). This action translated not only into the introduction of a new spirituality and rationality which didn't align to that of their families and ancestors, but also undermined "their cultural values, practices and language" (Timutimu, Simon, \& Matthews, 1998, p. 112) and attempted to replace them with those of the dominant cultures, Spanish in the case of Chile and English in the case of Aotearoa New Zealand. This undermining was often enforced through colonial legal frameworks such as Governor Grey's Education Ordinance of 1847 in New Zealand which, in order to aid the assimilation process, made English the compulsory language at school and established boarding schools which separated Māori children from their families (Ka'ai-Mahuta, 2011). This and similar initiatives in Chile were part of national projects aiming to remove Mapuche and Māori from what was perceived as a savage state and towards a civilised one (Chihuailaf, 1999), where civilisation was understood as "a more enlightened view of the world" (Ka'aiMahuta, 2011, p. 199).

\footnotetext{
11 Missionary schools in the Araucania region started being established after 1610 by catholic evangelising missionaries as a religious and political strategy geared to 'pacifying' the Mapuche who hadn't been defeated in battle (Gervás, Bilbao, \& Gómes, 2015, pp. 300-301). These religious initiatives were supported by the state which was attached to the Catholic Church up until 1925. Native schools were primary schools established by the government in Aotearoa/New Zealand in 1867 in order to assimilate Māori to the European culture. European families were appointed as teachers but Māori communities were to organise themselves, request a school and provide the land for it (Timutimu, Simon, \& Matthews, 1998, pp. 110-111).
} 
Through processes of colonisation, the civilisation of the savage indigenous came hand-in-hand with the domestication of nature. This early schooling period, up to the mid-nineteenth century, was accompanied by the beginning of massive changes in terms of territorial inhabitation where over ninety per cent of both Mapuche and Māori territory was occupied during the next century (Kingi, 2008; Marimán et al., 2006). Furthermore, this time was also the beginning of massive urban migration, and by the mid twentieth century both Mapuche and Māori people were in danger of losing their languages and, like most indigenous peoples, were also overrepresented in state indexes of poverty, isolation, political persecution, poor health and cultural marginalisation (de Leeuw \& Greenwood, 2016; Marimán et al., 2006; Richards, 2010; Rosas, 2013; G. H. Smith, 2000). Following from these changes it can be said that both Mapuche and Māori children who lived through this period experienced radical changes in their sense of identity as indigenous people and as citizens of the new nation-states in which they now resided (de Leeuw \& Greenwood, 2016). Furthermore, they experienced changes in the ways in which they were allowed or coaxed to relate to and with their environments.

The late twentieth century brought more radical changes. The 1970s in Aotearoa New Zealand began a journey towards becoming a 'bicultural' nation through the establishment of the Waitangi Tribunal to address main grievances at the time of colonisation. Whereas in Chile, the 1970s heralded seventeen years of military dictatorships. These and other changes affected formal schooling in both countries, as well as the position and status accorded to indigenous children's environmental knowledges and narratives.

\subsubsection{Chilean neo-liberal education}

As previously mentioned, the incursion of Missionary schools into Mapuche territory started as early as the seventeenth century. At this time Mapuche people were the only internationally recognised indigenous nation in Latin America; a recognition which was based on the Parliament of Quilin, verbally agreed upon with the Spanish Crown in 1641. After the Chilean independence in 1810, though, the Parliament of Quilin was dismissed as invalid by those dictating the laws, and 
Mapuche were to be considered as 'Chilean' and equal to any other citizen in the country. This dismissal came hand-in-hand with a campaign to portray Mapuche as the "savage and bloodthirsty indians of the South" (Bengoa as cited by Chihuailaf, 1999, p. 74, own translation) which supported the military campaigns initiated in 1883 to take the Mapuche territory, a process presented in Chilean history books as the 'Pacification' of Araucanía. This process resulted in 'land reductions', where Mapuche were given small plots of land (six hectares per person) which would later have to be subdivided, using straight lines and right angles. This division did not take into consideration natural landmarks, places of cultural/spiritual values or traditional forms of using the land (Marimán et al., 2006; Park \& Richards, 2007; Pinto Contreras, 2013). Thus, Mapuche children were not only immersed in an educational system geared towards assimilation, but their whole environmental and political context was changing in ways which reduced their possibilities of accessing and participating in Mapuche cultural practices based in territory.

Between 1962 and 1973 several agrarian reforms benefited Mapuche people in terms of land expropriation towards them; most of these laws viewed Mapuche as peasants, and only in 1972 a law was passed which recognised indigenous peoples in Chile (Richards, 2010). Most of the benefits these decades brought to indigenous peoples in Chile were removed with the onset of Pinochet's military dictatorship (1973-1990). The dictatorship implied a radical shift towards a strong neo-liberal agenda through which the land continued to be taken and eroded, especially with mining and forestry. Furthermore, the diverse indigenous cultures continued to be discriminated in an effort to assimilate them into a homogenous nation-state (Park \& Richards, 2007). Also during the dictatorship, several laws were passed which transformed the educational system in Chile to a mercantilised one, where schools would compete with each other in the market in order to increase their financial gains. This neoliberal approach, which would be strongly criticised in the nationwide student protests, the Penguin Revolution in both 2006 and 2011, further marginalised Mapuche students and knowledges by increasing the socio-economic gap in terms of access to education and lowering the standards and regulations especially for rural schools - in terms of quality (Webb \& Radcliffe, 2013). 
The return to democracy in the nineties brought with it a new mentality in terms of indigeneity. With the inclusions of multicultural policies, like the first Indigenous Law of 1993 and the signing of the ILO 169 Convention in 2009, the Chilean state took a step towards including indigenous language revitalisation and indigenous 'development' as a national project (Rosas, 2013). These multicultural approaches have been critiqued as "tantamount to recognising diversity without doing anything about the power inequalities that racial structures entail" (Richards, 2010, p. 65). An example of this tokenistic approach to 'multiculturality' is the fact that these projects were and are still put in place within other, more powerful legal frameworks - in particular the Chilean Constitution which doesn't recognise Mapuche or any other indigenous nation and stipulates an Anti-Terrorist Law (capture without trial) which is mostly applied to Mapuche people involved in acts of resistance.

The list of social injustices (Aylwin, 2006; Correa \& Mella, 2010; Richards, 2010) that have been condoned by this framework largely surpasses my knowledge and the space of this research but, to mention a couple of examples: over 100 Mapuche have been arrested without trial under this law; at least three young Mapuche involved in acts of resistance have been killed by police officers who have not been sentenced to prison. These and other violent issues which have resulted in both Mapuche and non-Mapuche victims stem from a history which has granted most of the Mapuche territory to private forestry companies and has failed to recognise and honour the fact that "the Mapuche has a relationship of identity with the land, and not only with the land but with the territory, that is, with all that within it lies" (Correa \& Mella, 2010, p. 181, own translation). This ongoing conflict continues to shape the experience of both adults and children within the territory and was an ever-present topic during my stay in Llaguepulli.

In terms of formal education, the new multicultural approach did carve spaces for educational programmes to focus on language revitalisation and cultural maintenance. Projects such as the Intercultural Bilingual Programme started in 2000 and the Decree Law 280 in 2009, which incorporates indigenous languages in the National Curriculum as optional for schools with high indigenous attendance, 
provided room for improvement in this area. Many of these initiatives have been critiqued due to their top-down approach, as they haven't been led by the Mapuche communities but are established by the central government without necessarily taking into account the depth of traditional knowledge and/or the appropriate way of transmitting it (Quilaqueo et al., 2014; Webb \& Radcliffe, 2013). But the twenty-first century has also brought several small resistance projects stemming from Mapuche communities which relate to tourism initiatives, small business endeavours and also to education. One of these projects is 'Kom pu Lof' the school which participated in this research project. As described in section 1.5, 'Kom pu Lof' is, up to date, the only fully autonomous indigenous school in the country and is bringing forth a Mapuche curriculum.

Currently Mapuche and other indigenous peoples in Chile are over-represented in indexes of poverty, completion of schooling and unemployment (INE, 2002). Added onto this, the neo-liberalisation of formal schooling and education in general in Chile have translated into a worsening of the country's already marked levels of social inequality (Rodríguez \& Winchester, 2001; Sabatini \& Wormald, 2004). Primary schools in Chile are free, but the differences in quality between private or subsidised and public schooling are extreme, a situation which has translated into "the appearance of new forms of educational inequality" (Puga, 2011, p. 215, own translation).

\subsubsection{Aotearoa New Zealand as a bicultural nation}

In order to better understand Aotearoa New Zealand's journey towards becoming a 'bicultural' nation, it is necessary to clarify the role and significance of the Tiriti $\bar{o}$ Waitangi (Treaty of Waitangi) as a founding document. The treaty was signed in 1840 between Māori iwi (tribes) and the English crown, and it stemmed from the Crown's desire to formalise the colony in New Zealand in order to protect it from other interested parties and to maintain civilised relationships with and within the Māori communities (King, 2003). The document itself was rapidly and haphazardly put together in English and translated into Māori, generating large discrepancies between one version and the other. This is particularly true for concepts like 
kawanatanga (sovereignty) and tino rangatiratanga (governorship), and also for what was governed or cared for: the taonga (treasures) which were understood by English as only material goods, and by Māori as including immaterial cultural treasures, such as te reo (the language). According to Timutimu et al. (1998), from the English Crown's perspective the treaty “effectively represented a license for colonial domination [whereas for Māori] it signalled the forging of a partnership [...] in which the sovereignty - and the culture - of each would remain intact" (p. 109)

These discrepancies, along with the large number of settlers arriving in Aotearoa New Zealand after 1840 and buying land ${ }^{12}$, resulted in the treaty being regarded by Pakeha (English) as irrelevant to the point where, in 1877, Chief Justice Prendergast ruled the treaty to be "a simple nullity" (Temm, 1990, p. 24) in the case of 'Wi Parata vs The Bishop of Wellington'. Nevertheless, several Māori iwi resisted the way in which land was being traded and Māori identity was being alienated (Belich, 2013, p. 86). This resistance evolved into what is known as the New Zealand Wars between 1845 and 1872 where a substantial amount of Māori land was confiscated under the 1863 New Zealand Settlements Act (Kingi, 2008). Added on to the confiscations, the purchasing of land actively diminished Māori ownership. It is estimated that by 1865 , for example, ninety nine per cent of the South Island had been purchased by The Crown and the New Zealand Company (Ministry for Culture and Heritage).

During this period and up until the 1970s, te reo Māori underwent a strong decline. It was affected by policies aimed to reduce its usage, such as Governor Grey's Education Ordinance previously mentioned and the policy of pepper-potting (Ka'aiMahuta, 2011) which placed Māori families migrating to cities after the Second World War within predominantly Pakeha (English) suburbs. This decline led to the prediction of the imminent death of te reo Māori by the Benton Research in 1971 (G. H. Smith, 2000) which, in turn, spurred Te Kohanga Reo ('the language nest'), an

\footnotetext{
${ }^{12}$ It is estimated that between 1831 and 1881 the number of English settlers increased by fifty thousand percent which went hand in hand with the increased number of Māori deaths from introduced diseases, so by the end of the nineteenth century Māori were only five percent of the total population of Aotearoa/New Zealand (Benton, 1991).
} 
initiative led by Māori elders "to take preschool children into total immersion Māori language nurseries" (G. H. Smith, 2000, p. 63).

'Te Kohanga Reo' was one of several initiatives, and Māori led acts of resistance during the 1970s in what has been called the Māori Renaissance, which is described by Gallegos (2007) as “a coalition of people's interests [where] arts merged with politics and activists" (p.61). Māori activists protested the breaches to the Treaty of Waitangi and, in 1975, the Waitangi Tribunal was established: a government organisation set out to investigate breaches of the Treaty. The strong Māori social movement and the government's response through the establishment of the Waitangi Tribunal signified a step towards the establishment of an actual bicultural nation.

As an attempt to include bicultural practices in education, the 'Taha Māori' programme was established in 1975; it included teaching of Māori culture and perspectives within schools - teachings imparted mostly by Pākehā educators. This programme was criticised as a display of "poorly understood notions of biculturalism" which "had the potential to be a disguise for assimilation" (Macfarlane, 2015, p. 180). By the 1980s, though, the situation radically changed in a process described by Smith as a "reawakening of the Māori imagination that had been stifled and diminished by colonisation processes" (G. H. Smith, 2003, p. 2) . This educational 'revolution' started out with the 'Te Kohanga Reo', as described above, and later developed to Kura Kaupapa Māori schools (Māori immersion medium schools) and Whare Wananga (Māori tertiary education). These formal institutions are run by Māori, for Māori, in their own language and with their own framework and curriculum based on Matauranga and Kaupapa Māori (Māori knowledge system and practices). Even though these Māori educational establishments are now recognised by the official legal frameworks, deficit theorising or the focus on social background, parenting and other social influences is still perceived as the main cause of Māori students underachievement (Macfarlane, 2015, p.183). As a response to this, and aiming to return the focus to cultural responsiveness, 'Te Whāriki' (literally 'The floor mat') and 'Te Marautanga o Aotearoa' (literally 'The Curriculum of Aotearoa') have become the official curricula 
for all early childhood centres and for Kura Kaupapa Māori respectively. Also, government programmes such as 'Te Kotahitanga', which strives to improve the educational achievement of Māori students in mainstream secondary schools (Bishop, Berryman, Cavanagh, \& Teddy, 2009), and 'Ka Hikitia', a strategy to provide Māori learners the opportunity to gain the skills and knowledge they need to realise their potential (Macfarlane, Webber, McRae, \& Cookson-Cox, 2014) have focused on researching and improving the educational achievement of Māori learners.

Nowadays the amount of students enrolled in Māori medium education represent $2.4 \%$ of the total school population, and $20.7 \%$ of the total school population are involved in learning te reo Māori (Ministry of Education, 2017). Also, and importantly, formal schooling in New Zealand is free and egalitarian in terms of performance differences between public and private school education, thus making it accessible for all children. Nevertheless, as Macfarlane, Webber, McRae and Cookson-Cox (2014, p. 19) identify in their research looking at Māori student's success:

"Māori students experience early disengagement from education, high levels of unemployment, early patterns of delinquency and criminal involvement, increased risk of mental illness and predictable loss of potential for future success."

The authors interpret this as a direct result of the history of colonisation and the overarching aim of assimilation within the education system in Aotearoa New Zealand.

\subsubsection{Mapuche and Māori children's environmental knowledges}

While seeking to better understand the learning processes at the intersection of indigenous epistemologies and formal schooling, Barnhardt and Kawagley (2005) assess that the methodologies used by mainstream schooling "are based on a worldview that does not adequately recognize or appreciate indigenous notions of an interdependent universe and the importance of place in their societies" (p. 10). The histories of Mapuche and Māori formal schooling exposed above present clear examples of this statement as, at least until the eighties in New Zealand and until 
today in Chile, the curricula which prescribe what is being taught do not take into account Mapuche and Māori knowledges. I will now briefly look at some environmental concepts stemming from their cultures and how they have mostly failed to be represented by formal schooling frameworks.

The strong connection of both these cultures to the territory can be perceived through the words used to describe themselves in their languages: Tangata whenua in te reo Māori and Mapuche in Mapudungun. As previously mentioned in section 1.1 , both these concepts roughly translate to 'people of the land'. Also, a key aspect in both cultures is the protocol of introducing yourself in conversation, in Māori this is called the pepeha where "the speaker facilitates connection through location and temporal signifiers (mountains, rivers, tribes, ancestors, etc.) to others present" (Penetito, 2009, p. 12), thus connecting genealogically to ancestors (human and non-human) who were here earlier. In Mapuche a similar protocol is called pentukun, the purpose of which is to "gain knowledge about the relatives, mainly about the territorial origin" (Quintriqueo \& Torres, 2013, p. 206, own translation), thus providing an activity which commits the ancestral territorial origin to memory. These introduction protocols are considered relevant in both culture's approach to formal education as they relate to the Māori concept of whakapapa (genealogy), which links all living beings back to Ranginui (Father Sky) and Papatuanuku (Mother Earth), and the Mapuche concept of "Mapu ñuke choyon iñchiñ", which translates into the saying "we are the sprouts of Mother Earth" (Chihuailaf, 1999, p.34, own translation).

The aforementioned concepts are taken from the literature and from my own personal experiences and conversation with Mapuche and Māori people. It is important to acknowledge that these concepts do not necessarily align to the relationships that the Mapuche and Māori children who participate in this research perceive with and within their environments. To do this would be to fall into essentialising notions of what indigenous knowledge is and, in a way, further marginalise the children's knowledges by forcing them within a known category. I will expand briefly on the concept of indigenous knowledge(s) and how it will be used throughout this research. 
Kincheloe and Steinberg (2008)define 'Indigenous Knowledge' as:

"... a multidimensional body of understandings that have [...] been viewed by Euroculture as inferior and primitive. For the vast numbers of indigenous peoples from North America, South America, Australia, New Zealand, Africa, Asia, Oceania, and parts of Europe, indigenous knowledge is a lived-world form of reason that informs and sustains people who make their homes in a local area. In such a context, such peoples have produced knowledges, epistemologies, ontologies, and cosmologies that construct ways of being and seeing in relationship to their physical surroundings." (p.136)

Several authors advocate for the profound benefits and social and environmental justice importance of moving indigenous knowledges from the margin to the centre (Barnhardt \& Kawagley, 2005; Berkes, 2010; Escobar, 2012; Kincheloe \& Steinberg, 2008; Maurial, 1999; Tzou, Scalone, \& Bell, 2010). This advocacy comes from different perspectives such as decolonial thought which seeks a shift towards multilogicality, or the opening spaces for dialogue between subjectivities that work under different logics (Kincheloe \& Steinberg, 2008), instead of working under a dualistic monological truth. From the perspective of environmental resilience, Berkes (2010) advocates for the benefits of holistic indigenous approaches instead of command-and-control views. And Barnhardt and Kawagley (2005) advocate for valuing knowledges and practices which are "rooted in the long inhabitation of a particular place" (p.9). Nevertheless, the concept of indigenous knowledge is also problematic, as it is often used in simplistic and reified ways which depict it as static body of knowledge which has a lower claim to truth than Western scientific knowledge (Johnson, Louis, \& Kliskey, 2014; Kincheloe \& Steinberg, 2008; Maurial, 1999; Walsh, 2012).

For this research project I will follow Kincheloe and Steinberg's (2008) contention that a definition of indigenous knowledge should always take into account "the colonial/power dimensions of the political/epistemological relationship between the indigenous cosmos and the Western world" (p.4). Following from this, it is relevant to be aware of De Leeuw and Greenwood's (2016) argument that 
indigenous peoples and youth who are living "increasingly mobile, urbanizing, and border-crossing lives" may struggle to attain clarity about what it means to be indigenous and will not fit into neat categories of what it means to be indigenous (pp.50-51). Furthermore, I have mostly avoided using the general concept of indigenous knowledge, as the main focus in this research was to explore the specific knowledge shared by the two groups of participating children.

While keeping the above comments in mind, it is possible to see that both Mapuche and Māori environmental concepts present similarities in terms of their kinship imaginaries or "the basis of how we imagine ourselves to be connected to the world around us" (Mikulak, 2008, p.66). They are both founded in an ethics of interconnectedness, where nature is not conceptualised as a passive space, but as an active agent. These notions, which are learnt through direct experiences with the world, perceive an interconnectedness or continuity between the human, nonhuman and the spiritual. This continuity is aligned to Barnhardt and Kawagley's (2005) insights when looking at Alaska native ways of knowing and how they intersect with Western knowledge systems. According to these scholars, Western science in formal schooling tends to "emphasize compartmentalized knowledge that is often decontextualized" (Barnhardt \& Kawagley, 2005, p. 11). Furthermore, in her research looking at pathways to improve Māori students engagement with science education, McRae (2014) presents the fact that the underachievement of Māori and other indigenous students around the world in science education is explained by "the lack of recognition of indigenous culture in the science classroom" (pp.33-34). This seeming opposition between indigenous knowledges and Western scientific knowledge is relevant when looking at the relationships Mapuche and Māori children perceive with and within the environment, because science is the category under which environment sits within the Chilean Primary School Curriculum (Ministerio de Educación, 2012) . In Aotearoa New Zealand the concept of environment is explored both under the category of science and of social sciences (Ministry of Education, 2007b, Ministry of Education, 2007a).

Within 'Te Marautanga o Aotearoa', the Māori curriculum used by Kura Reo (Māori immersion schools), the relationship with and within the environment, exemplified 
in the Science/Putaiao area, is firmly based in the Māori concept of whakapapa. For example, one of the main values in the Science/Putaiao area is: "Hold fast to traditional values, originating from a notion of the relationships between all living things" (Ministry of Education, 2007, p.38). In the emergent Mapuche curriculum, this concept of interconnection amongst all living things is also a strong pillar underlying all areas of learning. The words 'Itrofill Mogen' can be translated as a balanced coexistence with the Mapu (earth) from a natural, social and spiritual perspective (Pinto Contreras, 2013, p.21, own translation). This notion sees territory as a living unit where all members are legitimate and related and the 'che' (man) is responsible for preserving balance.

In New Zealand there are two parallel curricula which, in the words of McRae (2014) "is an example of validating two cultural bodies of knowledge" (pp.35-36). Both 'Te Marautanga o Aotearoa' and the National Curriculum recognise te reo Māori as an official language, are based on the conception of New Zealand as a bicultural nation (Ministry of Education, 2007a) and acknowledge and work with Māori philosophy in different areas (but not within the sciences in the case of the National Curriculum). This is quite different in Chile where the Primary School Curriculum only recognises Spanish as the official language and only refers to Mapuche and other indigenous nations in historical and reified terms: all references found in the Curriculum to 'Mapuche' referred to historical events or to cultural traditions (MINEDUC, 2012). The only exception to this is the inclusion of a special language section which has been developed since 2009 and allows schools which want to favour intercultural education or have over twenty percent of indigenous students in attendance to teach their own languages (Law Decree 280).

Drawing from the information presented above, it can be said that Mapuche and Māori children's environmental knowledges have a reduced space for exploration and expression in the majority of the current formal schooling systems. In Aotearoa New Zealand there are certainly more spaces, especially with the availability of full immersion autonomous Māori schools, though the majority of Māori children and youth attend schools which are not teaching the Māori curriculum (Ministry of Education, 2017). In both cases, children are attending institutions which mostly 
privilege Western scientific knowledge, a knowledge based in the conception of our world as a "physically observable entity [which opposes] many indigenous peoples' views of intangible spiritual phenomena" (Durie 2005 as cited in McRae, 2014, p. 35).

\subsection{Summary}

In the previous sections I have exposed, through the lense of decolonial thought and its concepts of disembeddedness, monological truths and marginalisation of knowledge, how environmental narratives which are embedded and experiential can provide a meaningful path towards the decolonisation of knowledge. I have also looked at the ways in which children's knowledges and experiences with, and within the environment, are often socio-spatially marginalised in an adult world where children's voices are considered to have a lower claim to truth. Finally I looked at how Mapuche and Māori children's environmental knowledges in particular are and have been marginalised within the formal schooling space through educational frameworks which reproduce structural inequalities and impose Western scientific-monological truths. But the questions still remain: How can we gain a better understanding of the ways in which Mapuche and Māori children represent relationships with, and within the environment? How can we nurture 'critical border thinking' spaces for these knowledges to emerge and be heard? 


\section{Critical Pedagogies of Place as a theoretical framework}

\subsection{Introduction}

Mapuche and Māori environmental knowledges, which share a notion of interconnectedness amongst human and non-human within the environment, are not currently fully validated and often not included in the dominant curricula, which privilege a fragmented conception of reality. Within this scenario, Mapuche and Māori children's environmental knowledges remain mostly silenced as they sit in an undefined and fluid zone between monological conceptions of environment and reified perspectives of perspectives of indigenous knowledge and what it means to be indigenous.

The main question of this research project aims to explore Mapuche and Māori children's environmental knowledges from a perspective which takes into account processes of colonisation. More specifically, it aims to analyse how the decolonial concepts of marginalisation of knowledges and disembeddedness are represented or subverted by Mapuche and Māori children when reflecting on their relationships with, and within the environment.

In order to shed some light into these questions I will present Critical Pedagogies of Place (CPoP) as a theoretical framework which sits at the convergence of decolonial thought and environmental rationalities within children's pedagogical experience. CPoP, as presented by Gruenewald (2003a), is the coming together of Critical Pedagogies and Place-Based education. It is a union which enacts "a pedagogy linked to cultural and ecological politics, a pedagogy informed by an ethic of ecojustice and other socioecological traditions that interrogate the intersection between cultures and ecosystems" (Gruenewald 2003a, p.10). For the aims of this research I focused specifically on the CPoP concepts of cultural decolonisation and ecological reinhabitation, which I describe in the following sections, as lenses to explore Mapuche and Māori children's environmental narratives from a decolonial perspective. 


\subsection{Cultural decolonisation}

In order to understand Gruenewald's (2003a) concept of cultural decolonisation it is necessary to begin by an understanding of Critical Pedagogy which stems from Freire's seminal work 'Pedagogy of the Oppressed' (1970). In this work Freire explores how oppression- the dehumanizing violence embodied by the oppressors, those who exploit the oppressed by virtue of their power and are immersed in an "unjust order" (Freire, 1970, p.44)- is perpetuated systemically by both the oppressor and the oppressed. This process takes place through structures of power, such as those enacted in a setting of formal education. An example of this can be seen in the previously mentioned cases of boarding schools in Aotearoa New Zealand where, with the 1847 Education Ordinance, Sir George Grey encouraged the schools to remove Māori children from their villages in order to assimilate them to European ways of life (Walker, 1990). Ka'ai-Mahuta (2011), who analyses the impact of colonisation on te reo Māori, qualifies this displacement of Māori children through structures of power, as "cultural violence" (p.201). Freire argues that, in order to break free from this oppressor-oppressed relationship, the oppressed must engage in a Transformative Action, a movement towards liberation. In this process, the oppressed become critically conscious of the power dynamics in which they are immersed, and they can then resist them through transformative action (FIG.3).

\section{Conscientisation $\longrightarrow$ Resistance $\longrightarrow$ Transformative Action}

FIG 3- Depiction of Freire's Transformative Action process

Freire's process of Transformative Action has been linked to decolonisation through its emphasis on "the ways that education operates as a site of colonial power" (Mackinlay \& Barney, 2014, p. 1) and its aim to transform the structures of power, starting from a conscientisation which takes action "against the oppressive 
elements of reality" (Freire, 1970, p. 17). Gruenewald (2003a), in his presentation of $\mathrm{CPoP}$, specifies cultural decolonisation as one of the main aims of Critical Pedagogy. He describes it as the process of identifying and uprooting dominant ideologies, confronting the dominant system of thought and recognising "disruption and injury [...] to address their causes" (p.9).

The relationship between Critical Pedagogy and decolonisation has been problematized by several authors (Allen, 2004; Ladson-Billings, 1997; Leonardo, 2002; Mackinlay \& Barney, 2014; Tuck \& Yang, 2012). Tuck and Yang (2012), who draw attention to the many discourses in which 'decolonisation' is used as a metaphor to reconcile settler guilt, critique Freire's concept of conscientisation because it has been used to describe a process of decolonising the mind. This usage reduces the project of decolonisation to an individual and internal process drawing attention and action away from "the need to give up land or power or privilege" (p.21). This contention is particularly relevant for non-indigenous academics, as identified by Mackinlay \& Barney (2014) because Critical Pedagogy discourses have "tended to ignore white race and colonial power and privilege" (p.2).

For the purposes of this research I will use the concept of cultural decolonisation which stems from Gruenewald's (2003) understanding of it as the awareness and confrontation of dominant ideologies. This concept will be one of the main lenses to look at the ways in which Mapuche and Māori children's environmental narratives represent relationships with, and within the environment. This lens will also allow me to work from a decolonial framework by being attentive to the ways in which Mapuche and Māori children express or represent an awareness of the marginalisation of their knowledges by dominant ideologies and discourses. Nonetheless, following on Mackinlay and Barney's (2014) contention, I acknowledge that this research and my role within it is framed within a settler colonial academic space. In 4.3. I will further explore my own position as a nonindigenous researcher and the ways in which I have strived to honour the voices of the participant children while using this thesis as a vehicle to share their narratives. 
Freire's Critical Pedagogy has been further criticised by ecological educators due to its lack of environmental awareness, as it fails to align the transformation of cultural situations with the carrying capacity of environmental systems or with the intrinsic value and relationships between human and environment. Bowers (2001), warns of the dangers of Critical Pedagogy reinforcing individualism, anthropocentrism and a "belief in the progressive nature of change" (Gruenewald, 2008, p. 312). These perspectives are said to fail at embracing indigenous knowledge and evidencing the connections between the human and non-human environments. Bowers advocates for eco-justice instead, which clearly links the subjugation of people, lands, resources, ecosystems and knowledge to the global economy (Bowers, 2001). In order to complement Critical Pedagogy with an approach to education which does stem from an eco-justice perspective, Gruenewald (2008) presents Place Based Education (henceforth PBE) and one of its main concepts, ecological reinhabitation.

\subsection{Ecological reinhabitation}

PBE, according to G.A. Smith (2002), responds to the issue of education becoming a passive and disembodied experience which drives attention away from the child's own circumstances and towards non-local knowledge. Under the theory of PBE, the art of teaching is embedded and intertwined with the local biophysical environment which needs to be inhabited by direct experience. One of its main concepts is ecological reinhabitation, understood as learning to live in place "in an area that has been disrupted and injured through past exploitation"(Berg and Dasmann 1990 as cited in Gruenewald, 2003a, p. 9). Berg and Dasmann (2014) give an example, looking at the case of California as a region whose life-sustaining capacities have been harmed through "chronic-misuse" and "waste" (p.36). They propose ecological reinhabitation in this area as a living in place or "becoming aware of the particular ecological relationships that operate within and around [that place, and] undertaking activities [...] that will enrich the life of that place" (Berg \& Dasmann, 2014 , p. 36). Gruenewald (2003a) identifies several paths and ideas that become 
relevant for this process of ecological reinhabitation, such as Sobel's (1996) ideal of "reclaiming young people's heart" (p.10), which relates to fostering experiences of care for surrounding places as a way of generating connectedness to the natural world.

One of the main weaknesses ascribed to PBE, nevertheless, is the fact that it is largely un-critical in terms of its awareness of the wider historical and cultural picture. In their online dialogue about these issues, Smith and Greenwood (also Gruenewald) use the example of school gardens, where children are encouraged to participate and learn about gardens, but are not necessarily encouraged to "grapple with the deeper forms of cultural change that motivate my commitment to place" (G. A. Smith, 2010, para.2).

For the purposes of this research I will use the concept of ecological reinhabitation as the process of actively inhabiting and caring for a place which has been ecologically disrupted, while being aware of the ecological (human and non-human) relationships occurring with that place. The concept of ecological reinhabitation presents itself as a helpful lens to further explore Mapuche and Māori children's environmental narratives from a decolonial perspective, as it brings attention to the contextualised and embodied connection to a specific place. This attention may provide a space for decolonising and contesting monological truths as it addresses the issue of disembeddedness.

\subsection{Conclusion}

CPoP, as a theoretical framework, allows for being attentive to the issues of marginalisation of knowledges and disembeddedness. This because it brings together a critical awareness of colonisation through its concept of cultural decolonisation, and the embodied experience of inhabiting a place through its concept of ecological reinhabitation. I will continue to use these concepts throughout the research as a tool for marginalised environmental narratives to be understood critically and in relationship to their environments. 


\section{Methodology}

\subsection{Introduction}

To better understand the relationships that Mapuche and Maori children are representing with and within the environment, I have chosen to do an exploratory project based on a relational constructionism ontology and informed by decolonial thought.

I will now establish its philosophical basis and, following this line, I will outline the research design and how it was (re) constructed during the experience of the field and while building relationships with the participants. I will return to my main research questions in order to outline the chosen methods of analysis paying attention to ethical considerations.

\subsection{Relational seeds of the research journey: An ontology}

As stated at the start of this thesis, I came to this research place and topic through several experiences. The first was travelling in the Araucanía region in Chile with my friends and learning about Mapuche people while realising my deep lack of knowledge and understanding of that culture. The second was the process of learning about Māori education in my Master's courses, the resistance movement that has led to its current development and the importance of a critical connection to place within it. The final step was participating, as a driver and translator, in a project which brought three people from Llaguepulli to travel around Aotearoa New Zealand connecting with Māori tourism and education initiatives. Through this process relationships were formed, strengthened and questioned between myself and several different territories, peoples, beliefs and ideas. From these relationships and the emotions, thoughts and questions they brought up, emerged the seeds of this research project.

In the previous paragraph's narrative I express a deep belief about the way in which reality is shaped. By explaining the emergence of this research project through the 
encounter of bio-physical, social, spiritual and cultural currents, I follow a relational constructionist ontology whereby reality is a continuously emergent construction process which occurs at the encounter of non-bounded persons/entities/ontologies (Hosking, 2011).

Constructivism, the main starting point of relational constructionism, views reality as multiple and knowledge as co-constructed by actors, a view contrary to the naturalist view of reality as something that is already there and can be known by observers (Denzin \& Lincoln, 2008; Hosking, 2011; Moses \& Knutsen, 2012). This naturalist view informs the positivism of the dominant Western scientific knowledge, the same dominant scientific knowledge which underpins the prevailing school Curricula in Chile and Aotearoa New Zealand (see section 2.5). The constructivist inquiry, similar to naturalism, is a search for patterns, but those patterns are not to be found in an external and established reality, but are established in the human mind (Hosking, 2011) and co-constructed through relationships with others. In order to access these patterns of mind, social constructivism emphasises the study of language and communication as formative processes and doorways to understanding human subjectivity (Hosking, 2011; Pearce, 1995). Resulting from this view, research is a process co-constructed amongst actors (researchers, participants and others), shaped by individual experiences and aimed towards gaining an understanding of subjective meanings (Creswell, 2013; Denzin \& Lincoln, 2008).

Relational constructionism comes from a psychology background and has been mostly applied to organisational research (Hosking, 2011; van der Haar \& Hosking, 2004) and communications theory (Deetz, 2010). For this research I shall work with Hosking's definition which, as she describes, differs from the dominant constructivism discourse outlined above mainly in that it shifts the attention from the product (the meanings) constructed by individuals, towards the processes of relational construction, with these processes being the medium in which "relational realities are always in construction" (Hosking, 2011, p.51). This shift implies a view of individuals as having multiple selves constructed in "particular relations with particular others" (Hosking, 2011, p. 51) through ongoing performances. This 
presents a highly fluid view of reality which is in continuous construction at the encounter of subjectivities which are in continuous construction themselves. However, these fluid processes materialise by forming particular forms of life (Wittgenstein, 1953) and not others, multiple local ontologies with power relations which are, themselves, open to change. Under this paradigm the process of research itself is the product, and is relationally constructed by un-stable and unbounded entities. It does not necessarily aim to generate further understandings which fit under the local ontology of scientific knowledge, but is oriented to a practice which opens up possibilities of multiple self-other relations, new ways of being in relationships and being aware of ongoing, emergent and multiple local realities (Hosking, 2011).

The openness to multiple possibilities and new ways of being mentioned by Hosking is strongly linked to decolonial thought. As previously mentioned (see section 2.1.1), Maori scholar L.T. Smith (1999) claims research as a field of resistance which brings critical awareness and transformative action to regimes of monological truths (Foucault, 1991). Complementary to this critical awareness, the MC proposes thinking from the border, "from the perspective of epistemic forces that have been turned into subaltern (traditional, folkloric, religious, emotional, etc.) forms of knowledge" (Mignolo, 2012, p. 11). Following from this, my understanding of practising this openness as a researcher translates into starting from the premise that there are several paths of relating to, and with, participants and environments, and we are all already involved in multiple ways of relating. Therefore, a research which maintains this openness is flexible by nurturing spaces where new ways of relating can emerge. This openness encourages multiple, and perhaps contradictory voices to come out throughout the process without marginalising them through the imposition of particular regimes of truth.

Similarly and drawing from the insight previously mentioned on doing research with children and in particular with indigenous children (see sections 2.1.2 and 2.1.3), relational constructionism's fluid view of reality aligns to the "messiness of documenting and theorizing children's encounters" (Malone, 2016, p. 186). By being open to new possibilities and attentive to the processes through which reality 
is constructed, this ontology allows for research with children which focuses on the ways in which they relate with, and within their environments and is open to their knowledges without requiring them to sit within a dominant positivist framework.

In conclusion, the epistemological basis of this research lies in relational constructionism, the existence of multiple and diverse truths and knowledges which are continuously formed through ongoing relationships between ever-changing human and non-human beings. In terms of looking at Mapuche and Māori childrens' ways of representing environmental relationships, this translates into a research process which nurtures a space for their narratives to emerge in their own terms and with openness and attention to the 'other' knowledges that they bring to the forefront. I will now elaborate on the chosen methods and research design to accomplish these goals.

\subsection{Plan and rationale}

From the ideas in the previous sections I can summarise my research design as a qualitative and exploratory research based on a relational constructionism ontology and informed by decolonial thinking. In order to address the question about the ways in which Mapuche and Maori children represent relationships with, and within their environments from the aforementioned theoretical basis, I have chosen digital storytelling and reflexive participant observation as methods. This choice has been informed both by the literature and by the circumstances and relationships which have shaped this research project.

\subsubsection{A knowledge exchange with appropriate methods}

During the time in which we were organising the Mapuche delegation's visit to New Zealand, we had a few email exchanges defining the goals and expectations for the trip. One of these goals remained close to my heart and was, in a way, the seed for this research project. This was the desire to "establish connections of support between Māori people and the Mapuche Lafkenche territory of Lake Budi in the 
educational sphere" and generate a "cultural and pedagogical exchange" between them (taken from email exchange while planning the visit, August, 2016, own translation). This goal was central in shaping the present methodology as I strove to include an element of exchange or dialogue so that Mapuche and Māori children could connect and share experiences in order to learn from and with the other.

\subsubsection{Digital storytelling}

Digital storytelling is a form of digital media which can include images, videos, music and voice. It has been used as a participatory method enabling groups and communities to tell their own lives and listen to other's stories. It can both enhance a participant's sense of personal and cultural identity, and be used with a political agenda for marginalised voices to emerge (Bliss, 2015; Bliss \& Fisher, 2014; Murakami, 2008; Palacios, 2012).

On the topic of research with indigenous children, several authors identify a gap as there is still little research being done with these groups and other minority group children (de Leeuw \& Greenwood, 2016; Holloway, 2014; Nairn \& Kraftl, 2016; Tzou et al., 2010; Williamson et al., 2012). De Leeuw and Greenwood (2016) state that this is a growing field where an increasing amount of research is being undertaken. They call for this research to acknowledge autonomous indigenous community partners and, highlight that there is "wide-open potential for geographers to engage indigenous young people through community-based participatory action research or other research frameworks that work to redress existing power imbalances between geographic researcher and research participants" (de Leeuw \& Greenwood, 2016, p. 61)

Much research supports the usage of visual methods when working with children as they can provide a powerful and creative path for both the children and subsequently for the adults to access their subjectivities (Bartos, 2013; Chakraborty, 2009; Lee \& Abbott, 2009). In her work with youth in New Zealand, Wood (2011) centres the importance of methods which pay attention to the where and allow youth to voice their stories about their own places (p.72). Bartos (2013), when 
presenting her choice of methods which were based in child-friendly techniques, explains that the usage of cameras and photography was what "solicited the most insight into the children's embodied sensory engagement with their environment" (p.92). She goes on to mention several studies which show the use of cameras can be a beneficial methodology to work with children as it clearly shows their own view-points which are different from adults (Chakraborty, 2009; Lee \& Abbott, 2009 and others). Both Bartos and Wood use Photovoice, a participatory method which enables participants to record and represent their realities and ideas to others (Wang \& Burris, 1997, p. 370) and enables them to "define for themselves what is worth knowing, remembering, and changing" (Freeman \& Mathison, 2009, p. 123). Their research experience on work with cameras and narrative shows that these are useful tools for children to express their own view-points and they can also stimulate reflexivity (Bartos, 2011; Wood, 2011). Nevertheless, Photovoice didn't seem to fit the characteristics of this research, mainly because the 'product' would be stand-alone photos without narratives to accompany them, which could potentially make the process of sharing it with the other group of children cumbersome and inaccessible. My research project aimed to create a mediated exchange between the two groups and therefore called for a 'product' which could be shared without requiring much explanation or context to be delivered. Digital Storytelling seemed to provide a solution to this issue.

In her thesis looking at Digital Storytelling as a methodology to understand how emotion and affect are produced, Bliss (2015) describes it as a performative, creative and messy methodology which "has the capacity to illuminate connections between emotion, affect and power relations in everyday life" (p.242). It has been used as a tool for social justice by bringing back image and story construction to the hands of the participants (Meadows, 2003), as a transformative tool for activism and identity construction by providing a performative space for nurturing identities (Murakami, 2008) and as an emancipatory tool for indigenous adults and children to narrate their realities (Palacios, 2012). So it can be said that it includes all the beneficial elements previously introduced for visual methods and work with cameras and, more importantly, it would also allow for the children to create a 
finished product which could be then shared with the other group. This because a Digital Story brings together the photos and a recorded narrative into one video which can then be seen in its entirety by different audiences. Moreover, as a technique, it is flexible and accessible as it doesn't require large amounts of equipment and can be tailored to different situations. For these reasons Digital Storytelling presented itself as an ideal methodology, however, in order to carry through a research project which cultivated an awareness of the power dynamics between myself, the participants and the communities, it was necessary to complement it with a methodology which brought reflexivity into the mix.

\subsubsection{Reflexive participant observation}

Guiding this research from a relational constructionist philosophy I aimed to reflexively look at the relationships that emerged and were represented throughout the process of creating the digital narratives.

Reflexivity refers to locating "the various subject positions of the researcher in order to acknowledge the limits of one's knowledge and maintain a close examination of how research is shaped by various research encounters" (Bliss, 2015, p. 27). Reflexive participant observation has been used as a tool to better understand the everyday lives of the participants and the researcher's own experiences in the field. It has been used to complement the visual methods used by several of the studies working with children mentioned above and others (Bartos, 2011; Bliss, 2015; Punch, 2002). Kullman (2012), who explores methodologies with children and cameras notes that even though visual methods might be perceived as fun and participatory, "researcher-participant power imbalances may easily compromise children's voices" (p.3) which is a reason to practice reflexivity and being aware of the "intrusiveness of our own perceptions when working with children" (Cook and Hess 2007, p. 44 as cited in Kullman 2012, p.3). Bliss and Fisher (2007), for example, kept reflective diaries during each workshop in order to reflect on the process of creation of the videos and the contexts in which they were produced. Punch (2002), on the other hand, calls for researchers working with children specifically to be reflexive and critically aware of 
the ways in which "research with children may be potentially different from research with adults" (p. 338). Therefore, critical reflexivity can be perceived as essential when working with visual methods and children as it allows the researcher to be attentive to both the contexts of creation and the ways in which different relationships shape the creations.

Bateson (2015) describes reflexive participant observation as a process in which you simultaneously observe and engage with the action, and being fully present with those processes is a thing to be learnt. It allows for practicing an awareness of both the local realities/ontologies and the researcher's role in building certain dynamics while also engaging in active participation.

Joining Digital Storytelling and Reflexive participant observation seemed to be an achievable, effective and respectful way of accessing a better understanding of Mapuche and Māori children's ways of representing relationships with, and within the environment. I will now outline the initial research plan and how it attempted to bring use these methods with the participants.

\subsubsection{Initial research design}

The process of finding/creating a methodology was in continuous dialogue with the process of establishing relationships with the participating communities. There were certain moments which required me to communicate these methodologies with more clarity than I actually had. Based on the literature and taking into account the amount of time and fluidity of communication I had with potential participants, I came up with an initial plan which is summarised in FIG. 4 and then explained in detail. My main resource for defining the Digital Storytelling steps was a resource for educators which outlines the eight main steps (Morra, 2014). I took this resource and distilled it to process which I thought would fit the circumstances of field research in terms of time and resources. 


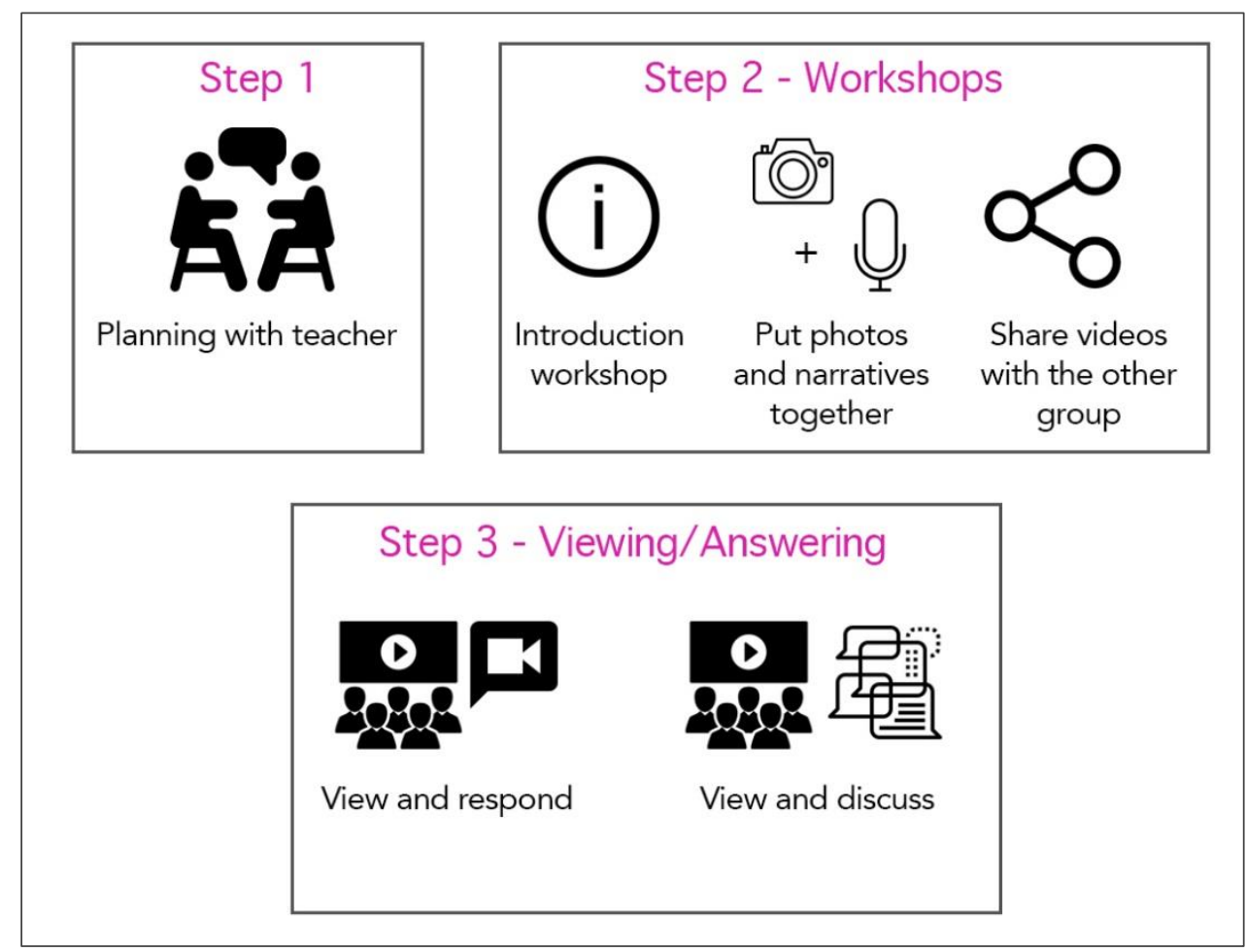

FIG 4- Initial research design

\section{Step 1: Planning with teacher}

A planning meeting with the teacher and/or parents. This meeting's goal was to introduce the project, get to know more about the children and plan the sessions so they' $d$ be aligned to their timelines and objectives.

\section{Step 2: Creating the digital stories}

Three workshops aiming to understand the project and how to make digital stories, collect and create materials and put the materials together in a digital story.

- Workshop 1: The children would learn about the other group, learn about digital storytelling and reflect on their own relationship with/in the environment in order to come up with ideas. Then they would take images in their own time as homework.

The first workshop presentation was structured as follows: 
- Introduce myself by situating me geographically using an 'upside down world map' (photo) so we could also talk about what the 'right' way of looking at geography was.

- Introduce Aotearoa New Zealand and Chile with brush-strokes of pre-Māori and Mapuche, colonial and contemporary history focusing in particular on the positions of Māori and Mapuche within that history.

- Introduce the other group of children with particular attention to their relationship with the environment.

- Ask them about what was important for them in their environment.

- Outline how we would go about creating the Digital Narratives. (The presentations I used for this first workshop are available as Appendices to this thesis)

- Workshop 2: Put the material together, create the first draft and review the videos.

- Workshop 3: Present the finished material to each other.

\section{Step3: Receiving and reacting}

Two workshops aiming to view the other group's videos and create a response.

- Workshop 1: View the videos of the other group, discuss and create a simple answer video.

- Workshop 2: View the other group's answer and discuss.

This initial plan was a useful tool in the process of visualising and communicating, but it was quite far removed from what was actually done. The process changed as relationships and connections changed too. These connections (re)create certain worlds which are, themselves laden with power dynamics, power-over and powerto and this is where the researcher's active reflexivity comes into play. Mason (2002) describes the researcher's expected active reflexivity saying that the researcher "cannot be neutral, or objective, or detached, from the knowledge and evidence they are generating. Instead, they should seek to understand their role in that process" (p.3). In the following section I will explore my positionality in order to further clarify the multiple and entangled roles I played within this journey. 


\subsection{Positionality}

Establishing the researcher's positionality is a step towards critically and reflexively acknowledging where the researcher's notion of knowledge comes from, which is making transparent aspects like race, gender, nationality class and historic context notion (G. Rose, 1997). Haraway (2013) theorises this act of situating oneself as an act of relinquishing a claim to universal truth (p.193), which aligns to decolonising methodologies by being clear and critical about the power of histories which are narrated as absolute knowledge within imperialist regimes of truth in order to open up possibilities for other narratives. In this space I explore where my own notions of what knowledge is come from.

I was born to a privileged Chilean family, but perhaps not that privileged and not that Chilean. My grandparents were all Eastern European Jewish who migrated at different stages throughout the period of the World Wars. I was raised in a not fully Chilean environment which privileged European knowledge and not much was mentioned about different Latin American knowledges or indigenous knowledges, and also not much was mentioned about the military dictatorship which already ruled the country when I was born and did so until I was six years of age. Growing up in dictatorship meant more silencing, a silence strategically perpetuated by the media which was and still is owned by those who wield political and financial power in the country.

My notions of Mapuche people and culture were mostly reduced to essentialist ideas about how they used to live (what they taught us at school) and a blurry notion about the injustices this and other indigenous groups had been subject to. This is for me especially harsh considering that the maids who lived in my house, fed me, cooked for me and combed my hair were mostly Mapuche, and we never talked about it. Again this is part of the realm of things that were simply not discussed in my bubble of Chilean society.

After a few years of studying and working I moved to Aotearoa New Zealand and started learning about and participating in different projects related to sustainable 
communities and other possible ways of living which made me deeply question the conceptions of knowledge with which I grew up. Being in New Zealand also brought me closer to Te Ao Māori (the Maori world), through new relationships, opportunities to stay in marae and starting to learn te reo Māori. Learning and experiencing Te Ao Māori drove me to reflect on the position of Mapuche and other indigenous groups in Chile and the world, and to strongly feel that I lived immersed in a society which mainly gave forum to one dominant voice. I started feeling that this main voice had been deafening for many years, as it silences other histories and experiences. And I started feeling a sense of the importance of hearing these histories and allowing those different experiences of the world to also be a part of it.

This somewhat 'new' mind-set then informed the roles and relationships I inhabited within the research process.

\subsection{Establishing connections (or failing to do so)}

As previously narrated (see section 1.1), my relationship with the Llaguepulli community and particularly with Roberto, a teacher at 'Kom pu Lof', was firmly established through the 'Hui/Trawun' journey we shared when the Mapuche delegation visited New Zealand. When we had conversations about the possibility of doing this project I asked the visiting group if there was any Maori community that they felt more connected with and two of them felt that was the Whanganui Iwi. This was mainly because of their close relationships with the river and because of the strong presence and participation of children and elders at our hui with them.

During the following months I attempted to establish a relationship with Whanganui Iwi in order to follow through with the connection the Mapuche delegation had felt. This attempt sometimes seemed fruitful as we had a meeting and some email communications, but eventually it fell through and my attempts to communicate did not elicit any replies. This apparent failure, as challenging as it 
felt, was actually quite constructive in terms of forcing me to communicate the project in a way that was ethical and understandable for an audience. It was also a good lesson by illustrating that establishing relationships is a process which requires trust built through shared experiences and time, something that I hadn't had much of with this particular group. I therefore turned to where I did have greater shared experiences and that was to 'Te Puna', the marae based programme coordinated by my friend Bianca.

Finally, the most meaningful connections were established during my time in the field. I had the privilege of working with two groups of creative and engaged children. The eight of them were generous enough to give their time and energy, they were open to hearing from other ways of being and sharing their own. Spending time with these human beings who playfully engage with their environments and also deeply think about and with it, was for me the greatest learning and source of joy during this project.

\subsubsection{The children in Llaguepulli}

In Llaguepulli I worked with a group of five Year Seven children (10-11 years old) and I also got to meet some of their families and spend time at their homes. Most of the families and children involved with 'Kom pu Lof' were, in their own words, mapuchistas. This concept could be described as strongly committed to the project of self-determination by revitalising their language and culture through the active practice of Mapuche spirituality and the inhabitation and re-claiming of their ancestral territories. I could perceive this background in most of the children who participated in the research through their words, actions and opinions (as will be reflected on the Analysis). Only one of them came from a different background as her family practice Evangelical Christianity. I could also perceive how this generated certain divisions in the group, but have not considered this dimension as relevant for this research project.

All of the participant children live in relative proximity to the school, though distant enough that they identified themselves with four different communities. All of 
these communities sit within the lowest income percentile in Chile (Fajardo Garrido, 2013) and the school and home environments were not lacking in terms of basic needs, but were humble spaces. There were no stores in these communities and the food sources were mostly what grows in the land and was bartered. All of these children were already participating and initiating activities geared to providing and caring for their homes and communities, such as chopping wood, feeding the chickens and pigs, helping out in the orchards, etc.

They all seemed very knowledgeable and interested in sharing their knowledge about Mapuche culture, and most of them would often participate in activities where that cultural knowledge was put in practice. Most of them had a very critical mind-set and vocabulary. They would often talk about the "colonisers", the "pollution" and the importance of the conservation of land, native forest and culture. As an example, when I started my presentation I showed them an 'Upside Down' map of the world in order to place the locations of research (see Fig.5 below), we talked about it for a while and they rapidly concluded that the positioning of countries in the map had been decided by the dominant European North and that the upside-down version was still geographically correct.

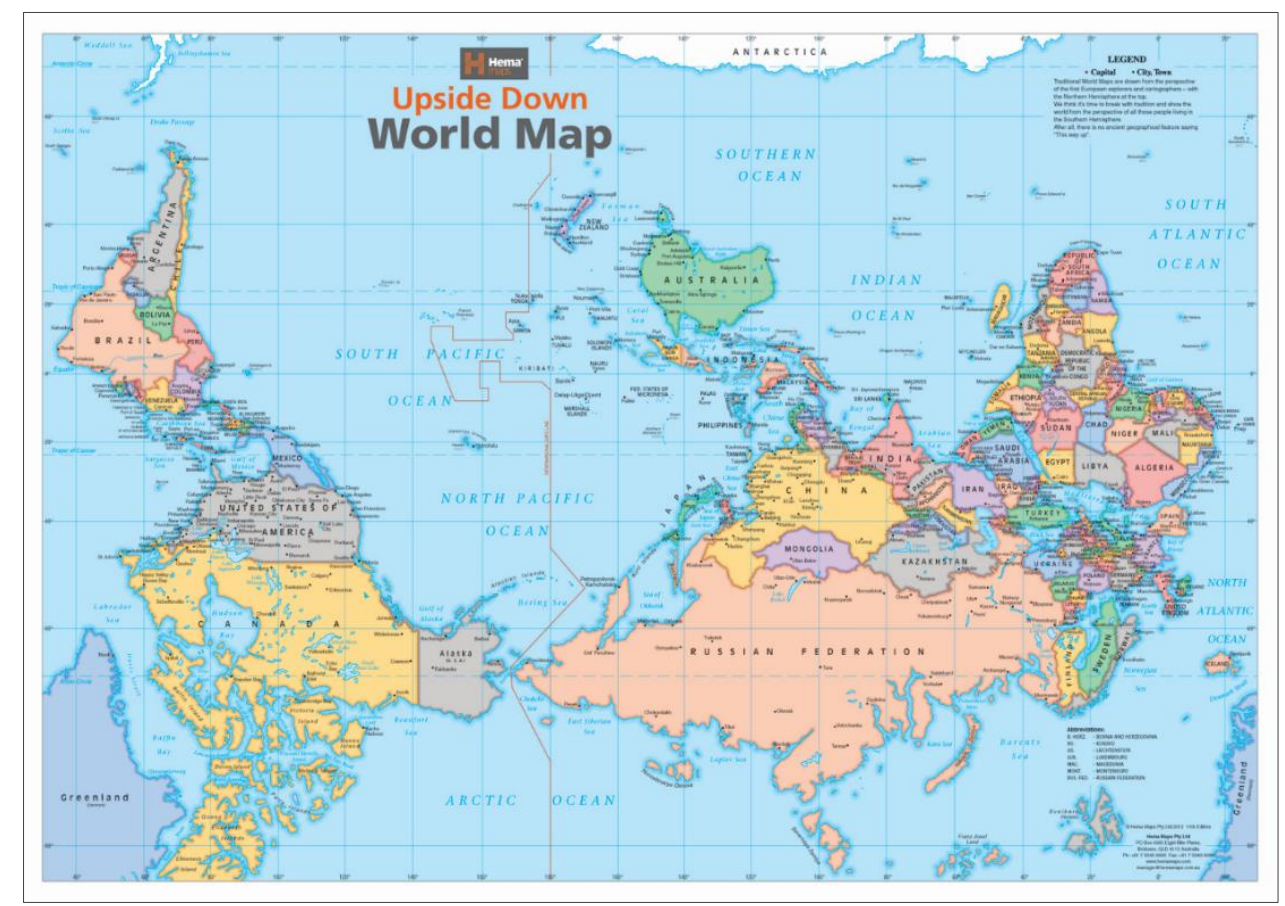

FIG 5- 'Upside Down Wolrd Map'. Hema maps.

Retrieved from mapworld.com.au on the $30^{\text {th }}$ of January, 2018 
When I met with the Llaguepulli children for the first time they were already aware of me coming from New Zealand and some features of that country because their teacher had visited a few months earlier. Most of them were very interested in learning more and expressed their desire to one day visit.

From these children I learnt not only about Mapuche practices and ways of relating to the territory, but also about being a poyenche (a loving and kind person) and a newenche (a strong person) who seizes opportunities and actively engages with the environment.

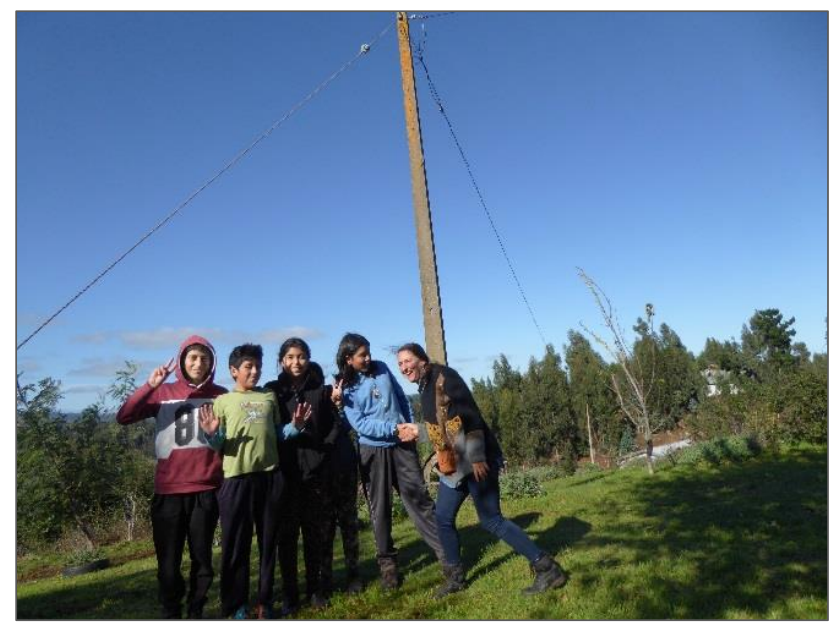

FIG 6-Timer photo taken at the end of the first workshop in Llaguepulli

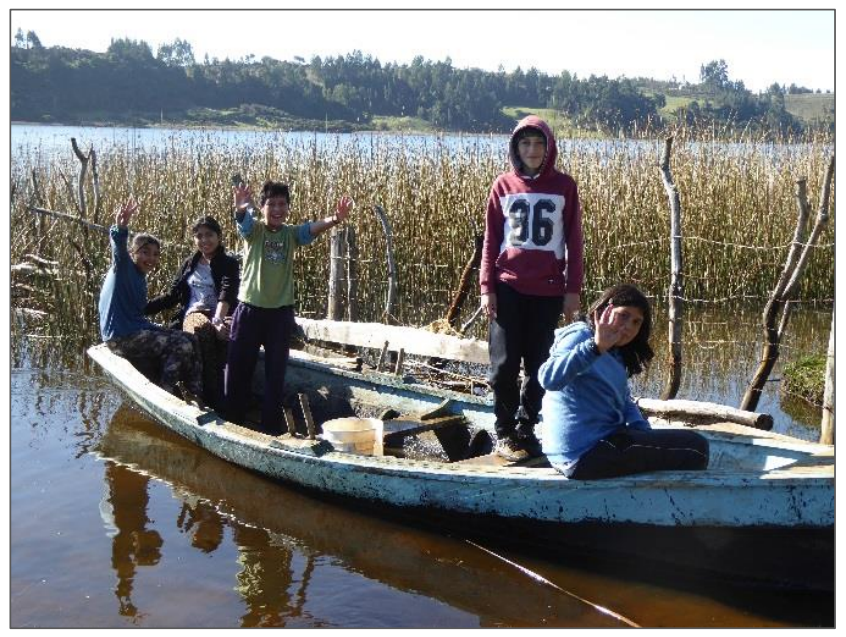

FIG 7- Photo taken by me during the first workshop in Llaguepulli 


\subsubsection{The children in Takapuwahia}

In Takapuwahia I worked with a group of three 10-11 year olds. I met some of their relatives who worked at 'Te Puna' and we only saw each other in that context. All of them live in the surrounding streets, around the marae, and are related to each other as a large extended family. The three of them attend a local primary school and attend 'Te Puna' once or twice per week to get extra assistance with their school performance.

Based on what they told me I gather that they often spend time at the marae participating and helping out in ceremonies such as pōwhiri (welcoming of visitors) and tangi (funerals). While they were at 'Te Puna', if there were no set activities, I would often see the boys playing with the iPads and the girl playing or caring for the baby. They would all converge often at the kitchen to grab whatever nibbles were available. Once we went out for a walk they all seemed totally comfortable with their surroundings, including things from speeding police cars to trees that they knew were good to climb.

As previously mentioned, I only shared time with this group within the premises of 'Te Puna' and when we went out walking. From these experiences I was not able to gain much knowledge or a clear perception of these children's access to resources or about their engagement with household activities. The space within 'Te Puna' was definitely well provided for with technology, learning resources, a great infrastructure and food. I also know that these children would often have access to some money as they were well aware of the prices of things in the local dairy and appreciated those things which were affordable.

This group of children had a more practical approach when we looked at the 'Upside-down' world map. Most of them agreed that it was good to have only one version of the map as otherwise it would be confusing for people to communicate about the geographic location of places. They mostly felt the upside-down version was wrong. 
When we met, this group of children had no background information about me and had never heard about Chile, less so about Mapuche people. They didn't seem to be overly interested and I think this is because there was no pre-existing relationship. Even though we had very little time together, five sessions of 30 to 40 minutes each, by the end I did feel we were all opening up and relaxing a bit more, and this project had come to be more of a part of their lives too. I perceived this in details like the fact that after the first few sessions finished they would just run to do something else, whereas for the last couple of sessions they would stay and talk and we would play together a bit.

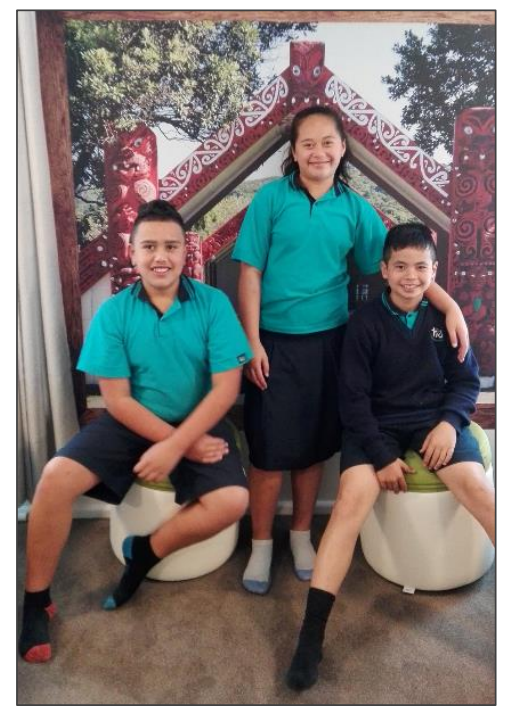

FIG 8- Photo taken by me after our final workshop in Takapuwahia

From the children in Porirua I learnt much about the value and warm feeling of whanau (family), a feeling that not only seemed to be present at 'Te Puna', but all through Takapuwahia.

\subsection{The field and changes}

In her research on experimental methods and attitudes to research with children, Kullman (2012) finds that "all methods are modest- they are fragile arrangements of bodies, technologies and practices that take on quite unexpected qualities when 
they encounter children" (p.14). My experience in the field relates quite closely to Kullman's findings as, throughout my attempts to try to put in place the initial research design, I had to remain flexible and open to the changes brought on by the children, the teachers, the parents and the territories themselves.

\subsubsection{Llaguepulli}

From a relational constructionist standpoint, research is a "process of (re)constructing realities and relations" (Hosking, 2011, p. 58), this perspective accurately describes my own process of transformation during the time spent in Llaguepulli. I was there for three weeks and stayed with one of the participant families. They were kind enough to host, feed and share their time with me. This was, personally, one of the most deeply valuable outcomes of this research for me as it meant establishing a new and caring relationship with five people who I now hold very dear to my heart.

During my time there I started getting used to the territory, the closeness of the lake cloaked in mist every morning, the presence of the rukas (straw houses) which to me felt like friendly hairy animals, the rolling hills with their strange acoustics which told tales of tomorrow's weather. I learnt from and with the territory by simply being there for an extended period, but also through the knowledge shared by the people I was meeting, especially the children who lived with me and shared their special places with their stories. 


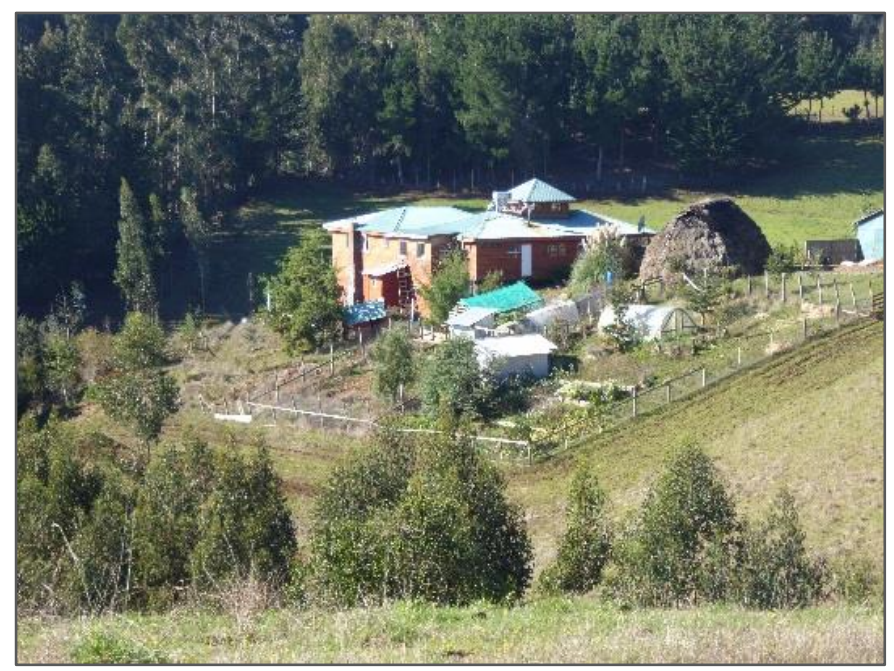

FIG 9- Photo taken by me of the house I stayed in in Llaguepulli

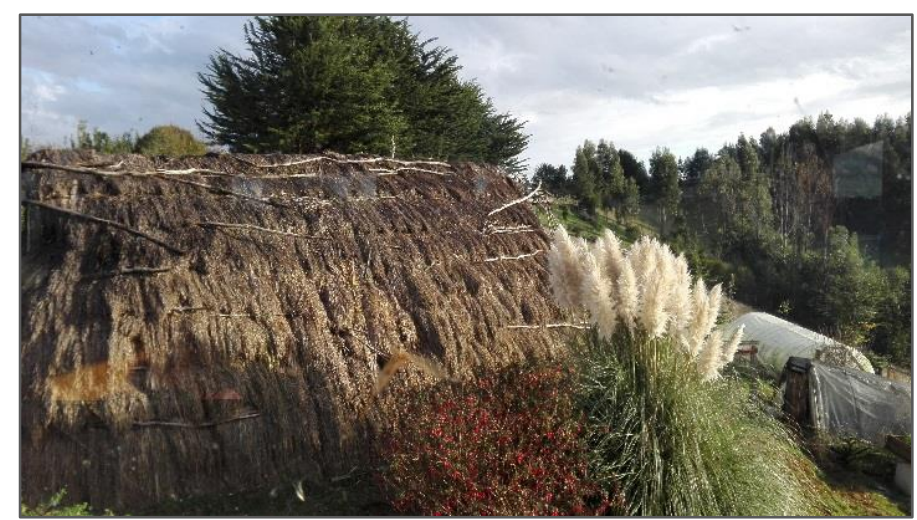

FIG 10- Photo taken by me of the 'ruka' beside the house

I also learnt about the community of Llaguepulli and the multiple projects people were involved in. The school was only one of the community initiatives geared to maintaining Mapuche knowledge, practices and cultures. There were also a wide diversity of tourism initiatives, from leisure cabins to organised tours which share knowledge about Mapuche ways of being in the world with both Mapuche and nonMapuche visitors. And there were also a wide variety of business projects, from sustainable traditional agriculture to micro-financing. All these projects seemed to be sustained by the relentless energy and clear motivations of most of the Llaguepulli community. 
During my three weeks in Llaguepulli, and even though I was living with Roberto, it was not until the end of the first week that we managed to sit down and plan how we'd approach the workshops and obtain permission from the parents. In different places, cultures and communities things move at different rhythms, I was aware of this, so even though deep inside I was frantic to get things moving and wondering how we'd manage to do it in only two weeks, I just waited for Roberto's timing trying to have faith in the process. The passage of time, or our living through it, embroiders relationships with different layers and textures, so even though we were not talking about the project for many days, subtle things were happening between us, hanging out with the kids, sharing food, even watching the soap opera at night, we get to know and trust one another, and then finally we had a very focused and strategic talk about how to do things. He immediately started editing and simplifying the forms, which to me felt like a great relief, as those forms had been created so far away and isolated from the reality of that community. I also felt a slight resistance to his views taking predominance, not necessarily over mine, but over the way others would understand the project. The main changes that he proposed were:

- $\quad$ Removing the word 'project', which is laden with Chilean government's empty promises, and substitute it for 'exchange' which actually reflects the process of sharing between two groups much better.

- $\quad$ Change the wording around the option to remove oneself from the project up to a certain date, and replace it by establishing a date until which the exchange would be happening. This felt to me a bit unclear, but Roberto thought that an 'exit' clause would make parents feel like they were getting themselves into an uncomfortable place which they might want to exit in the future.

- $\quad$ Having only the simplified consent form as a print out and making a point to speak face to face with each of the parents verbally explaining what was in the information sheet.

Most of these changes related to a strong mistrust felt in the community towards research and projects which often end up simply taking knowledge, land and/or ways of living in the territory away. In Llaguepulli, L.T. Smith's contention about 
research being "one of the dirtiest words in the indigenous world's vocabulary" (1999, p. 1) rings true. Previous experience with these kind of colonising projects has made the Llaguepulli community quite conscious of who they allow in and how deep can those people go. I will reflect further on these issues and provide some specific examples on the Ethics section (3.7).

During that planning section, Roberto and I also tuned the presentation for the first workshop. Once again he offered important insights which provided a pathway to better tailoring the presentation to the needs, knowledges and motivations of that group of children. The main change he proposed was changing the question about the importance of water to a question about what they identified themselves with in the environment. He perceived this as a useful way of evaluating if the kids actually identified themselves with the ocean which is their territorial identity as Mapuche Lafkenche (he thought it would be worrying if they didn't). We also decided that there would be only one outing with the whole group to a set location as this would be more attainable than asking each child to take photos and gather material in their own times (especially because most of them would not have access to a camera).

For that first workshop, after the presentation in the classroom, going out with the group and spending time walking around the community and playing by the lake was an excellent way of getting to know each other better and have conversations which I have included in the data analysis as content. But the places we visited were not satisfying for all of the children as some of them strongly identified with those places closer to their homes, so we made arrangements for them to take some pictures in those places.

The next phase was also co-designed with Roberto and his partner, who felt that a worksheet which included the pictures each child had taken would be a good way to elicit their narratives and for them to think, in their own times, about what they wanted to share with the other group. So I created these worksheets which the children completed over a weekend (see FIG 11) and then, on one-on-one sessions in the school's playground, we recorded their narratives so I could put them together with the sequence of photos. 

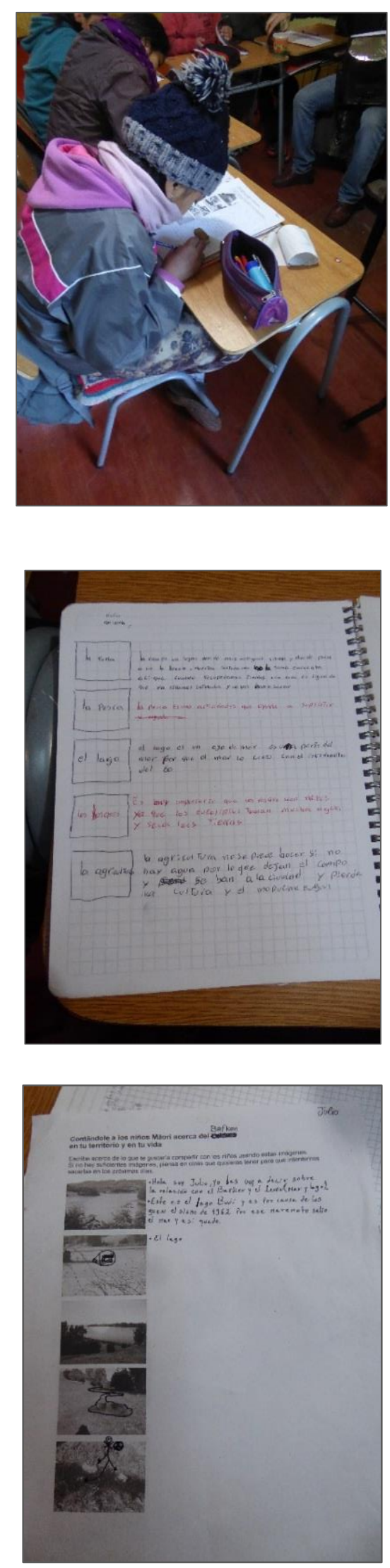

FIG 11- Photos taken by me of the worksheets 
Finally I put the audios together with the photos and after a couple of days went back to the class and invited each of them to have a look and tell me what they thought and if they wanted to make any changes. Most of them had a couple of comments about timing, but were mostly satisfied. One of them wanted to clarify a concept and another wanted to add a couple of sound effects. This last request inspired me to ask them if they wanted any background music, which became a bit of a challenge but also added some personalisation to the final product.

As may be appreciated, the process ended up being quite different from the initial plan. It was a messy and fluid journey which strived to maintain openness to participants' views, availability and interests while juggling our access to resources too. I will now narrate the other side of the journey back in Aotearoa New Zealand and working with the community in Takapuwahia.

\subsubsection{Takapuwahia}

My visits to Takapuwahia were always short and very goal oriented. I was aware that the experience would be quite different to Llaguepulli in this sense as I wouldn't be staying with them, immersed in the community's daily routine and also my mind would be much busier with all the other elements of life that surrounded these visits. Most of the times I went there I would make a point of parking my car by the harbour ten or fifteen minutes before so I could 'land' in Takapuwahia and make a conscious effort to fully connect to being there. I would do the same exercise after the sessions in order to write notes and do some reflection. The first time I did this I could immediately perceive the similarities between both places, even though Llaguepulli is quite rural and Takapuwahia urban, they are both geographically marked by the presence of a large and contained body of water surrounded by round hills and traversed by swans. 


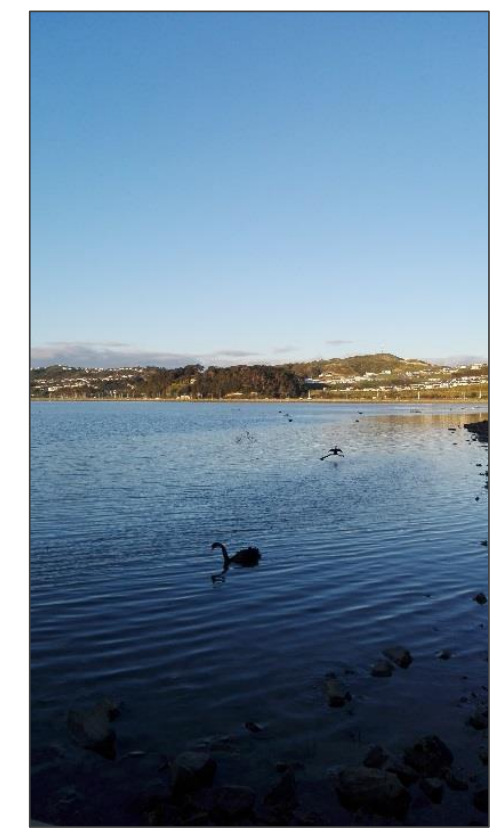

FIG 12- Photo taken by me at the harbour in Takapuwahia

I do feel I was only able to access a very superficial level of the experience of being in this place and with the community here. At the same time I believe those levels of access are not something that can be quantified and they change and move in unexpected ways.

One of the first steps when planning the workshops was discussing different possibilities in terms of delivering the consent forms with Bianca. We agreed the best path was for me to email her the consent forms and information sheets so she could print and get them to the parents. After the experience in Chile I thought the process around the forms might entail more involvement on my part, but Bianca's stance was that they were a simple formality and the parents would be happy to sign, so I left it in her hands. But after a month I hadn't received any of the forms back, mainly because Bianca is the gatekeeper and a very busy person, but also because those forms didn't appear to have the weight they carried in Llaguepulli. I only had the chance to talk to one of the parents who also works in 'Te Puna' and she had an absolutely relaxed approach to signing something like this, which meant that she didn't feel any reservations about what could happen with the project, but also that it was challenging to convey a sense of importance to that process. I did 
finally get the consent forms back and got to briefly meet the parents during the last session. I will discuss this issue further in section 4.6.

When doing the first workshop in Takapuwahia I based the initial presentation on the one I did in Chile but this time focusing on Mapuche people. In this case we also got to look at a couple of the Mapuche children's videos which were already finished and I could observe their reactions to them. During the videos one of the kids seemed very interested and the other two quite distracted, though they seemed to be drawn in by the soundtrack, especially in the one that has traditional Mapuche music. We talked about the content of the videos at the end and they commented about the landscape being quite similar to New Zealand. For example, one of the Mapuche narratives talked about Pine and Eucalyptus being non-native species which are being problematic for the environment, this narrative was related by one of the children in Takapuwahia to the issue of rodents and possums as pests. Then we talked about some Mapuche environmental concepts, especially the gen (owner or spirit of a place), which one of them related to Tāne-Mahuta (the guardian of the forest). Finally we talked about their own environment, what it is, and what they identified with. The conversation started with environment as nature, described as the wind, the trees and the grass, but then it evolved to include us and the table and the dairy. At this point we ran out of time and said farewell.

Most of the sessions were ran at this pace, as we had only thirty to forty minutes each time. In the following sessions we defined together the places we could go and visit which needed to be nearby as we were bounded by that amount of time. The final decision was: The harbour, the marae and the dairy.

Walking with the Takapuwahia children was a very urban experience. We walked through busy streets with police cars rushing around, each of the children carrying an iPad, which meant that some of them would be playing games as we went along. Through this short walk I learnt much more about them too, I learnt for example that they are all related and most of their families live around that area, and I learnt about what they do in those places, like going fishing or helping out at events in the marae. Where in Llaguepulli I just allowed myself to relax and enjoy the space with 
the children, here I was much more active in the role of keeping them thinking about what we were doing, taking pictures and moving along. Many insights and layers of information about their relationship with/in that environment emerged during that twenty minute walk and I shall look at some of these in the Analysis chapter.

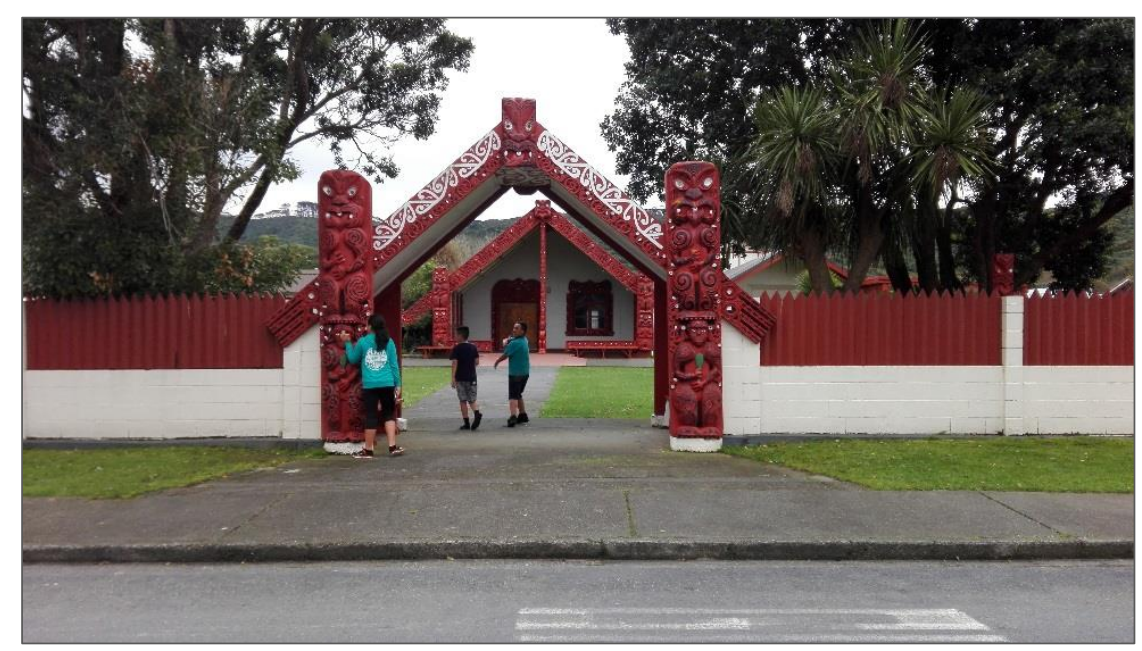

FIG 13- Photo taken by me at the marae in Takapuwahia

The process of collecting the pictures was also quite messy because as soon as their iPads were connected to the Wifi network all of the pictures were collated between them, so it was hard for me to know which belonged to whom. I collated the material as best as I could and created working sheets like the ones I used in Llaguepulli, but next time I saw them I realised that they had not received or completed the worksheets. This turned out to be a good thing as it generated the opportunity to have one-on-one sessions with the kids looking at the photos and talking about their narratives. Just as in Llaguepulli I let them flow with whatever they wanted to communicate but did encourage them to structure the narrative by remembering to introduce themselves and close with a farewell. During this process my position of power as an adult and researcher also became quite evident to me, especially with $K$, the only girl in the group, as she reacted with resistance and vulnerability to the idea of being recorded and having her portrait included in the video. I tried to be supportive and reassuring by pointing out how well made her narrative was, how cool it would be for the other kids to know about her life 
and by being clear when stating that this wouldn't be a video available to everyone and that the portrait idea was only a suggestion.

Finally I collated the narratives and the photos and put together the videos which I showed to the children in the following session. They all seemed satisfied, albeit slightly embarrassed by the results. I also asked them if they wanted to make changes or include music, but they all preferred to leave them as they were.

Several Māori authors point to the fact that academic research has mostly failed to benefit those who are the subjects (Bishop, 1996; G. H. Smith, 1992; L. T. Smith, 1999). As a response Kaupapa Māori discourses and research were developed during the 1960s (Gibbs, 2001), this research approach starts from a position where "Māori language, culture, knowledge and values are accepted in their own right" (G. H. Smith, 1992, p. 13). Throughout the workshops with the children in Takapuwahia and the conversation I had with Bianca and some of the parents, I aimed to maintain an open and flexible approach in order to make this research as aligned to the priorities of 'Te Puna' as possible. I will expand further on this topic in section 4.6.

\subsubsection{Summary of changes and final research design}

Throughout my field research these groups of children guided me into different territories which were for me unexpected and often required a high level of improvisation. This, and the reduced amount of time I had with them (especially with the Takapuwahia group), translated into major changes to the initial research design. The main changes related to specific wording of forms and presentation of concepts in the case of Llaguepulli (and I will expand on this in the Ethics section), different ways of using technology and deciding on places to visit in the case of Takapuwahia and less participation in the putting together of the videos in both cases due to lack of time. The sharing of the videos was highly mediated by me when I showed the Mapuche ones to the Takapuwahia children. On the other side, I sent the videos to Roberto to be shown to the Llaguepulli children, but still haven't heard back from them. Finally, the last group of workshops I had planned, where children would be able to respond to each other, was not possible, again due to 
lack of time and fluidity of communications. Nevertheless, I expect to keep the doors open to continue the communication between these groups in the future.

FIG.14 provides a summary of the final research design and then I describe it in detail.

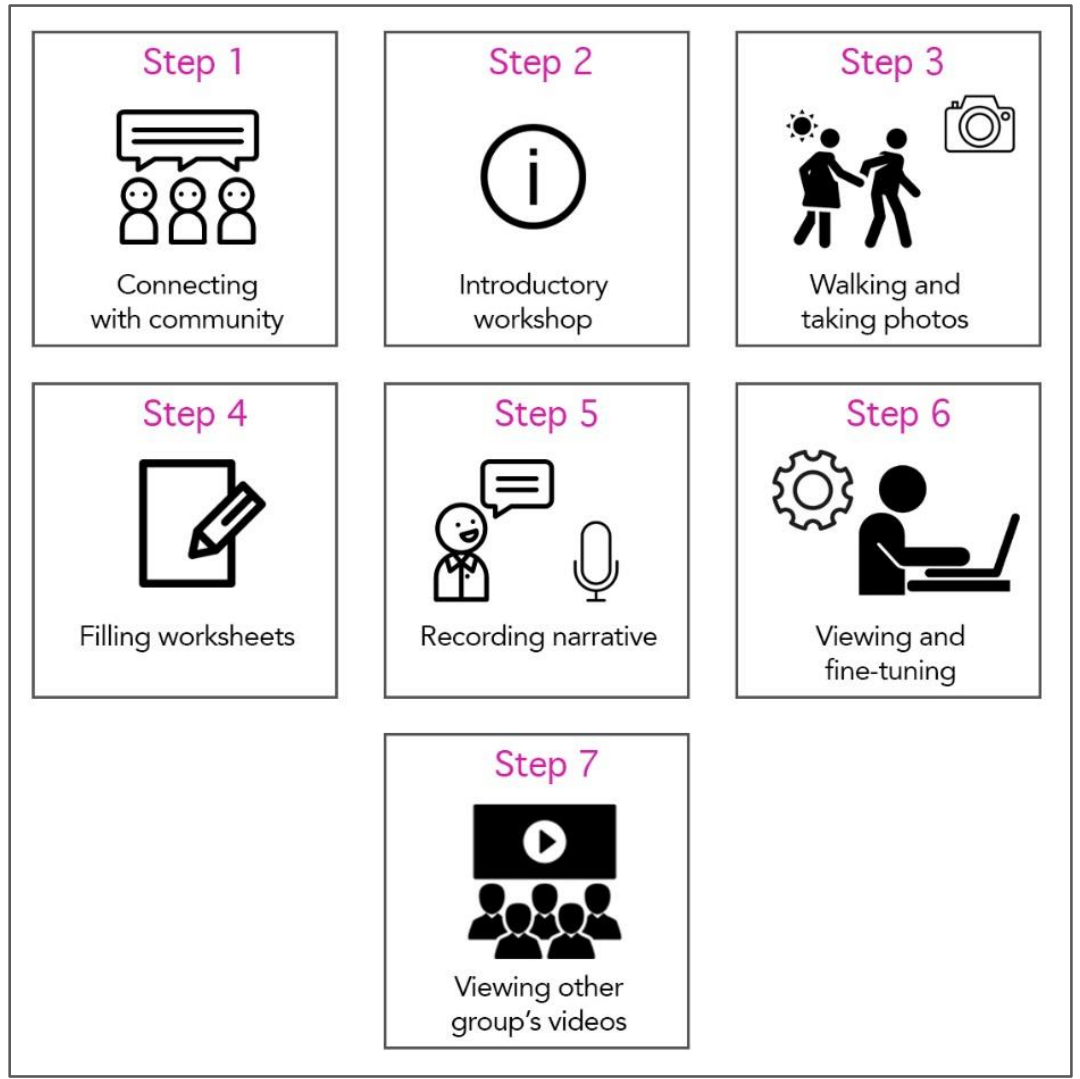

FIG 14- Final research design

1. Engagement with community: (Re) connecting to teacher/coordinator, parents and school/education organisation. This engagement was about clarifying what the project was about, exploring how it could align to their own objectives and working together to define the best way of going about it. It also included obtaining consent and ensuring the terms were clear and all questions were answered.

2. Introductory workshop with kids: Introducing ourselves, providing context about the other group of children and talking about what they identified themselves with in their environment. During both workshops we looked at the upside-down world map to geographically position the different locations and also to talk about different perspectives and colonialism. 
3. Walking together and taking photos: Going out on a mission to a determined location so they could take photos to build their stories. The amount of time, locations and cameras varied depending on what we had available.

4. Completing work sheets which put together the photos and some narrative: These were completed by some kids in their own time, by others during class and by others with my help.

5. Recording narrative: Playing the timed photos on a computer while the children are recorded narrating them. Some children chose to read out a particular script and others decided to talk freely based on some bullet points and/or previous practice.

6. Watching videos and fine-tuning details: This was a one on one activity where the kids got to see the first draft of their videos and decide if they wanted to make any changes (like changing the timing, correcting details and/or adding music or sound effects).

7. Showing the videos to the other group: I was able to show the Llaguepulli videos to the children in Takapuwahia and expect to send the Takapuwahia videos as a link so they can view them together back in 'Kom pu Lof'.

Having clarified the enacted methodology I will now reflect on the experience of being in the field.

\subsection{Reflections and ethical considerations}

Continuing to draw from the relational constructionism ontology, I will now reflect on some learnings and ethical issues which arose throughout this process. In order to do this I will use Bishop's Kaupapa Maori educational research framework as a guideline (FIG. 15). These questions will help me to critically look at ethical issues which came up with the research design in the field, reflect on my relationship with the participants and finalise by exposing ethical considerations for the following analysis. 


\begin{tabular}{|c|c|}
\hline Power issue & Related questions \\
\hline Initiation & $\begin{array}{l}\text { Who has initiated the research? } \\
\text { Do the research participants have power to be decision- } \\
\text { makers within the project? }\end{array}$ \\
\hline Benefits & $\begin{array}{l}\text { Does the research support Māori and Māori endeavours and } \\
\text { aspirations? }\end{array}$ \\
\hline Representation & Whose voice, interests and concerns are heard? \\
\hline Legitimisation & $\begin{array}{l}\text { Is the data legitimate, valid and robust from a Māori } \\
\text { worldview? }\end{array}$ \\
\hline Accountability & $\begin{array}{l}\text { Who shares in the knowledge? Who distributes it? Who } \\
\text { controls the knowledge? }\end{array}$ \\
\hline
\end{tabular}

FIG 15- Kaupapa Maori educational research framework, (Bishop, Denzin, \& Lincoln, 2005)

\subsubsection{Ethical considerations in the field}

As described in the previous section, during my time in the field, especially in Llaguepulli, several issues came up in regards to the wording of the project and the process with consent forms. These situations related mostly to Bishop's identified power issues of initiation and representation. I will draw on two examples to illustrate this.

During my first meeting with the teachers and principal at the school, they stated specifically that I was there because Roberto was vouching for me and I had hosted part of the community in Aotearoa New Zealand. The ideas I presented were perceived as beneficial and aligned to their goals and values, but were not considered open to the participation of the wider school community, and this was not ideal. Their main goal when dealing with academic researchers was to participate in the creation of the projects and of the outcomes in order to ensure it was research with them and not on them. Following this consideration, they also expressed the hope that the project did provide a space to grow those MapucheMāori relationships in the area of education in the future, and that those relationships would be wider than a group of Year Seven children. 
The perspectives raised during the aforementioned meeting evidenced for me the ways in which those decolonising principles I had been reading and writing about were embodied by this community. It also made me acutely aware that this project was not initiated by the participating communities at all, but they did have a certain amount of power as decision-makers within the project.

In terms of representation, there were instances in which the voices of participants were clearly heard, and others in which the needs to satisfy the official academic processes seemed to rule. An example of the first case was Roberto's active participation in the content and wording of the presentation and the consent forms (see section 4.5.1), what felt to me as the most participatory part of the project. And an example of the second case was the reaction of one of the Llaguepulli parents to signing a document which to him seemed to feel like a risky action. He seemed to agree with the ideas in principle and we thoroughly talked about the details, but he kept postponing the actual signature. I felt very uncomfortable in the position of somewhat pushing a pen into his hand, almost as if we were both replicating models and postures that had been taking place in that land for a long time. I told him a little bit about this feeling and tried to be very open, honest and reassuring about the intentions of the project. This seemed to release some of the tension as he also talked about his own resistance to signing things because of previous bad experiences.

This situation and the difficulty and seeming irrelevance of the consent forms in Takapuwahia (see section 4.5.2) for me represent issues of representation as only certain ways of speech are heard in this process. Consent forms enact a complex form of coloniality as, on the one hand, they are there to ensure that the research process is respectful and ethical to all parties but, on the other hand, they are formulated in a language and process which does not pay attention to the ways in which voices are heard and relationships are established in particular places and cultures.

These situations for me brought to light the multiple local realities in the dynamics through which I was welcomed (or not) as a researcher. The community of Llaguepulli has plenty of experience with researchers, experiences which have often 
replicated models of colonialism, racism inequality and injustice by considering them a research object being represented by an expert (L. T. Smith, 2007). Therefore they have developed mechanisms to, in a sense, protect themselves and use those relationships in a strategic manner, as what I experienced in the teacher's meeting that I attended. On the other hand, I experienced the reality of the practice of being warm, caring and welcoming towards another human being, a practice which, as I learnt, is an essential quality of being a wholesome Mapuche person. These two forms of life overlapped while I was in the territory, sometimes in a conflicting and sometimes in an enriching manner.

With the children, several issues identified by Bishop et al. (2005) as initiation and accountability came up. I will look again at two examples in order to illustrate this. Doing research with children always implies issues of power due to the hierarchical relationship which is commonly perceived between adults and children (Morrow, 1999). I often felt that this was true in terms of initiation because as an adult researcher I had power over the children by defining and guiding what we were doing. Nevertheless the children also had power to access and initiate other ways of being with/in the environment, such as playing with a boat or climbing trees instead of writing, and they had the power to invite me to participate in these relationships. This for me also relates to the Hosking's (2011) concept of multiple selves constructed in ongoing relational process, because both me and the children would fluctuate between states like being playing buddies or researchers-andparticipants for example. In this sense reflexive participant observation was a key methodology in order to maintain awareness of these multiple roles, but it was also often a tiring mental juggling of information.

The power dynamics of my relationship to the children, the adults and the territories in which the research took place were in continuous flux depending on what we were doing. As a researcher I had power to make several things happen in the community, but this was curated and limited by the power the communities had over what and where I was allowed to access. 
In terms of accountability, especially in the question of who controls the knowledge, there were several layers to this issue. Starting from the ontological notion exposed by the Modernity Coloniality Programme, that knowledges are multiple and ever-changing (Escobar, 2007), the children always had power over the knowledge they wanted to share through their narratives. The openness of the methodology allowed them to go as wide, narrow, deep or shallow as they felt comfortable with. However, the knowledge they did share with their digital stories is now under the control of the academia (bounded by the limits established through the Human Ethics Commission). This is directly related to the following section in which I reflect on the ethical issues which might arise with the usage of this knowledge throughout the process of analysis.

\subsubsection{Ethical considerations for the analysis}

In terms of the analysis, the main power issues which I perceive might arise are those of representation and of legitimisation. I will now explore these issues by using Bishop et al.'s (2005) questions and proposing solutions.

The first question is: How to perform analysis (which translates into slicing and dissecting the knowledge shared by children) in a way which is respectful and honours their voices, interests, needs and concerns?

I addressed this issue by presenting the children's un-edited narratives and images in the analysis so they spoke for themselves as much as possible. This approach was also informed by theories looking at analysis of visual material which contend that the interpretation is more than the transformation of the visual to the verbal and that every viewing of the material, by the same or a different spectator, is a new viewing and interpretation(G. Rose, 2001).

In the analysis I present my interpretation, but keep the un-edited material which speaks clearly through the voices of the participant children.

The second question is: How to keep data legitimate from a Mapuche and Māori worldview?

Through the act of slicing and fragmenting the material it was I deciding what constituted legitimate data. Furthermore, even though I chose a relational 
constructionism ontology, I framed this analysis within academic notions which mostly sit within a dominant scientific paradigm. I opted to address this issue by clearly stating which are my opinions and interpretations and which the original knowledge shared by these groups of children. In order to do this I tried to graphically and verbally distinguish between my content and their content, and also tried to be critically reflexive of my own biases and conceptions of knowledge.

\subsubsection{Summary and beyond analysis}

As can be observed from the previous sections, this research which used visual methods and worked with indigenous children raised several ethical issues related to initiation, representation and legitimisation which I hope to have addressed in a respectful way.

Beyond the analysis and thinking about giving back to the communities which supported this research project, issues of benefits and accountability also arose. In terms of benefits, I expand Bishop's Kaupapa Māori model to Mapuche and ask: Does the research support Mapuche and Māori, and Mapuche and Māori endeavours and aspirations?

I feel this is a question that should be answered by the communities with which I did my research rather than myself. Nevertheless, I will attempt to provide an answer based on my experiences and conversations with them. As described in section 4.2.1 the idea for this research was based in the goal expressed by the Llaguepulli community "establish bonds of support between the Māori people and the Mapuche Lafkenche territory of Lake Budi in the educational space" (email exchange, August, 2016, own translation). Also, before initiating fieldwork in both places, I had conversations with the teachers which tailored the workshops so they would suit the goals and needs of the children involved. In this sense I would say that the research did support Mapuche and Māori endeavours and aspirations as, throughout the process, I paid attention to these endeavours and aspirations and kept the activities open in order to respond to them. Furthermore, both 'Kom pu Lof' and 'Te Puna' during the initial conversations, expressed a strong interest in the children reflecting on their own relationships with, and within the environment and 
accessing other indigenous children's thoughts on this too. These goals were achieved to a higher or lesser degree during the research process.

Despite these benefits, it must be acknowledged that Llaguepulli's initial goal of generating a "cultural and pedagogical exchange" between them (taken from email exchange while planning the visit, August, 2016, own translation) was only partially achieved during this research and in a highly mediated manner. At no point were the two groups of children able to interact directly and, even when watching each other's videos, this experience was framed by my own presentation of the other group. In this sense there is much more space to keep nurturing relationships between these groups of children in order to achieve a real environmental knowledge exchange.

In terms of Bishop's questions about accountability: Who shares in the knowledge? Who distributes it? Who controls the knowledge? These questions are particularly relevant considering the present research focused precisely on knowledges and explored ways to bring the participant children's knowledges to the forefront. But, what is the 'forefront'? For the purposes of this research the forefront appears to be mainly academic space, as this is where this piece of research will live and potentially be accessed by other researchers working within this space.

Notwithstanding, throughout the process, the children's environmental knowledges and narratives were shared amongst them and both communities have and will continue to have access and control of the videos the children produced. Thus, the process of research itself has been one in which the knowledges have been shared by and with the participating communities. The knowledge produced by the analysis and which concludes this research, on the other hand, will be duly communicated to the communities but will mainly stay and be used within the space of academia.

As a closing reflection l'd like to come back to Tuck and Yang's (2012) call to avoid falling into metaphorical concepts of decolonisation and bring attention back to "the need to give up land or power and privilege" (p.21). I know that this contention is particularly relevant for the community of Llaguepulli and Mapuche 
people in general who, as described in section 1.4.1, are still marginalised and oppressed by a legal framework which denies them access to their land, cultural practices and ways of being in, and with the environment. This research, which was framed in decolonial thought, did not directly respond to the need raised by Tuck and Yang, but it did address power and privilege by nurturing spaces where Mapuche and Māori knowledges moved from the margins to the centre of conversations about relationships with, and within the environment.

\subsection{Analysis}

In this section I will present the ways in which I organised data and how I used Grounded Theory and literature around visual data analysis and children's narratives. These will be presented and justified as my chosen pathways to look at the ways in which the children's narratives represented relationships with and within the environment. I will then present my main areas of focus, planes of analysis and the themes which came up by using these lenses to look at the narratives.

\subsubsection{Organising and visualising collected data: Four areas of focus}

Having done my field research in Takapuwahia and Llaguepulli, the children created eight Digital Stories composed of photos, spoken narratives and sometimes background music or sounds, of between one and four minutes each. In addition to these videos I also had the notes I'd taken during field work and my reflections on the process.

In her work exploring ways of putting visual ethnography in practice, Pink (2013) points out that "the purpose of analysis is not to translate visual evidence into verbal knowledge, but to explore the relationships between visual and other (including verbal) knowledge" (p.119). Following on this assertion I set out to organise data in a way which allowed me to see the emergent relationships between image, narrative, context and my observations. Freeman and Mathison's (2009) work looking at different approaches to conducting research with children 
provided a useful framework in order to bring the aforementioned relationships forward. I particularly drew from their four areas of focus for data analysis which define and categorise content, different kinds of contexts and effects of the data. The following table (FIG.16) explains each of these focus areas drawing from Freeman and Mathison (2009) and other authors (as detailed in the table), and shows which elements of the children's narratives I grouped under each of the areas.

\begin{tabular}{|c|c|c|}
\hline $\begin{array}{l}\text { Areas of focus } \\
\text { (As defined by } \\
\text { Freeman and } \\
\text { Mathison-2009) }\end{array}$ & Description & $\begin{array}{c}\text { How I applied it } \\
\text { to my data }\end{array}$ \\
\hline $\begin{array}{l}\text { Content of } \\
\text { the data }\end{array}$ & $\begin{array}{l}\text { What Banks (2001) refers to as the 'internal' } \\
\text { narrative or the story inside the frame. The } \\
\text { concept of 'frame' in photography is a useful } \\
\text { way of understanding this as it is what } \\
\text { contains what can be seen within the } \\
\text { viewfinder. }\end{array}$ & $\begin{array}{l}\text { - The } \\
\text { photograph } \\
\text { or image } \\
\text { - Its duration } \\
\text { - The music }\end{array}$ \\
\hline $\begin{array}{l}\text { Context in } \\
\text { which the data } \\
\text { was created }\end{array}$ & $\begin{array}{l}\text { Relates to Banks' (2001) concept of } \\
\text { 'external' narrative which is the social } \\
\text { context in which the product was created. }\end{array}$ & $\begin{array}{l}\text { - The wider } \\
\text { social context } \\
\text { (e.g.: Usage of } \\
\text { 'rukas' in } \\
\text { Llaguepulli) } \\
\text { - The context of } \\
\text { what was } \\
\text { taking place } \\
\text { while we were } \\
\text { out together } \\
\text { taking the } \\
\text { pictures (e.g.: } \\
\text { One child } \\
\text { dominating the } \\
\text { use of the } \\
\text { camera). } \\
\text { - The affective } \\
\text { and sensory } \\
\text { dimensions as } \\
\text { perceived by } \\
\text { my } \\
\text { observations or } \\
\text { made explicit } \\
\text { by the children } \\
\text { in our } \\
\text { conversation. }\end{array}$ \\
\hline
\end{tabular}




\begin{tabular}{|l|l|l|}
$\begin{array}{l}\text { The contexts } \\
\text { in which and } \\
\text { the } \\
\text { subjectivities } \\
\text { through which } \\
\text { the data are } \\
\text { interpreted }\end{array}$ & $\begin{array}{l}\text { The viewer's and interpreter's subjectivities } \\
\text { when viewing the image. It relates to the } \\
\text { idea that viewers are active participants in } \\
\text { the creation of data (Becker, 2002, pp. 4-5) } \\
\text { and also to the fact that the researcher's } \\
\text { interpretation is "framed by his/her own } \\
\text { culturally and individually specific } \\
\text { subjectivity" (Pink, 2013, p. 124). }\end{array}$ & $\begin{array}{l}\text { - The children's } \\
\text { oral/written } \\
\text { narrative }\end{array}$ \\
\hline $\begin{array}{l}\text { The effect or } \\
\text { impact of the } \\
\text { data on } \\
\text { interpreters } \\
\text { and readers }\end{array}$ & $\begin{array}{l}\text { The site that Rose (2001) defines as the } \\
\text { 'loudiencing' stage or how the image is } \\
\text { "lo the ways of seeing and the kinds of } \\
\text { knowledge they bring to the viewing" } \\
\text { (Rowsell \& Pahl, 2015, p. 622). }\end{array}$ & $\begin{array}{l}\text { - Reactions } \\
\text { from viewers } \\
\text { other than } \\
\text { myself }\end{array}$ \\
\hline $\begin{array}{l}* \\
\text { The children's narrative doesn't sit neatly within this category as it is not only an }\end{array}$ \\
$\begin{array}{l}\text { interpretation of the image but also a way of presenting it or a second frame around it. } \\
\text { Due to this ambiguity my own interpretation includes both the children's image and the } \\
\text { narrative. }\end{array}$
\end{tabular}

FIG 16- Table of 'Areas of focus' based on Freeman and Mathison, 2009

Having defined the main areas of focus to organise the data I proceeded to organise it in a way which allowed for visual cross-reading between the narratives. Drawing from literature concerning analysis of Digital Narratives and Digital Storytelling (Bliss \& Fisher, 2014; Hull \& Katz, 2006; Hull \& Nelson, 2005) I created a table (Fig.19) which brought the data together in a timeline based on each of the videos. This data table is an attempt to bring together the multiple dimensions of content which is ambiguous and not able to be subjected to defined categories (Pink, 2013). FIG. 19 below is an excerpt of one of the tables and provides an example of how I did this for each of the videos. I have followed the same colour coding as the previous table (FIG.17) to draw attention to how the areas of focus were used. 


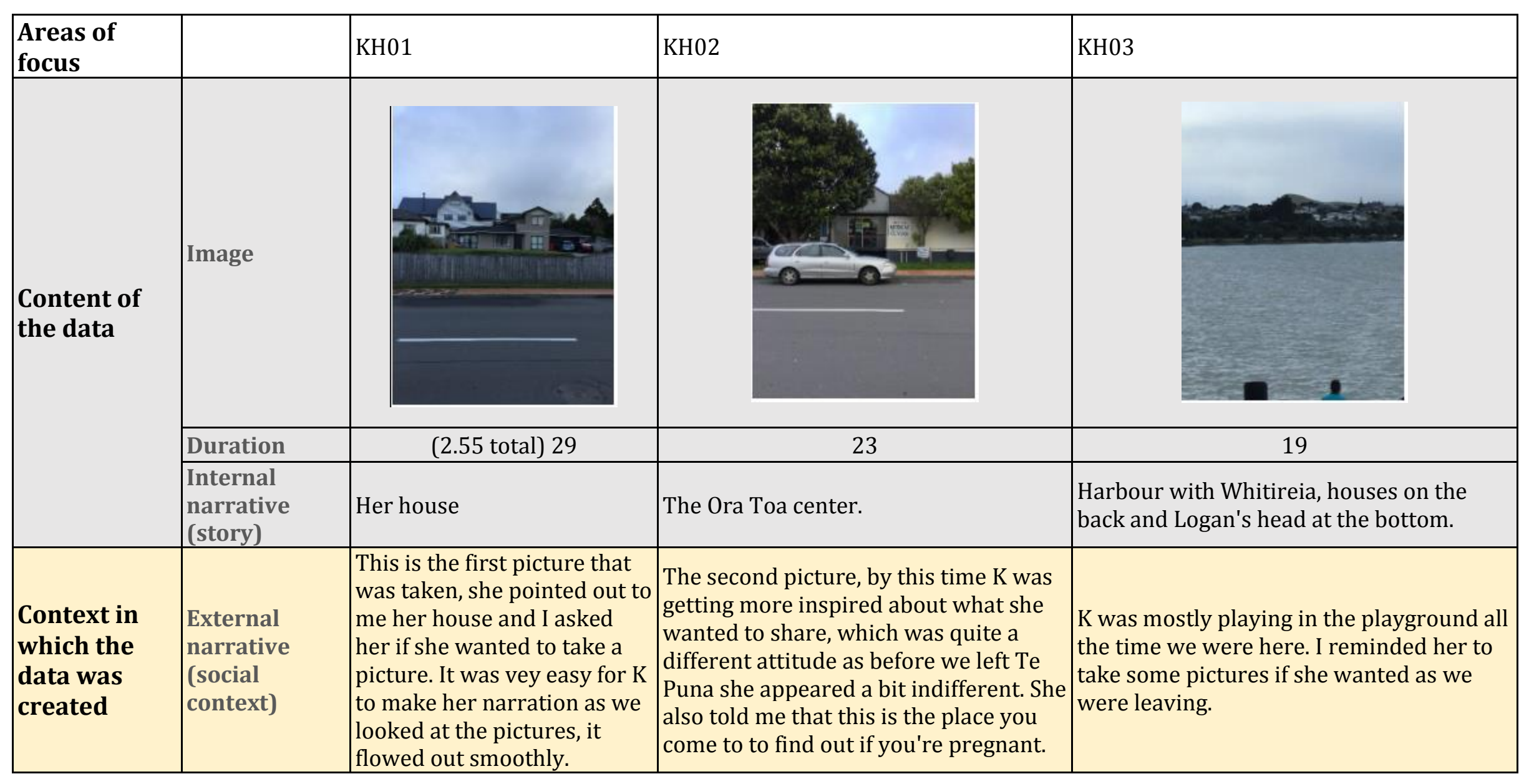




\begin{tabular}{|c|c|c|c|c|}
\hline \multirow[t]{2}{*}{$\begin{array}{c}\text { Contexts in } \\
\text { which, and } \\
\text { subjectivities } \\
\text { through } \\
\text { which, the } \\
\text { data are } \\
\text { interpreted }\end{array}$} & $\begin{array}{l}\text { Children's } \\
\text { narrative }\end{array}$ & $\begin{array}{l}\text { Hi, my name is } K \text {, } \\
\text { I live here. } \\
\text { It's very big because I have } 8 \\
\text { no, } 6 \text { no, } 5 \text { siblings. } \\
\text { It's } 8 \text { of us in one house } \\
\text { including me. } \\
\text { My cultures are mostly } \\
\text { Samoan and Maori because } \\
\text { I have heaps of other cultures } \\
\text { but I can't just name } \\
\text { all of them. } \\
\text { I'll name at least two: I'm a } \\
\text { part German from my } \\
\text { dad's side and part Chinese } \\
\text { from my mom's side. } \\
\text { But I don't look like any of } \\
\text { them. }\end{array}$ & $\begin{array}{l}\text { This is the medical center, sometimes I } \\
\text { come here } \\
\text { when I am sick or I am wounded. } \\
\text { Whenever I come here I see heaps of } \\
\text { people hurt } \\
\text { or sick. } \\
\text { I have family working here and they do a } \\
\text { good job } \\
\text { of taking care of people. } \\
\text { And I like it here because the doctors } \\
\text { and nurse } \\
\text { make me feel better. }\end{array}$ & $\begin{array}{l}\text { This is the harbour. You can't really swim in } \\
\text { it } \\
\text { because people pollute it a lot, they throw } \\
\text { rubbish } \\
\text { in there. } \\
\text { And in the background there's a little wave } \\
\text { curve } \\
\text { and that's my mountain, and that Mountain } \\
\text { is } \\
\text { called Whitireia. } \\
\text { You can hike up there and watch the sun go } \\
\text { down. }\end{array}$ \\
\hline & $\begin{array}{l}\text { My } \\
\text { interpretation }\end{array}$ & $\begin{array}{l}\text { K talks about 'her' cultures } \\
\text { with a sense of ownership, } \\
\text { she 'has' them. Her } \\
\text { confusion about the amount } \\
\text { of siblings and of people } \\
\text { inhabiting the house also } \\
\text { seems to show a fluidity of } \\
\text { roles in the house. When } \\
\text { saying she doesn't look like } \\
\text { any of them there's a strong } \\
\text { 'me' and 'them' division. }\end{array}$ & $\begin{array}{l}\text { There seems to be a sense of safety in } \\
\text { K's description and the fact that the } \\
\text { medical centre is so close and that her } \\
\text { family works there. Also a sense of } \\
\text { wellbeing as she feels sick when she } \\
\text { gets there but then they 'make' her feel } \\
\text { better. Perhaps because her family } \\
\text { members work here, she knows a lot } \\
\text { about the cases of people who go there. } \\
\text { It also sounded a bit like a magical } \\
\text { place: Where you go and find out if } \\
\text { you're pregnant. }\end{array}$ & $\begin{array}{l}\text { Pollution is presented as something that } \\
\text { 'people' or 'they' do, as an ongoing fact } \\
\text { (instead of something that happened in } \\
\text { the past or can be remedied in the future). } \\
\text { She knows the land and talks about the } \\
\text { mountain as 'her' mountain which is } \\
\text { probably related to a Maori conception of } \\
\text { identity and place. The fact that you can go } \\
\text { up and the sun goes down also implies a } \\
\text { sense of movement, dynamism and cycles. } \\
\text { The way that she describes the mountain } \\
\text { by its shape is very sensory. }\end{array}$ \\
\hline
\end{tabular}




\begin{tabular}{|c|l|l|l|}
\begin{tabular}{c|l|l|} 
Effect or \\
impact of the \\
data on
\end{tabular} & $\begin{array}{l}\text { Some of the Te Puna } \\
\text { facilitators watched this and } \\
\text { were surprised and also } \\
\text { interpreters } \\
\text { and readers }\end{array}$ & $\begin{array}{l}\text { Viewing } \\
\text { heard about K's other } \\
\text { cultures }\end{array}$ &
\end{tabular} \mid

FIG 17- Excerpt of one of eight video analysis tables 
I will now explain how Grounded Theory provided a path to allow the answer to my main research questions about the ways in which children represent relationships with and within the environment, to emerge from the data.

\subsubsection{Applying Grounded Theory and planes of analysis}

Grounded Theory is "a qualitative strategy of inquiry in which the researcher derives a general, abstract theory of process, action, or interaction grounded in the views of participants in a study" (Creswell, 2013, p. 14). Its inductive approach, from the specific to the general, has been identified as being advantageous for exploratory research and allowing for intuition and creativity to play a role in the systematic analysis of data (Hussein, Hirst, Salyers, \& Osuji, 2014; Myers, 2013). These advantages align to the multimedia nature of my data and my relational ontology, by providing a fluid way of looking into the data and allowing answers to emerge about the creative ways in which children represent relationships with and within the environment in their narratives.

Following on Creswell's process of applying this theory I looked at my data tables starting from the specific to the general in order to uncover emerging relationships and patterns. The main layers which intuitively started emerging related to individual, social and cultural narratives as these were present and connected in different ways in all of data tables. In order to theorise further on these layers I used Tzou, Scalone and Bell's (2010) planes of analysis which focus on children's narratives conceiving "place is an inseparable part of a social narrative" (p.106). They describe three planes and how they relate to each other as explained in the FIG. 28: 


\begin{tabular}{|c|c|c|}
\hline $\begin{array}{l}\text { Plane of } \\
\text { Analysis }\end{array}$ & Conceptual Focus & $\begin{array}{l}\text { Interaction with } \\
\text { other planes }\end{array}$ \\
\hline $\begin{array}{c}\text { Cognitive } \\
\text { Ecology }\end{array}$ & $\begin{array}{l}\text { Narratives the individual has about his/herself } \\
\text { (based on cultural, gender, age, class identities) } \\
\text { which influence the way he/she acts upon the } \\
\text { world. }\end{array}$ & $\begin{array}{l}\text { Engage in and } \\
\text { construct Situated } \\
\text { Activity Systems. }\end{array}$ \\
\hline $\begin{array}{l}\text { Situated } \\
\text { Activity } \\
\text { Systems }\end{array}$ & $\begin{array}{l}\text { Activities that happens within a socially } \\
\text { constructed place. Individuals can move } \\
\text { between activity systems and each of these } \\
\text { contains culturally-based narratives. }\end{array}$ & $\begin{array}{l}\text { Are influenced and } \\
\text { shaped by } \\
\text { Cultural Toolkits. }\end{array}$ \\
\hline $\begin{array}{l}\text { Cultural } \\
\text { Toolkits }\end{array}$ & $\begin{array}{l}\text { Ideologies, technologies and narratives which } \\
\text { are uniquely present at a given historical } \\
\text { moment. }\end{array}$ & $\begin{array}{l}\text { Can be in tension } \\
\text { with Cognitive } \\
\text { Ecology, may need to } \\
\text { be bridged. }\end{array}$ \\
\hline
\end{tabular}

FIG 18- Three planes of analysis bases on Tzou et al. (2010)

I used these three planes as sensitizing concepts' or analytic categories derived from the literature (Freeman \& Mathison, 2009, p. 155). The following example (FIG. 19) shows how I applied the three planes to the data by identifying elements within each data column relating to each of the planes. I have synthesized the content of the data (which is already shown on FIG.17) for ease of reading. 


\begin{tabular}{|c|c|c|c|c|}
\hline Areas of focus & & KH01 & KH02 & KH03 \\
\hline \multirow[b]{3}{*}{$\begin{array}{c}\text { Content of the } \\
\text { data }\end{array}$} & Image & & & \\
\hline & Duration & $(2.55$ total) 29 & 23 & 19 \\
\hline & $\begin{array}{l}\text { Internal } \\
\text { narrative } \\
\text { (story) }\end{array}$ & Her house & $\begin{array}{l}\text { The Ora Toa } \\
\text { center. }\end{array}$ & $\begin{array}{l}\text { Harbour with } \\
\text { Whitireia, houses } \\
\text { on the back and } \\
\text { Logan's head at } \\
\text { the bottom. } \\
\end{array}$ \\
\hline $\begin{array}{c}\text { Context in } \\
\text { which the data } \\
\text { was created }\end{array}$ & $\begin{array}{l}\text { External } \\
\text { narrative } \\
\text { (social } \\
\text { context) } \\
\end{array}$ & $\begin{array}{c}\text { This is the } \\
\text { first picture } \\
\text { that was } \\
\text { taken... }\end{array}$ & $\begin{array}{l}\text { The second } \\
\text { picture... }\end{array}$ & $\begin{array}{l}\text { K was mostly } \\
\text { playing... }\end{array}$ \\
\hline \multirow[b]{2}{*}{$\begin{array}{l}\text { Contexts in } \\
\text { which, and } \\
\text { subjectivities } \\
\text { through which, } \\
\text { the data are } \\
\text { interpreted }\end{array}$} & $\begin{array}{l}\text { Children's } \\
\text { narrative }\end{array}$ & $\begin{array}{l}\text { Hi, my name } \\
\text { is } K . . .\end{array}$ & $\begin{array}{l}\text { This is the } \\
\text { medical } \\
\text { center... }\end{array}$ & $\begin{array}{l}\text { This is the } \\
\text { harbour... }\end{array}$ \\
\hline & $\begin{array}{l}\text { My } \\
\text { interpretation }\end{array}$ & $\begin{array}{c}\text { K talks about } \\
\text { 'her' } \\
\text { cultures... }\end{array}$ & $\begin{array}{c}\text { There } \\
\text { seems to be } \\
\text { a sense of } \\
\text { safety... }\end{array}$ & $\begin{array}{l}\text { The pollution } \\
\text { issue is } \\
\text { presented... }\end{array}$ \\
\hline $\begin{array}{l}\text { Effect or impact } \\
\text { of the data on } \\
\text { interpreters } \\
\text { and readers }\end{array}$ & $\begin{array}{l}\text { Viewing } \\
\text { reactions }\end{array}$ & $\begin{array}{l}\text { Some of the } \\
\text { Te Puna } \\
\text { facilitators } \\
\text { watched this } \\
\text { and were } \\
\text { surprised.. } \\
\end{array}$ & & \\
\hline \multirow{3}{*}{$\begin{array}{c}\text { Three planes of } \\
\text { analysis }\end{array}$} & $\begin{array}{l}\text { Cognitive } \\
\text { Ecology }\end{array}$ & $\begin{array}{l}\text { Name - } \\
\text { House - } \\
\text { Siblings- } \\
\text { Cultures- } \\
\text { What she } \\
\text { looks like }\end{array}$ & $\begin{array}{l}\text { Visiting } \\
\text { medical } \\
\text { centre- Her } \\
\text { family who } \\
\text { do good job } \\
\text { - Feeling } \\
\text { better } \\
\end{array}$ & HER mountain \\
\hline & $\begin{array}{l}\text { Situated } \\
\text { Activity } \\
\text { Systems } \\
\end{array}$ & $\begin{array}{l}\text { What } \\
\text { happens/ } \\
\text { who is at } \\
\text { home }\end{array}$ & $\begin{array}{l}\text { The medical } \\
\text { centre - } \\
\text { Taking care } \\
\text { of people }\end{array}$ & \begin{tabular}{|c|} 
Can't swim there \\
because \\
pollution - \\
Mountain \\
walking \\
\end{tabular} \\
\hline & \begin{tabular}{|l|} 
Cultural \\
Toolkits \\
\end{tabular} & $\begin{array}{l}\text { Big house } \\
\text { because they } \\
\text { are many }\end{array}$ & $\begin{array}{l}\text { What to do } \\
\text { when } \\
\text { feeling sick }\end{array}$ & \begin{tabular}{|c|} 
Pollution \\
because people \\
rubbish - Name \\
of mountain \\
\end{tabular} \\
\hline
\end{tabular}

FIG 19- Three planes of analysis applied to excerpt of video analysis table 
After this, and in order to compare the elements which came up for each of the children within these three planes, I proceeded to collate them. These led me to the following three tables (FIGs $20-22$ in the following pages) which represent an axial analysis of the data. Each of them focuses on the main elements which came up for each of the three planes of Cognitive Ecology, Situated Activity Systems and Cultural Toolkits. 


\begin{tabular}{|c|c|c|c|c|}
\hline & \multicolumn{4}{|c|}{$\begin{array}{l}\text { Cognitive Ecology: } \\
\text { Narratives about themselves }\end{array}$} \\
\hline & ID with territory & ID with group & $\begin{array}{l}\text { Relating through } \\
\text { ancestors/family }\end{array}$ & $\begin{array}{c}\text { Knowing } \\
\text { through } \\
\text { feeling } \\
\end{array}$ \\
\hline $\mathbf{A L}$ & $\begin{array}{l}X \text { - Represented by } \\
\text { flora/fauna (07) }\end{array}$ & $\begin{array}{c}\mathrm{X} \text { - They are } \\
\text { represented by } \\
\text { flora/fauna (07) }\end{array}$ & X - Ruka (01) & \\
\hline $\mathbf{A K}$ & $\begin{array}{c}\mathrm{X} \text { - Intro (01) - His } \\
\text { territory represents } \\
\text { him (02) - Lake } \\
\text { represents them } \\
(04) \\
\end{array}$ & $\begin{array}{c}\text { X - Mapuche } \\
\text { Lafkenche (04) - } \\
\text { Proud to be } \\
\text { Mapuche (06) }\end{array}$ & & $\begin{array}{c}\text { X- Feels good to } \\
\text { come from } \\
\text { unique culture } \\
(06)\end{array}$ \\
\hline $\mathbf{J U}$ & $\begin{array}{l}\mathrm{X} \text { - Coexists with } \\
\text { lake and sea (01) }\end{array}$ & $\begin{array}{l}X \text { - What they do } \\
\text { and don't (10) }\end{array}$ & & $\begin{array}{c}X-\text { Beautiful } \\
\text { things }(03,04, \\
11) \\
\end{array}$ \\
\hline No & $\begin{array}{c}\mathrm{X} \text { - Intro }(01)-\mathrm{Her} \\
\text { territory and lake } \\
(04)\end{array}$ & $\begin{array}{c}\text { X - Their } \\
\text { Lafkenche } \\
\text { territory (05) }\end{array}$ & $\begin{array}{l}X \text { - Ancestors lived } \\
\text { in Rukas (01) }\end{array}$ & $\begin{array}{c}\mathrm{X} \text { - Beautiful } \\
\text { things (02) - } \\
\text { Sensing the sea } \\
(06) \\
\end{array}$ \\
\hline Ro & $\begin{array}{c}\mathrm{X}-\text { Intro(01) - } \\
\text { Lafkenche=Ocean } \\
(04)\end{array}$ & $\begin{array}{c}X \text { - Lafkenche } \\
(04)\end{array}$ & & \\
\hline $\mathbf{K}$ & $\begin{array}{c}X \text { - Her mountain } \\
(03) \text { - Her park (04) } \\
\text { - Her Marae (07) }\end{array}$ & $\begin{array}{l}X \text { - Welcoming } \\
\text { visitors (07) }\end{array}$ & $\begin{array}{c}\text { X - Her family } \\
\text { inhabits }(01,02) \text { - } \\
\text { Cemetery (06) - } \\
\text { Ancestors in Marae } \\
(07)\end{array}$ & $\begin{array}{c}\text { X - Feeling } \\
\text { better } \\
\text { (02)Playground } \\
\text { flying (04) - } \\
\text { Yummy F\&C } \\
\text { (04) - Peaceful } \\
\text { cemetery (06) - } \\
\text { Cheap food } \\
(08)\end{array}$ \\
\hline LA & $\begin{array}{c}\mathrm{X}-\text { Tribe }=\text { territory } \\
(01)\end{array}$ & $\begin{array}{l}X \text { - His culture } \\
(06) \& \text { tribe }(01)\end{array}$ & $\begin{array}{c}\text { X - Ancestors in } \\
\text { Marae (06) - His } \\
\text { ancestor Haka (07) }\end{array}$ & $\begin{array}{c}X \text { - Beautiful } \\
\text { things }(03,04, \\
06) \text { - Interior } \\
\text { spaces }(05-09)\end{array}$ \\
\hline LO & & & $\begin{array}{c}\text { X - His koro's } \\
\text { experience }(01)\end{array}$ & $\begin{array}{c}\text { X - Boring } \\
\text { harbour (02) }\end{array}$ \\
\hline & $\begin{array}{l}\text { Most of them id } \\
\text { Mountain, or m } \\
\text { particular cultu } \\
\text { together. The wa } \\
\text { places having been } \\
\text { and most of them } \\
\text { ones in re }\end{array}$ & $\begin{array}{l}\text { entioning it as 'o } \\
\text { ral (Maori or Ma } \\
\text { y they relate to p } \\
\text { or being inhabit } \\
\text { describe their fe } \\
\text { lation to certain }\end{array}$ & $\begin{array}{l}\text { with their territory } \\
\text { r' territory) and alsc } \\
\text { uche Lafkenche) an } \\
\text { aces is often framed } \\
\text { d by their ancestors } \\
\text { lings, especially plea } \\
\text { laces (playground, b }\end{array}$ & $\begin{array}{l}\text { (by naming } \\
\text { o with their } \\
\text { d link them } \\
\text { within those } \\
\text { (Marae, Ruka) } \\
\text { asant sensory } \\
\text { oats). }\end{array}$ \\
\hline
\end{tabular}




\begin{tabular}{|c|c|c|c|c|}
\hline & & $\begin{array}{r}\text { Situated Ac } \\
\text { Local/Social nar }\end{array}$ & $\begin{array}{l}\text { tivity Systems: } \\
\text { ratives about places }\end{array}$ & \\
\hline & $\begin{array}{c}\text { Traditional or } \\
\text { cultural activities } \\
\text { in certain places } \\
\end{array}$ & $\begin{array}{c}\text { Use (and it's } \\
\text { effect) of } \\
\text { 'resources' } \\
\end{array}$ & $\begin{array}{c}\text { Culture and language } \\
\text { associated with territory }\end{array}$ & $\begin{array}{l}\text { Money } \\
\text { related } \\
\text { things? }\end{array}$ \\
\hline $\mathbf{A L}$ & $\begin{array}{c}\mathrm{X} \text { - Ruka to reclaim } \\
\text { land (01) - Use of } \\
\text { native plants found } \\
\text { in the forest (06- } \\
09) \\
\end{array}$ & $\begin{array}{c}\mathrm{X} \text { - Fishing and } \\
\text { fish population } \\
(02)- \\
\text { Pine/Euca dry } \\
\text { land (04) }\end{array}$ & $\begin{array}{c}\mathrm{X} \text { - Moving to the city } \\
\text { results in losing language } \\
(04)\end{array}$ & $\begin{array}{c}\mathrm{X} \text { - Moving } \\
\text { to the city } \\
(04)\end{array}$ \\
\hline AK & & $\begin{array}{l}\text { X - Pine/Euca } \\
\text { dry nature (05) }\end{array}$ & $\begin{array}{c}\mathrm{X} \text { - His community is } \\
\text { Mapuche (02) - Lafkenche } \\
=\text { Sea(04) }\end{array}$ & \\
\hline JU & $\begin{array}{l}X-\text { Machi to calm } \\
\text { the forces of earth } \\
(10)\end{array}$ & $\begin{array}{c}\text { X - Materials } \\
\text { used for rukas } \\
(06)- \\
\text { Pine/Euca dry } \\
\text { land (02) - } \\
\text { Pollution and } \\
\text { fish population } \\
(07)\end{array}$ & & $\begin{array}{c}\text { X - Plating } \\
\text { Euca/Pines } \\
\text { for money } \\
(02)\end{array}$ \\
\hline No & & & & $\begin{array}{l}X \text { - Living in } \\
\text { houses and } \\
\text { modern } \\
\text { things (03) }\end{array}$ \\
\hline RO & \begin{tabular}{|c|} 
X - Rituals in the \\
Ruka (03) - Rituals \\
by the sea (05) \\
\end{tabular} & $\begin{array}{c}\mathrm{X} \text { - Materials } \\
\text { used for rukas } \\
(02)\end{array}$ & $\mathrm{X}$ - Lafkenche $=$ Sea $(04)$ & \\
\hline $\mathbf{K}$ & $\begin{array}{c}\text { X - Cemetery (06) - } \\
\text { Marae (07) } \\
\end{array}$ & $\begin{array}{c}\mathrm{X} \text { - Rubbish and } \\
\text { pollution in the } \\
\text { harbour (03) } \\
\end{array}$ & & $\begin{array}{c}\text { X - Dairy } \\
\text { (08 }\end{array}$ \\
\hline LA & $\begin{array}{c}\mathrm{X} \text { - Hangi, haka and } \\
\text { places in Marae } \\
(06-07) \\
\end{array}$ & $\begin{array}{c}\mathrm{X} \text { - Sewages and } \\
\text { pollution }(02)\end{array}$ & $\begin{array}{c}\text { X - Ngāti Toa= } \\
\text { Takapuwahia(01) }\end{array}$ & $\begin{array}{c}\text { X- Walking } \\
\text { to Te Puna } \\
\text { (08) - Going } \\
\text { to the dairy } \\
(09) \\
\end{array}$ \\
\hline LO & & $\begin{array}{l}X-\text { Never been } \\
\text { much fish }(02)\end{array}$ & & $\begin{array}{c}\mathrm{X} \text { - Buying } \\
\text { in the Dairy } \\
(04)\end{array}$ \\
\hline & $\begin{array}{l}\text { Most children sit } \\
\text { Marae. Most o } \\
\text { environmental da }\end{array}$ & $\begin{array}{l}\text { uate traditional } \\
\text { of them describe } \\
\text { amage. There is } \\
\text { happens in th }\end{array}$ & $\begin{array}{l}\text { or cultural activities in th } \\
\text { activities which have res } \\
\text { strong perception that th } \\
\text { lat specific place. }\end{array}$ & $\begin{array}{l}\text { e Ruka and } \\
\text { llted in } \\
\text { neir culture }\end{array}$ \\
\hline
\end{tabular}




\begin{tabular}{|c|c|c|c|c|c|c|}
\hline & \multicolumn{6}{|c|}{$\begin{array}{c}\text { Cultural Toolkits: } \\
\text { Prevailing cultural narratives }\end{array}$} \\
\hline & $\begin{array}{l}\text { Use of language } \\
\text { (Zugun, Reo) }\end{array}$ & Changes & $\begin{array}{c}\text { Scientific and } \\
\text { historical knowledge }\end{array}$ & $\begin{array}{c}\begin{array}{c}\text { Maintenance of } \\
\text { environment }\end{array} \\
\end{array}$ & Maintenance of culture & $\begin{array}{c}\text { Tools to navigate } \\
\text { environment }\end{array}$ \\
\hline AL & & $\begin{array}{c}X \text { - Negative, Spanish (02) - } \\
\text { Neutral, Earthquake (03) - } \\
\text { Negative, Pine/Euca (04) }\end{array}$ & $\begin{array}{c}\text { X - Earthquake (03) - } \\
\text { Pine/Euca (04) - Lawen } \\
(06)\end{array}$ & $\begin{array}{l}X \text { - Native forest }(04, \\
07,08) \text { - Lawen }(06)\end{array}$ & $\begin{array}{c}\text { X - Land reclaim (01) - } \\
\text { Migration=Loss of culture } \\
\text { (05) - Lawen (06), Copihue } \\
(09)\end{array}$ & $\begin{array}{l}\text { X - Baskets from } \\
\text { vines (09) }\end{array}$ \\
\hline $\mathbf{A K}$ & $\begin{array}{l}X \text { - Intro (01) - } \\
\text { Maintenance } \\
(09)\end{array}$ & $\begin{array}{c}\mathrm{X} \text { - Negative, Evangelical } \\
(03) \text { - Negative, Pine/Euca } \\
(05) \text { - Negative, Colonisers } \\
(09)\end{array}$ & X - Pine/Euca (05) & & $\begin{array}{c}\text { X - Active endeavour }(04) \text { - } \\
\text { Traditional practices } \\
(06,07) \text { - Resistance }(09)\end{array}$ & \\
\hline $\mathrm{JU}$ & $\begin{array}{c}X \text { - Open, close } \\
(01,13)\end{array}$ & $\begin{array}{c}\text { X - Neutral, Earthquake } \\
(07) \text { - Neutral, Spanish } \\
(06) \text { - Negative, Pine/Euca } \\
(02) \\
\end{array}$ & $\begin{array}{l}\text { X - Earthquake }(01,08) \\
\text { - Lake }(03,05) \text { - } \\
\text { Pine/Euca }(02) \\
\end{array}$ & $\begin{array}{c}\text { X - Pine/Euca(02)- } \\
\text { Clean agriculture } \\
(12) \\
\end{array}$ & & $\begin{array}{l}\mathrm{X} \text { - Shrimp from } \\
\text { meadows (05) }\end{array}$ \\
\hline NO & $X$ - Casual (05) & $\begin{array}{l}\mathrm{X} \text { - Positive modern } \\
\text { things }(03)\end{array}$ & X - Lake (04) & & & \\
\hline RO & $\mathrm{X}$ - Intro (01) & & & $\begin{array}{l}\mathrm{X} \text { - Taking care of } \\
\text { the lake (06) }\end{array}$ & $\begin{array}{c}\mathrm{X} \text { - Ceremonies (03) - Gnen } \\
(05-08)\end{array}$ & $\begin{array}{l}\mathrm{X} \text { - How to make } \\
\text { rukas (02) }\end{array}$ \\
\hline $\mathbf{K}$ & & $X$ - Negative, pollution $(03)$ & X - Pines (05) & & $\begin{array}{c}\text { X - Cemetery (06) - Marae } \\
(07)\end{array}$ & $\begin{array}{l}X \text { - Price of things in } \\
\text { shop (08) }\end{array}$ \\
\hline LA & $\begin{array}{l}\text { X - Casual }(04, \\
06,07)\end{array}$ & $\begin{array}{c}X \text { - Negative, Pollution (02) } \\
\text { - Neutral, English (08) }\end{array}$ & X - Haka (07) & & X - Marae practices $(06,07)$ & $\begin{array}{c}\mathrm{X} \text { - Location of } \\
\text { things }(01,03,04, \\
05) \text { - Prices }(09)\end{array}$ \\
\hline LO & $\begin{array}{c}\mathrm{X} \text { - Casual 'Koro' } \\
(01) \\
\end{array}$ & & $\begin{array}{c}\text { X - Harbour history } \\
\text { (01) - Qualities (02) - } \\
\text { Marae history (03) } \\
\end{array}$ & & & $\begin{array}{c}\mathrm{X} \text { - Price of things in } \\
\text { shop (04) }\end{array}$ \\
\hline
\end{tabular}


Most children mention pollution as a negative change, though only a couple mention its origins and only one approaches the topic of solving the issue. Most children express their participation in cultural practices, though only two of them reflect on it as an important endeavour of resistance.. Most Mapuche kids have a strong understanding of the earthquake, lake formation and its qualities. Most Mapuche kids perceive Euca/Pine as a negative disruption due to dryness, though only one mentions why they are planted. Some neutral and some negative perceptions of 'colonisers'. 
The insights obtained from this axial analysis allowed me to identify a final and emergent layer of analysis- the representation of an intimate connection between Territory, Culture and Self-Conception. For the purposes of this analysis I understand territory as a physical space which, in the words of Rosas $(2013$, p. 10) "is more than the inhabited land, also a land with which the indigenous people have a natural, ancestral and metaphysical relationship". I understand Culture as a socially shared pattern: "a collective and incessant process of production of signifiers which shape the social experience and configure the social relationships" (Escobar, Álvarez, \& Dagnino, 2001, p. 19). Finally, my understanding of selfconception is based on Gergen's (2009) relational and constructionist view as "discourse about the self... as a narration rendered intelligible within ongoing relationships", the stories we tell ourselves to "make ourselves comprehensible" (pp. 185-186).

The interconnected pattern between territory, culture and self-conception was strong in all of the narratives but the ways in which each of these themes was presented and the relationships between them varied. I used this main pattern to describe the relationships the children represented as shown in FIG. 23 below.

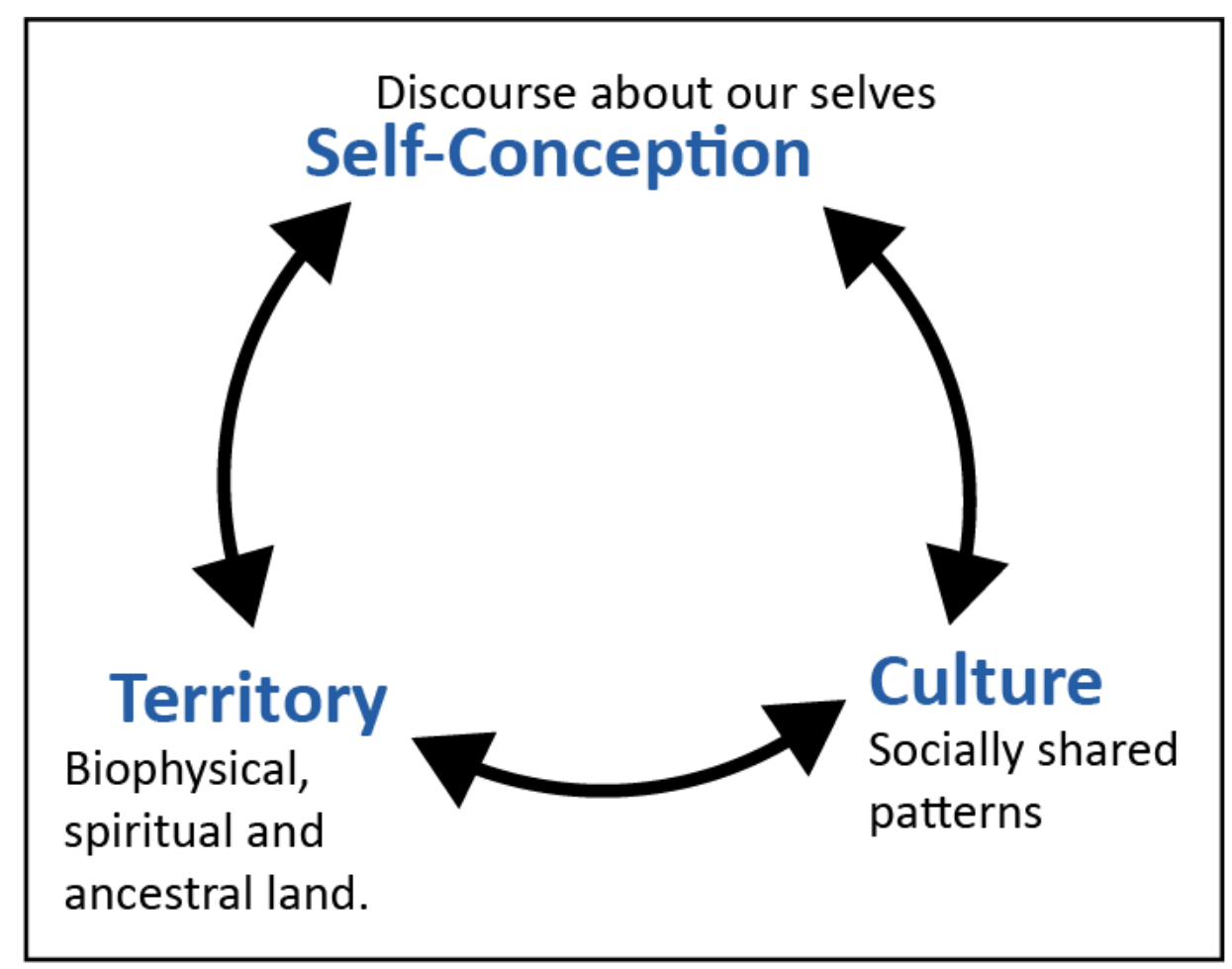

FIG 23- Main pattern of analysis: Territory, Culture and Self-Conception 
Each of the children's narratives was rich and multi-layered with sensory, emotional, scientific, historic and visual data. I kept my focus on bringing forth the children's complex subjectivities in the ways they represented relationships with and within the environment while trying to honour these multiple layers. In order to do this the next two chapters centre around two particular narratives using others to further illuminate the relationships represented. Choosing two has allowed me to go into more depth of analysis, nevertheless, each one of the narratives which were created by the children for this project present meaningful insights into the ways in which they relate to and understand their environments.

\subsubsection{Challenges and limitations}

In order to understand the ways in which the Mapuche and Māori children who participated in this project represent relationships with, and within the environment, I subjected the Digital Stories they created to the analytical process described above. This process, framed within a relational ontology and decolonial thought, aimed to honour the voices of the participants by allowing their images and narratives to 'speak for themselves' and clearly differentiating my interpretations from their narratives. One of the main challenges for attaining this aim was doing that differentiation in a clear manner, as often my own assumptions and interpretations seemed to get confused with what actually happened and the narratives of the children. In relation to this challenge, having access to the notes in my reflective journal was beneficial as it allowed me to get a better sense of the experiences we lived during the workshops and what my own interpretations were at the time. As previously mentioned, I use colour coding in the next couple of chapters to make this differentiation clear.

Another challenge relates to the difficulties to access and reveal the "multisensuous and open-ended aspects" (Kullman, 2012, p. 12) of children's photos and oral narratives. I have tried to explore and take these aspects into account by paying attention to the sensory and affective within the narratives but, in the words of Punch (2002), who explores some differences between conducting research with 
adults and with children: "Ultimately the power lies with the adult researcher to interpret children's perspectives" (p.327). During my research project this power imbalance can be seen in the fact that I am limited (as all researchers are) in the amount and quality of aspects that I am able to capture and compare in the search for a deeper understanding of the children's subjectivities.

Furthermore, the aspects I have captured and analysed are focused on the underlying patterns related to Territory, Culture and Self-Conception which emerged mostly from the focus on the content and context of the data. But the content of the data gathered can be considered limited in terms of audio-visual analysis as it lacks depth of 'multimodal analysis', meaning the pictorial, the music, and other aesthetical aspects (Hull \& Nelson, 2005). These aspects are present as an expression of the data, but not present enough in the analysis.

Finally, and as a summary of the above, I share Wood's (2011) struggle to find balance between "not appropriating or speaking for those we have worked with but at the same time in some way telling their stories in their own words" (Skelton, 2001, p. 95, as cited in Wood, 2011, p.93). I hope the following chapters allow the reader to access the children's narratives and images clearly and my interpretations allow to access some of the aspects within them which reveal relationships with, and within their environments.

\subsection{Summary}

In this chapter I have introduced relational constructionism as the ontology underpinning this research project. Relational constructionism perceives reality as a continuously emergent construction process which takes place through relationships between and through humans, non-humans and diverse ontologies (Hosking, 2011). In terms of my research project exploring how Mapuche and Māori children represent relationships with, and within the environment, a relational constructivist ontology has translated into a nurturing of relationships and 
processes which allow the children's knowledges to emerge through their own voices.

Based on this ontology I then proceeded to narrate the different journeys and knowledges which brought me to this research project, focusing particularly on the relationships I established with the community of Llaguepulli and the community of Takapuwahia. I also explain how these relationships were framed by my interest in the connections between decolonial thought and environmental sustainability which was sparked through my Masters courses. Connections and interests which drove me to approach the Llaguepulli school and start working with Roberto, a teacher there, to develop this project.

I then explain my choice of methods: Digital storytelling and Reflexive participant observation, based on literature concerning decolonising research with children and with indigenous people. And I proceed to describe the initial research design and the ways it changed through the experiences in the field and with the participants. I finish this section by presenting the final research design and reflecting on some ethical considerations in regards to the field and the analysis. Finally, I present the process I went through in order to analyse the data which were eight videos made by the children and my own observations. I drew from different bodies of literature concerning visual research with children and used grounded theory to analyse the data and present a main pattern of analysis: The relationships between Territory, Culture and Self-Conception. Then I reflect on the challenges and limitations of this process.

As a conclusion I can say that for this research project pre-existing relationships were key. I believe this is because there is a personal level of trust that comes from knowing each other, a trust which still cares about the final outcomes and goals of the project, but is based on a human connection that comes from time spent together. L.T. Smith (1999) echoes this perception by situating the importance of the ability "to enter pre-existing relationships; to build, maintain and nurture relationships; and to strengthen connectivity" (p.129) specifically when working with indigenous participants. 


\section{AL's narrative:}

\section{Entanglements of Culture Territory and Personal Identity}

The following chapter focuses mainly on AL's narrative and the ways in which the relationships she represented with, and within the environment speak about a strong interdependence between culture, territory and self-conception. I will look at how, throughout her narrative, territory is often presented a contested space which both supports and challenges her self-conception and her culture. Later on I complement her story with those shared by other children and close by pointing to the main relationships I interpret within these narratives.

\subsection{AL and her narrative}

As $A L$, the other four children and I were walking back to school from the lakeside where we had the first workshop, we looked at a makeshift greenhouse which is very common in Llaguepulli. AL hadn't taken many pictures as she wanted to photograph around her house which was far away, but we had been talking about water and she mentioned that it was essential for growing food, so I offered her the camera and she took this picture (FIG. 24):

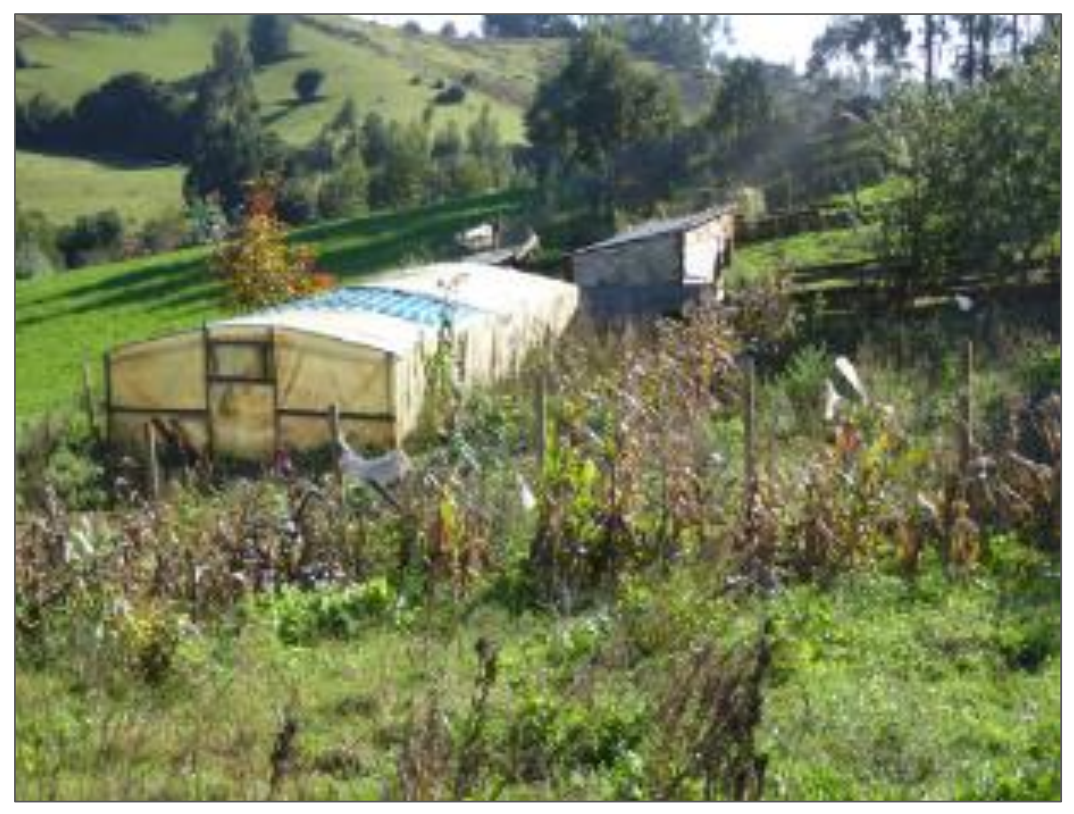

FIG 24- Photo taken by AL [ALO5] 
She later wrote the following about this image:

Forests are very important the ones that are native because Eucalyptus trees drink lots of water and dry the land. Agriculture can't be practised if there is no water so people leave the fields and go to the city and lose their culture and their Mapuche zugun (their language).

[AL04-05] My translation.

I had the privilege of meeting AL's family and spending some time in their land just walking, weaving and talking. They are very committed to the school as a project of revitalisation of culture and to reclaiming their territory for their families and practices. When I visited her to bring the camera, we spent a while walking down a river bank behind her house where AL told me about how she often does that and how the plants and flow of water change throughout the year. She seemed to have total clarity about how things are and how things should be.

My interpretation of $A L^{\prime} s$ aforementioned paragraph was of a strong line of logic depicted in FIG. 25 below:

\begin{tabular}{|c|c|c|c|c|c|c|c|c|}
\hline $\begin{array}{l}\text { Planting of } \\
\text { Eucalyptus }\end{array}$ & $\Rightarrow$ & $\begin{array}{l}\text { Dries } \\
\text { the } \\
\text { land }\end{array}$ & $\Rightarrow$ & $\begin{array}{l}\text { Agriculture } \\
\text { can't be } \\
\text { practiced }\end{array}$ & $\Rightarrow$ & $\begin{array}{l}\text { People } \\
\text { move } \\
\text { to the } \\
\text { city }\end{array}$ & $\Rightarrow$ & $\begin{array}{l}\text { People } \\
\text { lose } \\
\text { their } \\
\text { culture } \\
\text { and } \\
\text { language }\end{array}$ \\
\hline
\end{tabular}

FIG 25- My interpretation of $A L$ 's line of logic

Furthermore, later on in her narrative she inserted herself and her culture into this line of logic by saying that:

Also the plants and animals represent us because Araucania, the place where we live, is still preserved with some forests and there are few places where you can still find big forests. There is one where I live.

[AL07-08] My translation. 
Through her line of logic AL shared her knowledge which ranges from the biophysical effects of Pine and Eucalyptus in the land and the fact that water is essential for agriculture, to the bio-cultural fact that agriculture is the main source of sustenance in the territory. This finally leads to her knowledge that when people move away from their territory and to the city they will lose their culture and language.

Her words and concepts were fully supported by her images (FIGs 26-28) immersed in native forest and the fact that she was clear from the beginning about wanting to take the photos in her own land, which shows that strong sense of identification with that particular land.

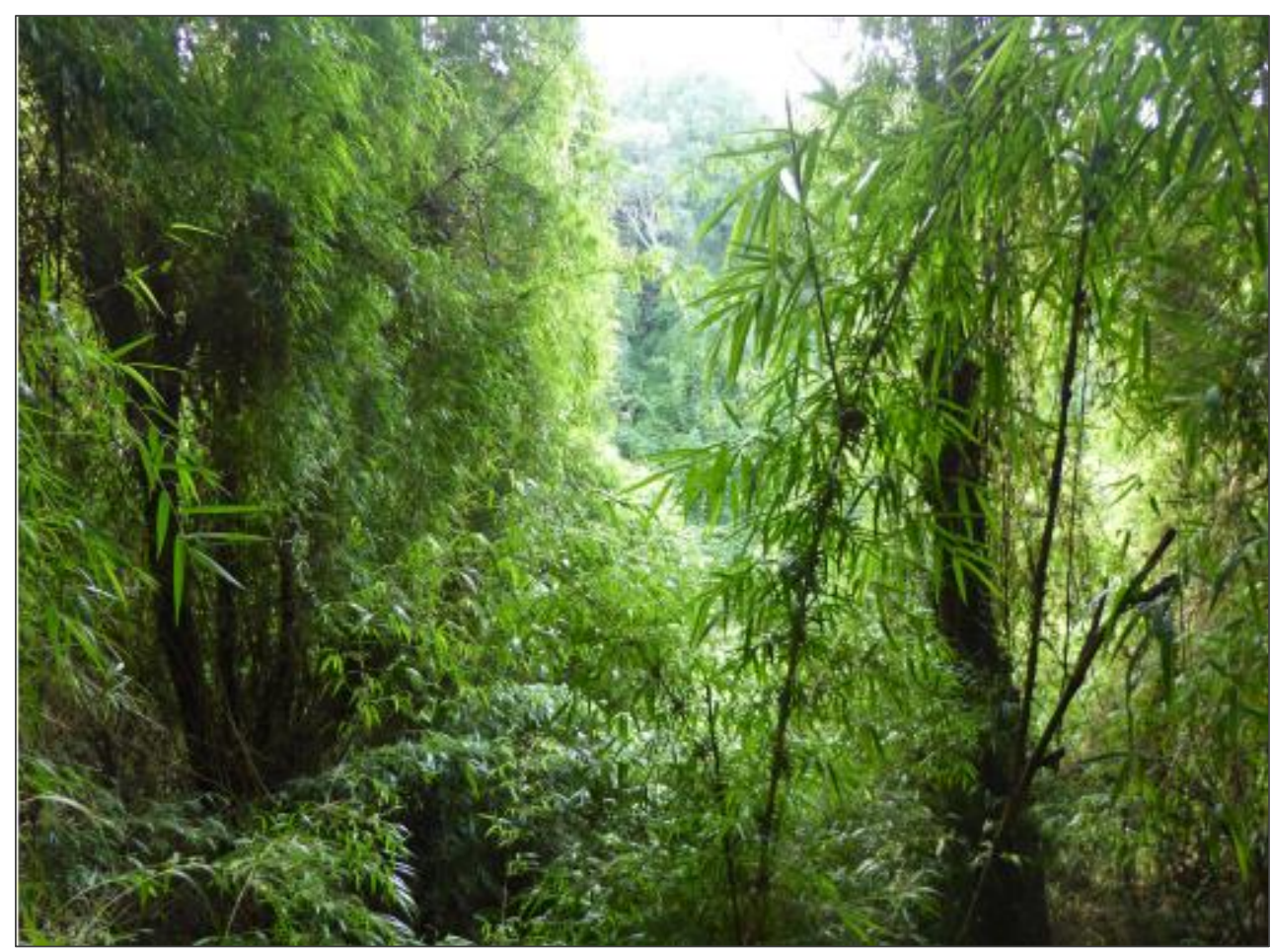

FIG 26- Photo taken by AL [ALO4] 


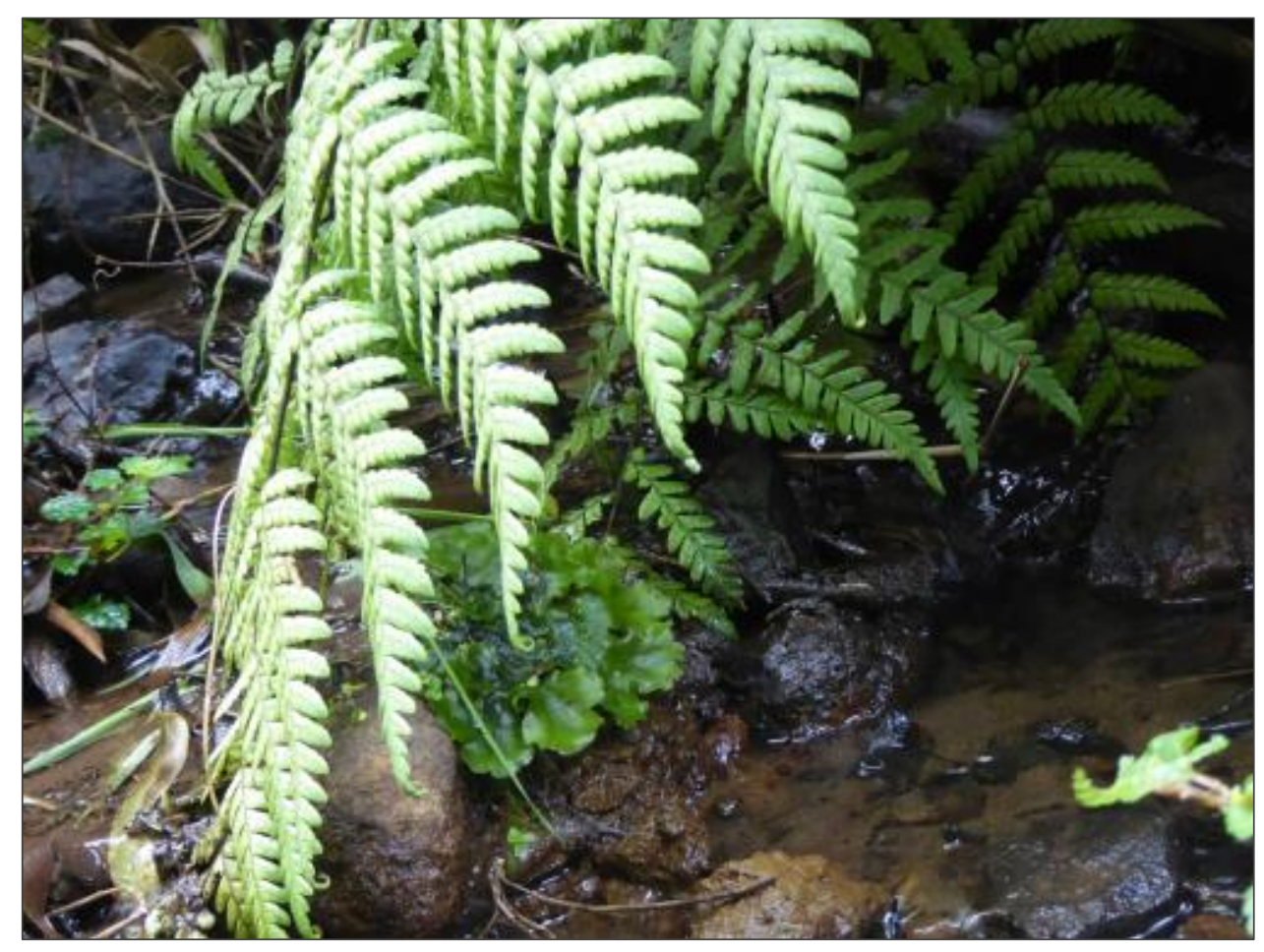

FIG 27- Photo taken by AL [ALO7]

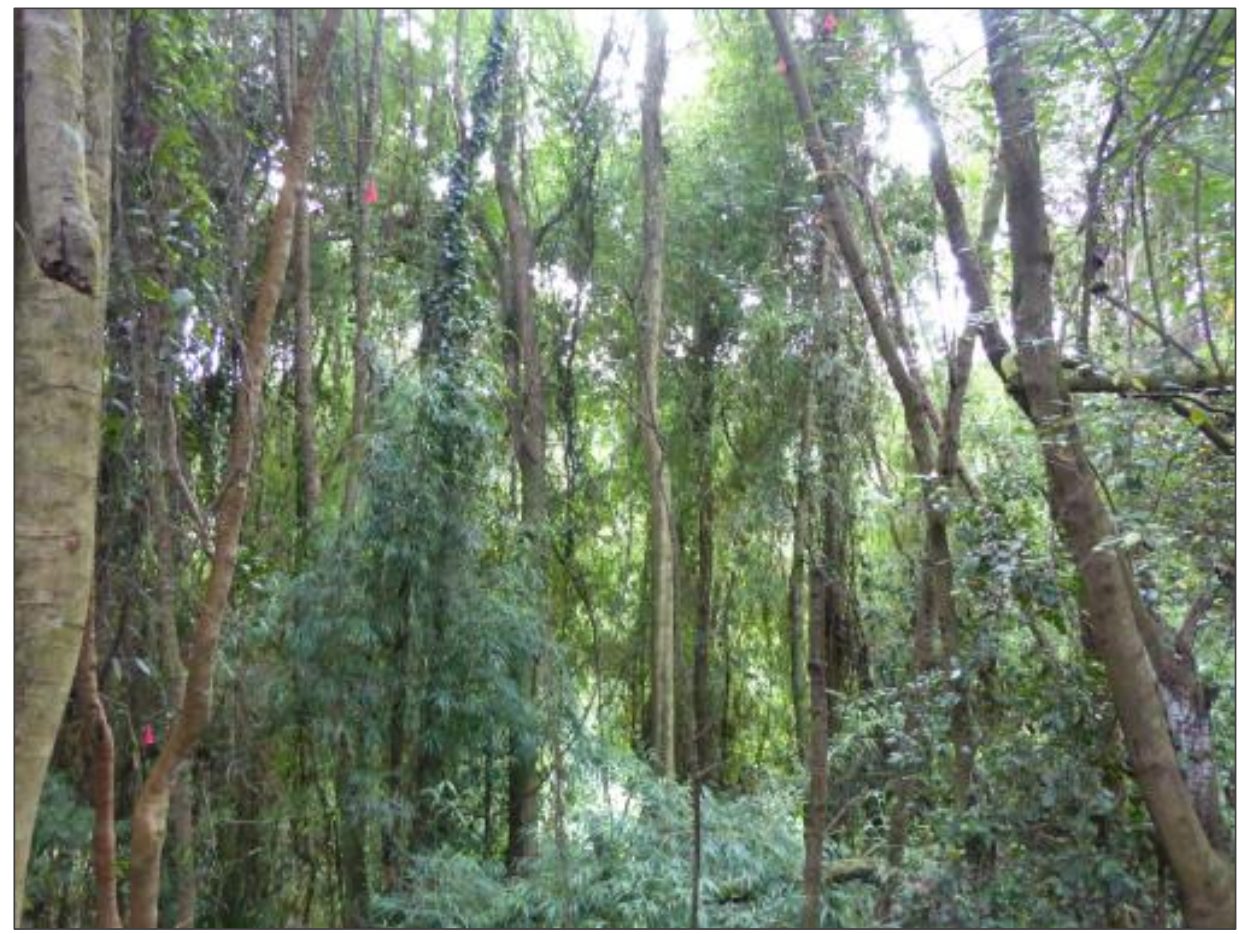

FIG 28- Photo taken by AL [AL08] 
FIG. 29 brings AL's narrative elements back to the three areas identified for analysis:

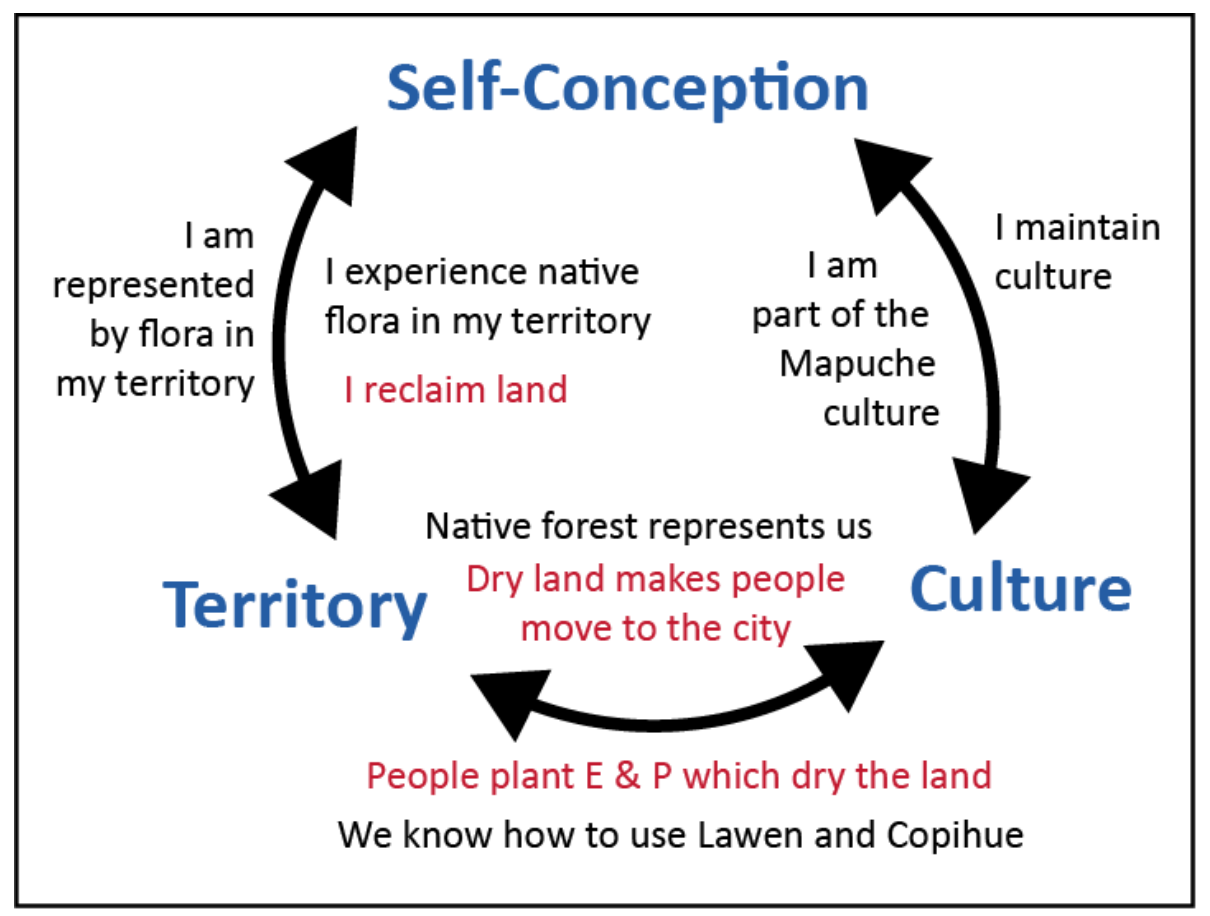

FIG 29- Main pattern of analysis applied to AL's narrative

In this FIG. 29 I use the red colour to represent what I interpret as either negative perceptions of issues (such as Eucalyptus and Pines drying the land) or what I interpret as active responses to perceived issues (such as reclaiming land). Following on from this diagram, I interpret AL's conception of territory to be a contested area, a place from which self-conception stems but which is being challenged by cultural changes. This in turn, brings forth a response of resistance to change which was perceived as negative, by actively maintaining territory and culture through the reclaiming of land and the prioritising of native flora. The following quote from AL's narratives illustrates this:

Well, the 'ruka' is a place where my ancestors lived and where few people still do. Our culture is still not giving it importance, so when we reclaim land a 'ruka' is a sign that we are all settled and they won't move us out. 


\subsection{Entanglements of territory, culture and self-conception in the other narratives}

AL's case was somewhat unique in that her wider family owns and shared a large area of land which still has preserved native forest. Most other families didn't have access to that amount of land and/or had subdivided it in individual properties dedicated to intense agriculture. But the relationships she represents are also echoed in other children's narratives.

All children clearly expressed a strong sense of belonging and identification with their specific territories. One way this could be seen is through the usage of possessive nouns when describing it:

This is all I wanted to tell you about our Lafkenche territory.

[NO05] My translation.

This is our harbour...

[LAE02]

And in the background there's a little wave curve and that's my mountain...

Also by the clear expression of being represented by the territory as in AK's case:

Well, I want to tell you about the place I come from, about my territory which represents me. 
This sense of belonging went beyond the discursive and could be perceived through the sensory and experiential descriptions by children narrating how it felt to be in their territory:

For me the sea is a beautiful place because in the afternoons I like to listen to its sound. I feel relaxed feeling the sound and when I look at it every afternoon.

[NO06] My translation.

My favourite thing on the park is the swing because I feel like I'm flying.

These examples show that in most narratives, descriptions which refer to selfconception were intimately connected with the territory.

In relation to self-conception and culture, most children clearly stated their cultural belonging by mentioning the name of their culture:

What characterises us as Mapuche Lafkenche is the sea...

[AK04] My translation.

My cultures are mostly Samoan and Māori...

[K01]

We are Lafkenche.

[R04] My translation.

This sense of belonging could also be gathered from the casual usage of their indigenous language and their certain knowledge of, and experience in specific places:

Mari mari, iñche [name]...

[Most Mapuche narratives start with this greeting in Mapudungun] 
My koro [grandfather] used to always go fishing there...

[LO01]

There's a hangi pit, a hangi is a special Maori way of preparing food. It's where you put food in the ground with the fire and it cooks, we put chicken and vegetables and other meats.

The identification of cultural changes was stated clearly in most Mapuche narratives and several times it was done in the context of mentioning the changes from living in rukas to living in houses. For example in NO's comparison between rukas and houses:

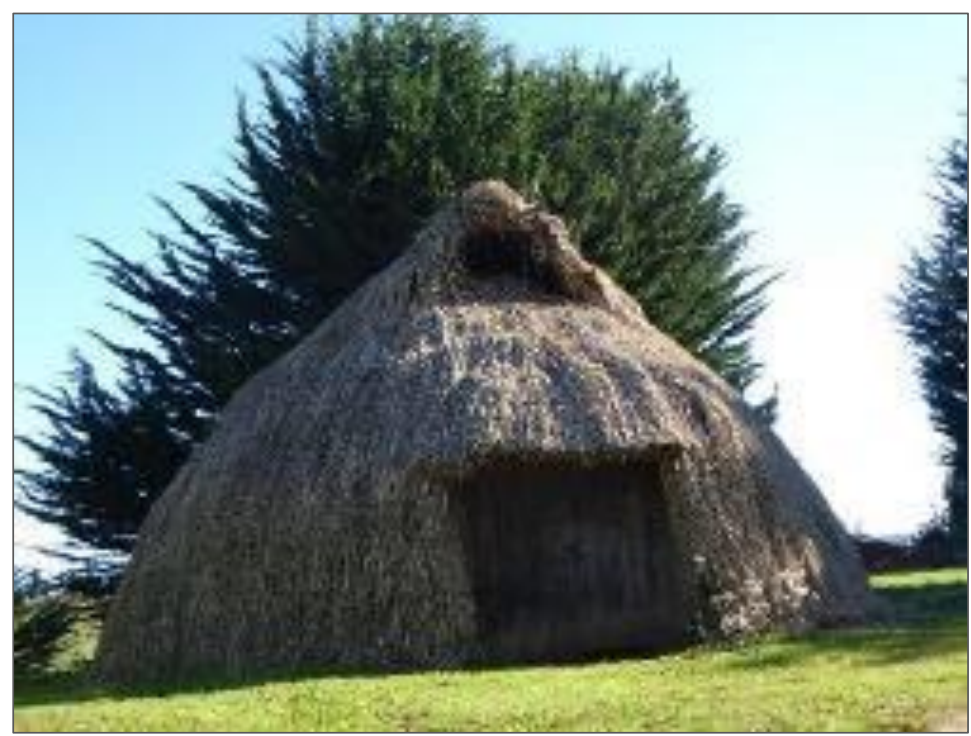

FIG 30-NO's photo [NO02] 


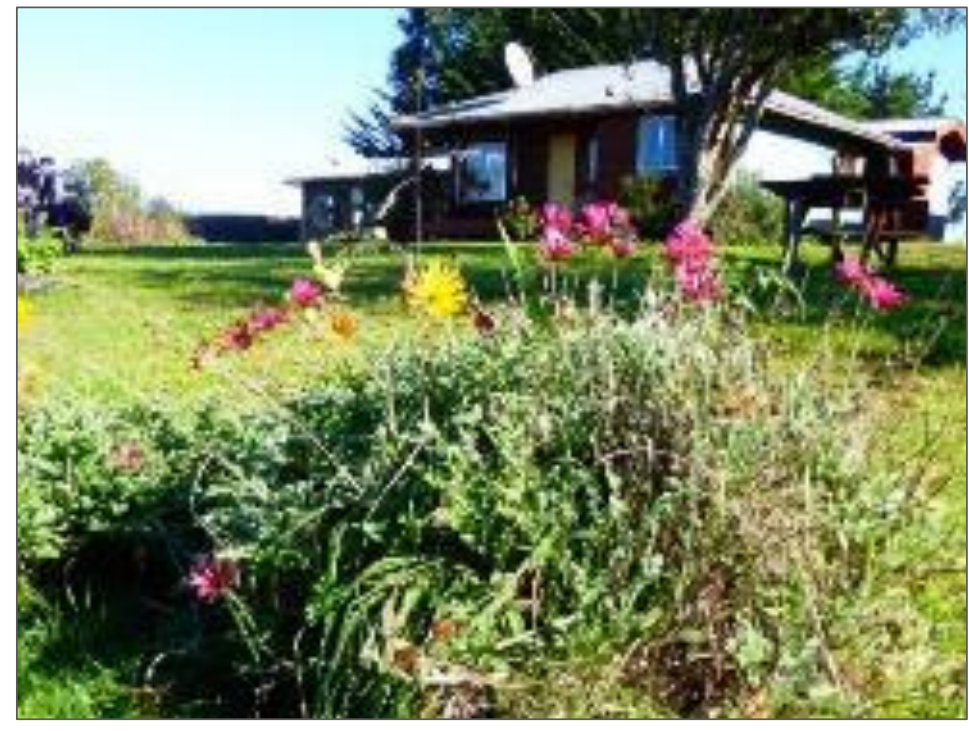

FIG 31- NO's photo [NOO3]

In this third image we can already see the changes having moved from a 'ruka' to a house.

[NO03] My translation.

And a couple of children mentioned the agent of this change as the Spanish colonisers:

... the rukas, which here it is said are the Mapuche houses.

And that was true until now the Spanish came and we only live in houses.

[JU06] My translation.

One of the Māori narratives described a similar cultural shift when describing a painted bus stop (FIG.32) which: 


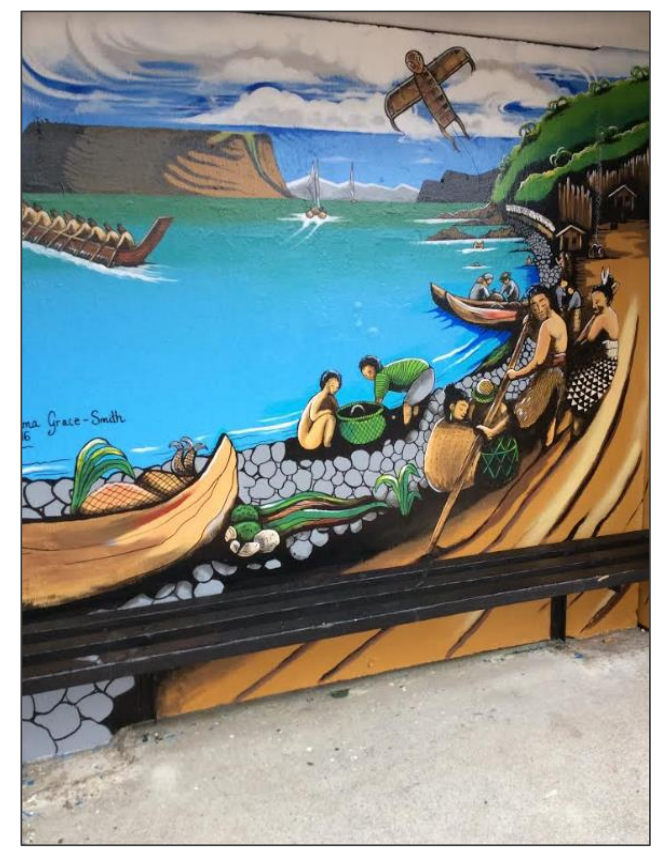

FIG 32- LA's photo [LA08]

... has a drawing on it of the harbour before it was polluted and what life was like before the English came.

Cultural change was only presented as negative in a couple of narratives and as positive in one of them, but most of the time it was depicted as a neutral fact.

Finally, in terms of culture and territory, the strongest relationship established in most narratives was the interconnectedness of children's cultural belonging and their particular territories:

What characterises us as Mapuche Lafkenche is the sea...

[AK04] My translation.

My name is L, I come from the tribe Ngāti Toa so I live in Takapuwahia. 
Several Mapuche children mentioned the effects on the soil of planting Pine and Eucalyptus, though only one of them mapped this back to cultural changes and projected its development through cultural changes too by saying:

Sadly also here, due to the issue of Pines and Eucalyptus there's a lot of dryness, but that's an issue we need to start solving as time goes by.

Here some people plant Eucalyptus for money and others just for planting.

[JU02] My translation.

Another territorial change that was mentioned by most children in their narratives was pollution, which in most narratives also implied a change in cultural activities in certain parts of the territory:

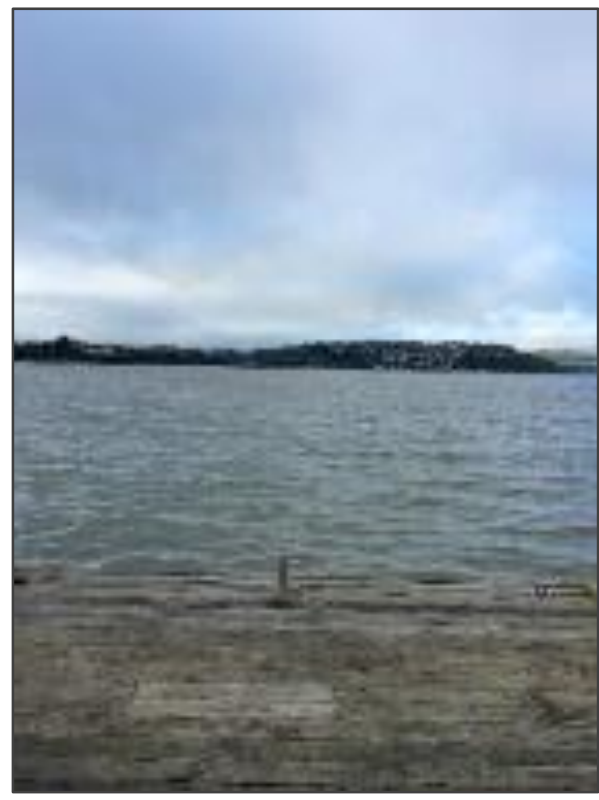

FIG 33- LA's photo [LA02]

This is our harbour, it used to be crystal clear but now it's been polluted due to all the pollution due to all the sewages. At the harbour you can go sailing but you can't go swimming, because the water is too polluted to go swimming any more. 
Actually pollution here is quite worrying as, because of the pollution fish have died and only in October a few of them come out.

[JU07] My translation.

Finally, one of the Mapuche children's narratives focused almost entirely on the cultural and spiritual rituals that were practiced in certain parts of the territory:

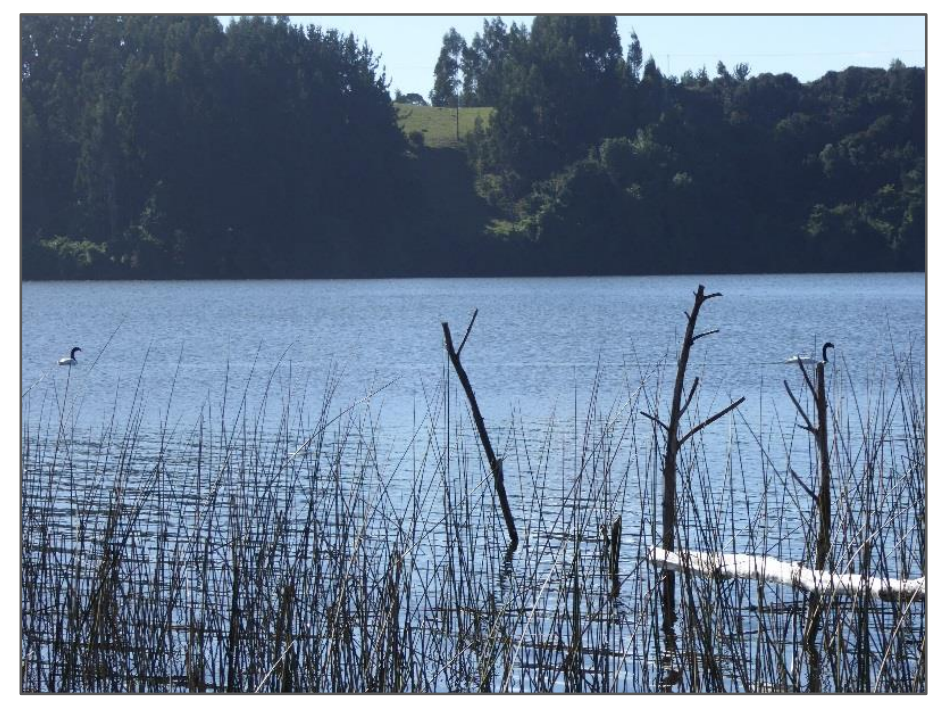

FIG 34- RO's photo [RO06]

And well, what we do in the sea is, not only go fishing, we also do prayers to our 'genechen' [guardians] and ask for things...

In the lake you can go fishing, and you also have to take care of the lake because it has its gen [guardian], it also has strength.

[R05-06] My translation.

Drawing from these examples it can be said that cultural activities and cultural belonging were represented as interconnected and interdependent with the territory.

\subsection{Summary}

Throughout the children's representations of their environmental knowledge, there were strong connections between culture, territory and self-conception. Some of these connections support each other consistently, as in the case of a strong sense 
of belonging to a determined culture which takes place on and with a certain territory. But other ones were perceived as conflicting, as when changes to one of the elements, like the cultural practice of planting Eucalyptus and Pine trees which changes the environment, effect other things like language.

In AL's narrative, the biophysical change in her territory due to the planting of Pines and Eucalyptus resulted in an active menace to the conservation of the Mapuche culture. This, in turn, implied an active stance on her part towards that conservation through the reclaiming of land and the active maintenance of knowledge. Even though this cycle is not repeated in all narratives it is echoed in several of them. Following on from this interpretation, some of the children's narratives took an active stance towards what was perceived as an experience which questions their self-conception by changing elements in the territory and culture. 


\section{K's narrative:}

\section{Inhabitation through personal and ancestral experience}

The following chapter focuses mainly on K's narrative and how she represents a strong relationship with and within the environment through the active inhabitation of the territory, both her own and her ancestors. I then look at other children's narrative to further develop this view and close by pointing to the main relationships this narrative displays.

\section{1. $K$ and her narrative}

During our short walk between 'Te Puna' and the harbour, $\mathrm{K}$ mostly stayed by my side and told me about the different places we were walking past. First we saw her house on the other side of the road:

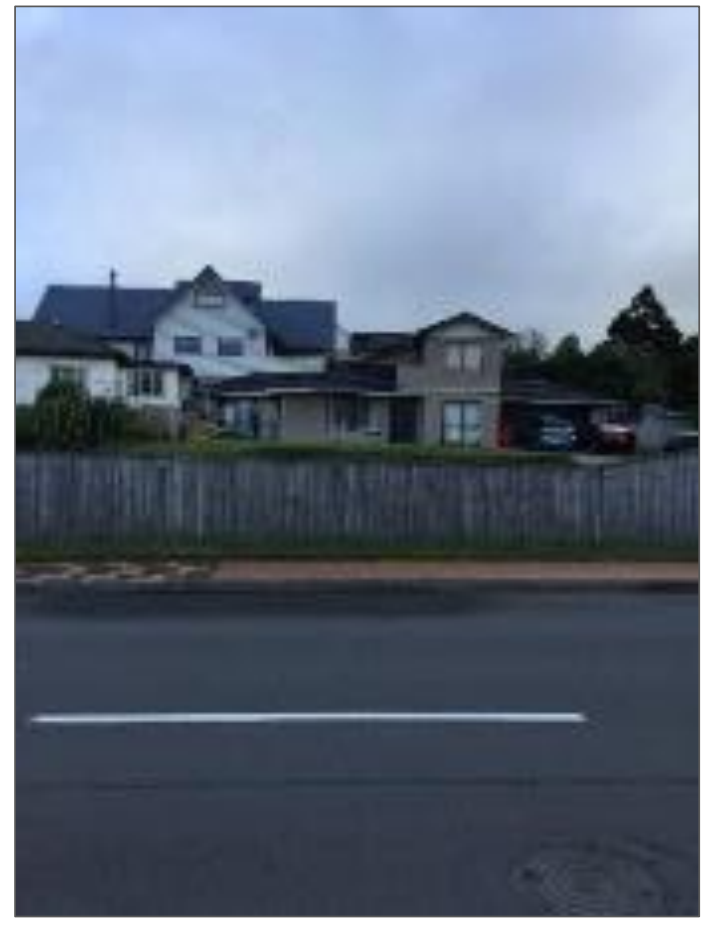

FIG 35- K's photo [K01]

Then the marae where she told me she'd been helping out at a tangi (funeral) during that weekend. This is something she would often do as her aunty told her it was good to help out as then others would support your whānau (family) too. 
She waved to some people at the end of the road saying they were cousins and then pointed out the fact that the three of them who were doing the workshop with me were also related, which the other two confirmed.

$\mathrm{K}$ also took several photos and talked about particular places which were important for her because they related to her ancestors:

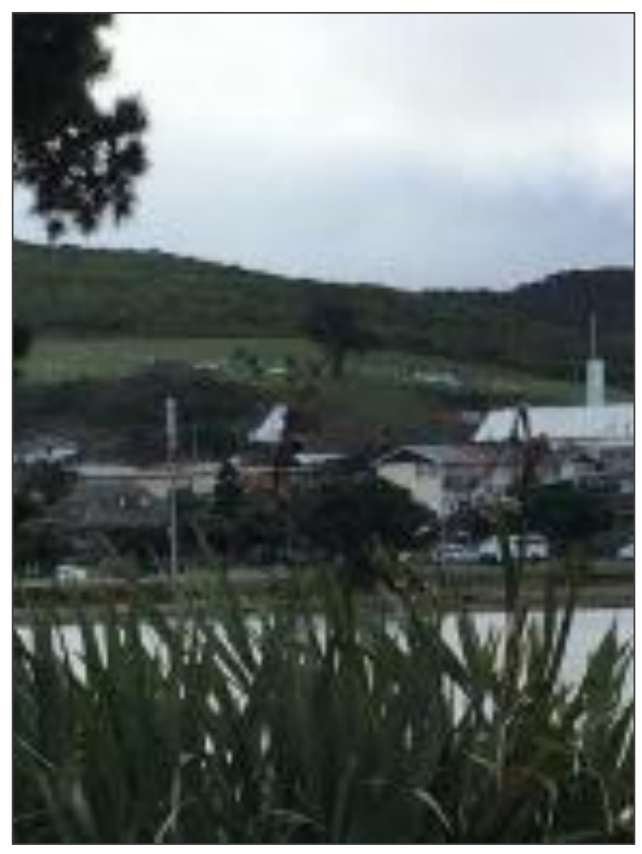

FIG 36- K's photo [KO6]

If you see in the background there is a cemetery, and most of my relatives are buried there. It's very peaceful... 


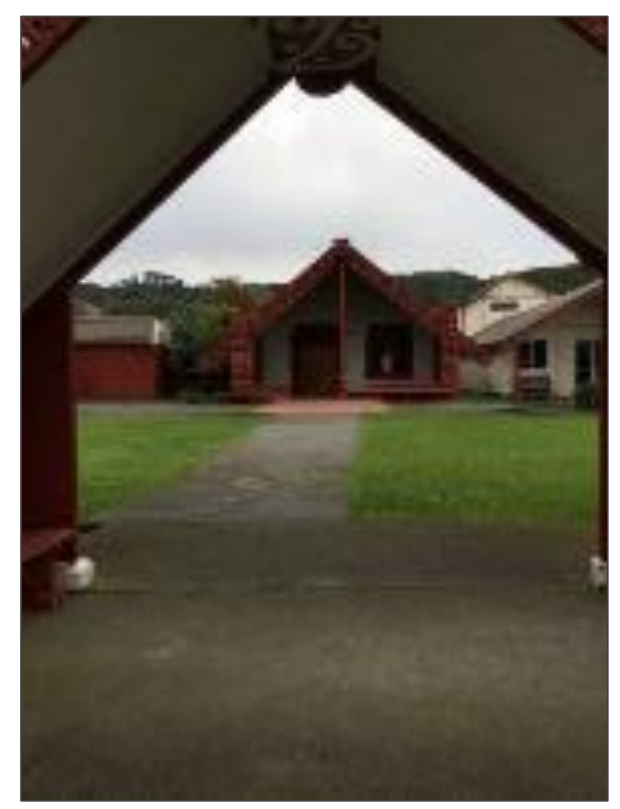

FIG 37- K's photo [KO7]

This is my marae, this is where people have their funeral. All of my ancestors are carved on to the marae...

[K07]

And she also talked about her own sensory experience in the different places:

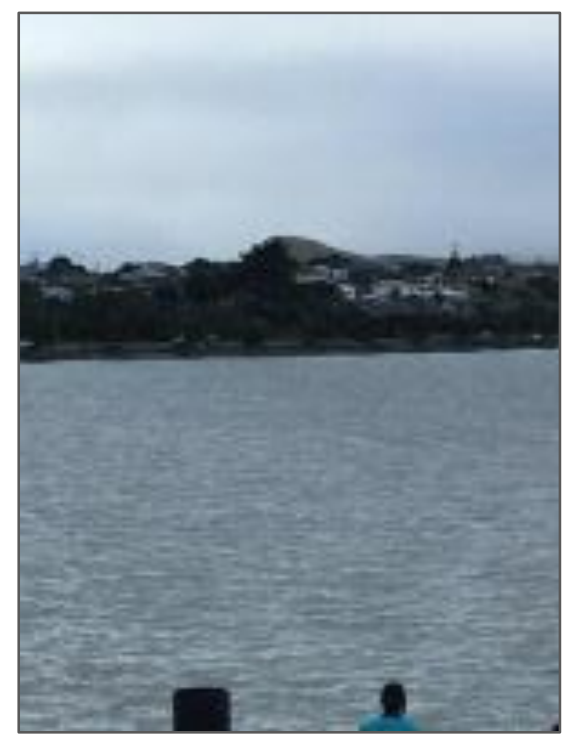

FIG 38- K's photo [KO3]

And in the background there's a little wave curve and that's my mountain, and that Mountain is called Whitireia. You can hike up there and watch the sun go down. 


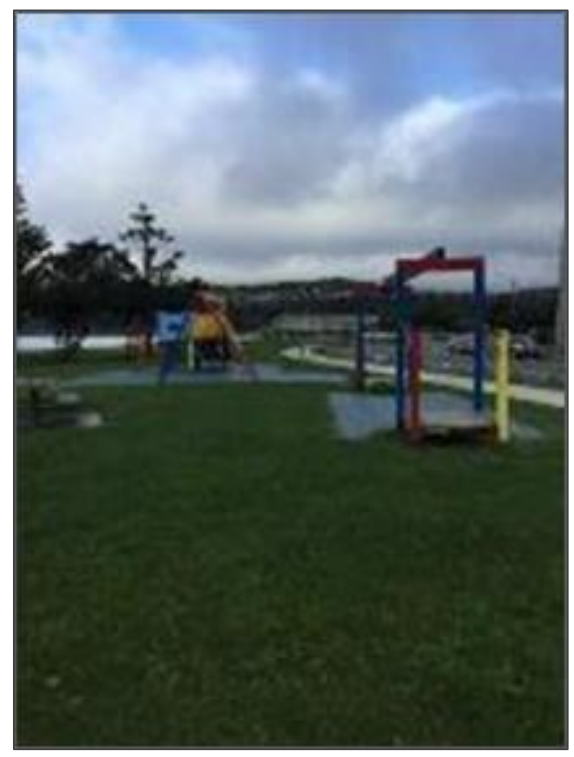

FIG 39- K's photo [K04]

My favourite thing on the park is the swing because I feel like I'm flying. I see other people eating fish and chips there and I watch them because it's yumm.

[K04]

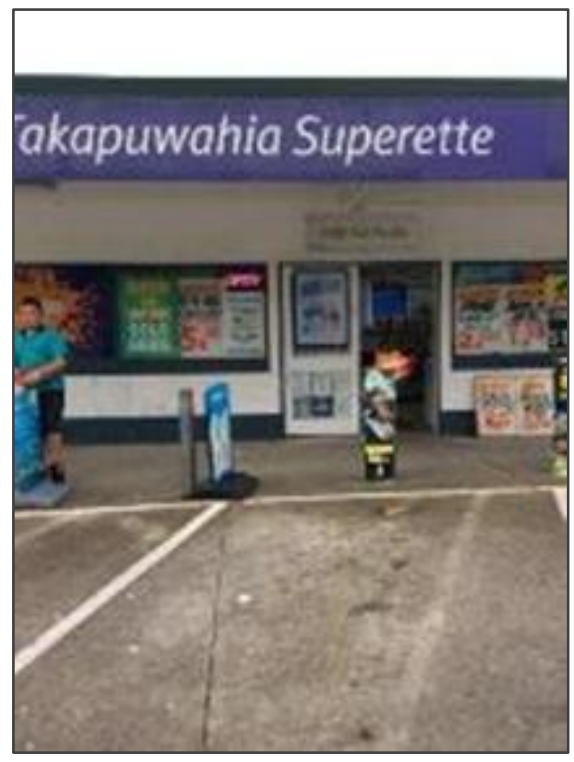

FIG 40- K's photo [K08]

This is the Dairy, this is where I go after school to get food or lollies... I love it here because it's close and it's cheap and bread is only a dollar. 
The time I spent with $\mathrm{K}$ at 'Te Puna', when we were just hanging out and not working, I could perceive that she was totally at ease with the space and the people there as she would just head to the kitchen and grab something or spend time with the adults in the office. She was often holding and taking care of a little baby, the daughter of one of the teachers, who was passed from hand to hand at 'Te Puna'. She was also particularly happy hearing about my pregnancy and I could strongly perceive her caring stance towards little ones and that strong sense of family belonging with many of the people at 'Te Puna'.

In her narrative $\mathrm{K}$ shared knowledge about the fact that her ancestors are buried in the cemetery and carved in the marae, the name and characteristics of her mountain and what you can do there, what she likes to do in the park and how that feels and what she does in the dairy, how much things cost and why she likes it.

Bringing this knowledge back to the three dimensions of self-conception, culture and territory, K's representation can be depicted as follows:

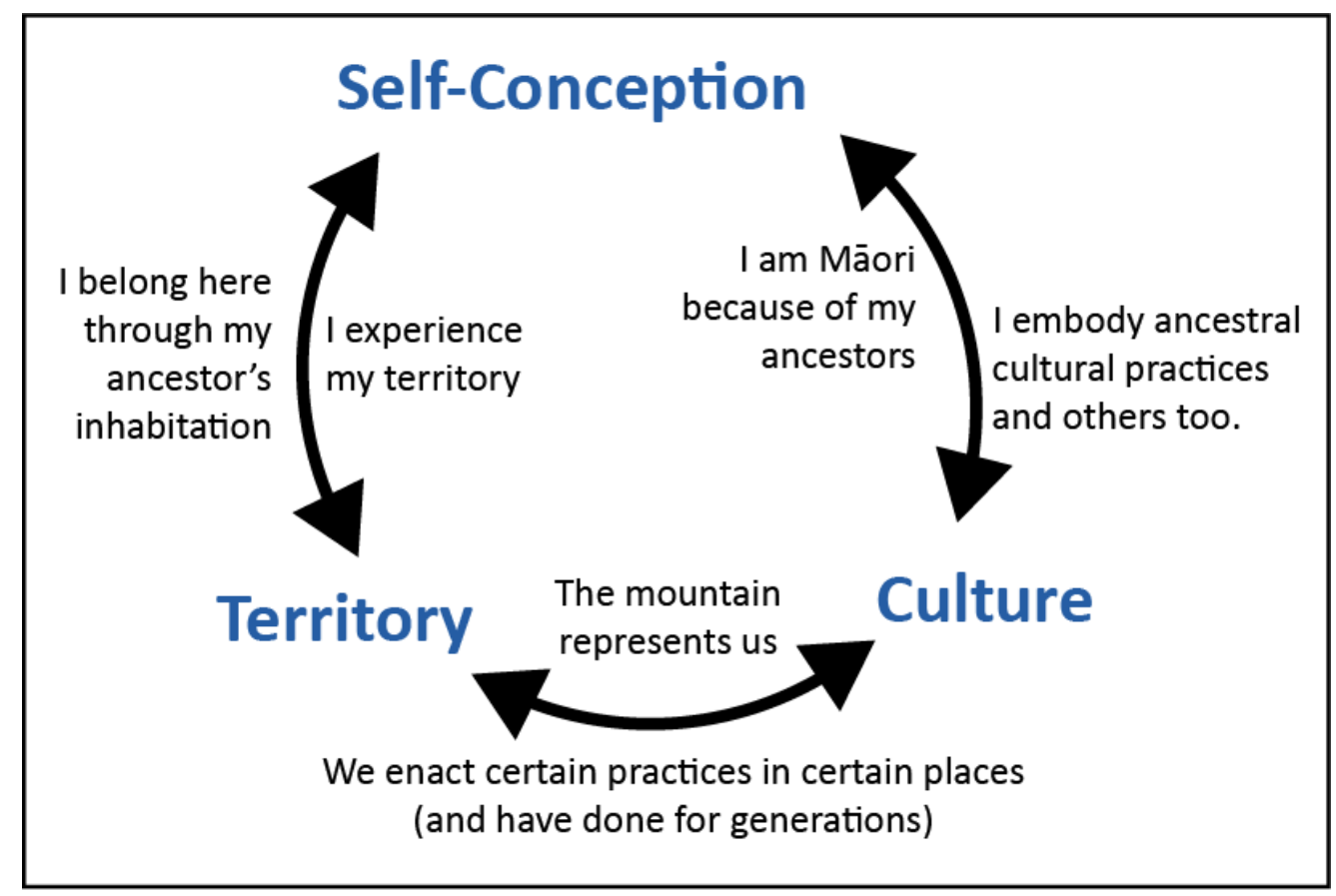

FIG 41- Main pattern of analysis applied to K's narrative 
In this diagram a supportive cycle can be observed where her self-conception was grounded in a sense of belonging to a culture and territory through the active experience of it, its history and the ancestral inhabitation.

\subsection{Inhabitation through personal and ancestral experience in other children's narratives}

The groundedness described above for K's narrative can also be perceived in the other children's narratives. In those narratives they communicated knowledges about their territory through the knowledges transmitted by their ancestors and/or their inhabitation of those spaces:

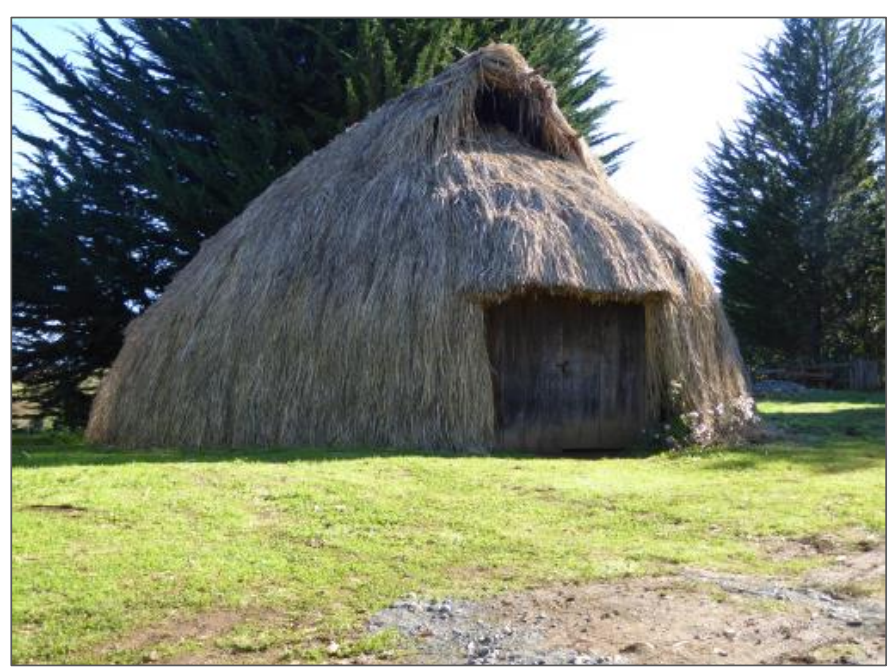

FIG 42- N's photo [NO01]

Today l'd like to show you the spaces where our ancestors lived.

[NO01] My translation. 


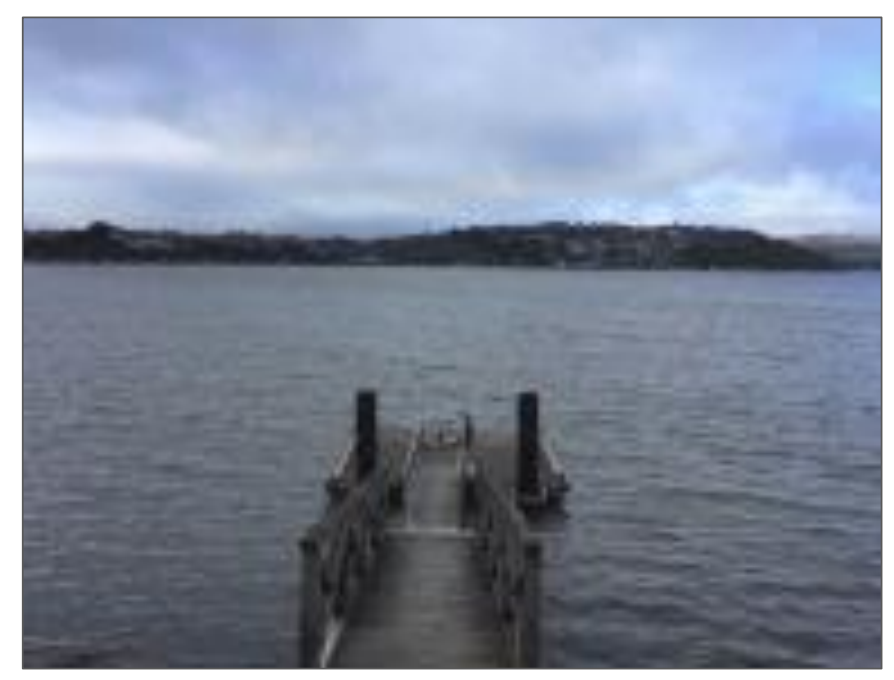

FIG 43- LO's photo [LOO1]

My koro used to always go fishing there, he caught some fish but not a lot. I don't really usually go to the harbour because there's nothing to do there.

The knowledge passed on from the ancestors was complemented by their direct experiences in the territory:

And here the sun also shines a lot, and the lake looks like a mirror. Here one really likes to go out on a boat...

[JU04] My translation.

We also like to play games on the field and climb the trees.

[LA07]

From these examples it can be gathered that the narrative about the self was grounded both on personal and ancestral experiences and stories in the territory. The children's self-narrative could also be perceived as being grounded in the ancestral cultural practices: 


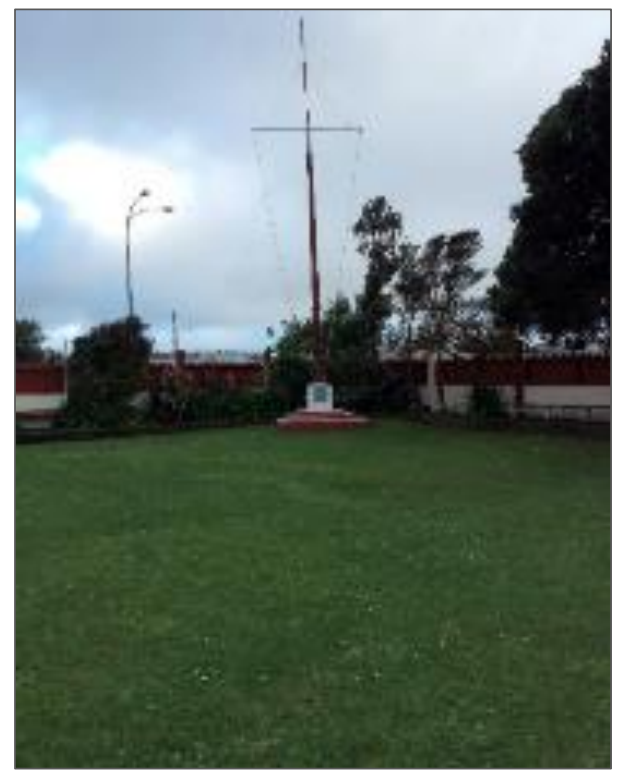

FIG 44- LA's photo [LA07]

And we also like to do the haka in there, the haka is a traditional war dance created by my great (x7) grandfather, Te Rauparaha.

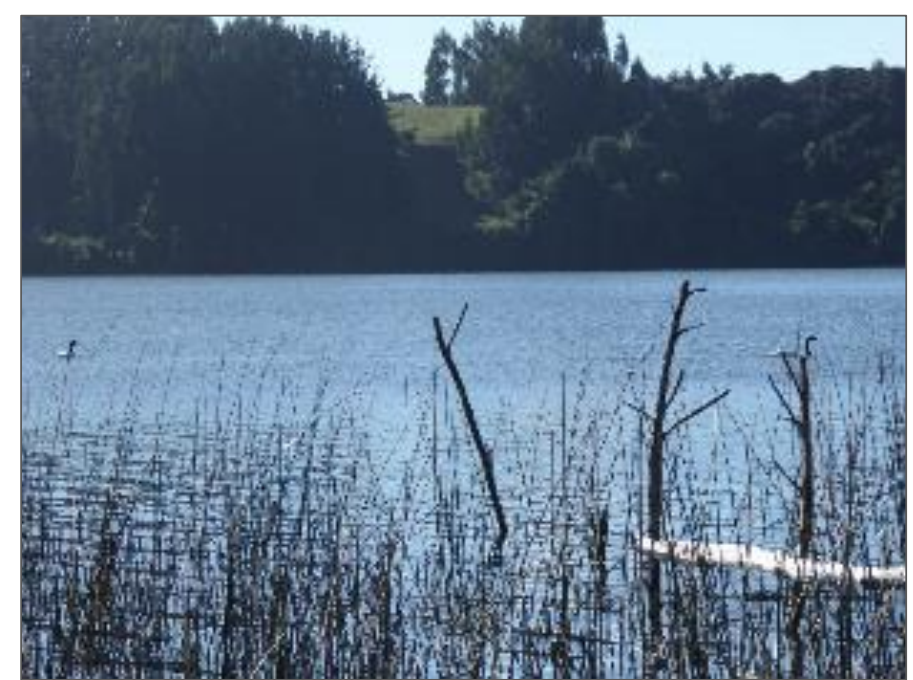

FIG 45- R's photo [RO05]

...we also do prayers to our genechen [guardians] and ask for things. But first of all, before asking, we always give them something, it can be all kinds of things, but it has to be Mapuche food. 
And in the knowledge transmitted about the history of certain places:

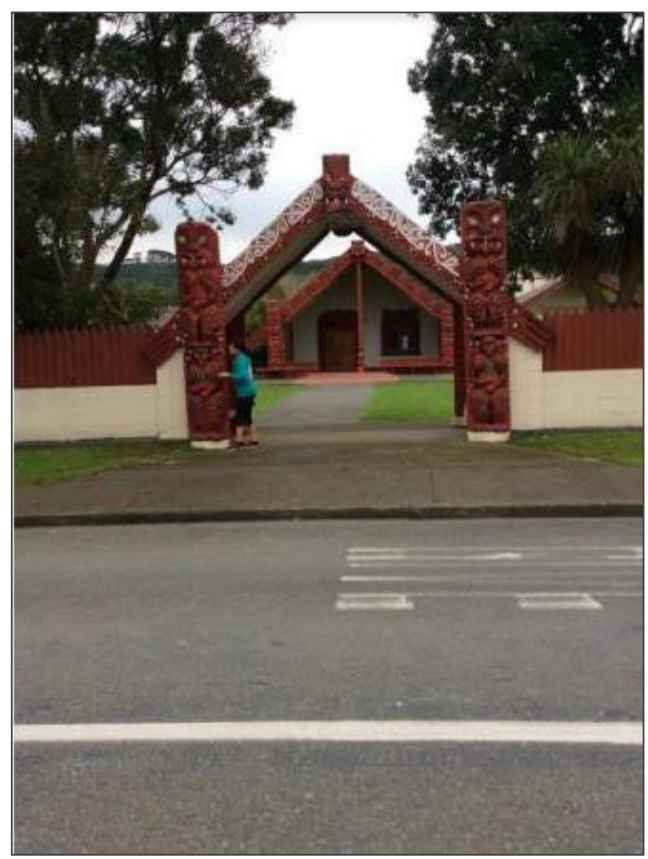

FIG 46- LO's photo [LO4]

...the one that you can see right now isn't the first marae. There's one beside it which is the actual first Marae.

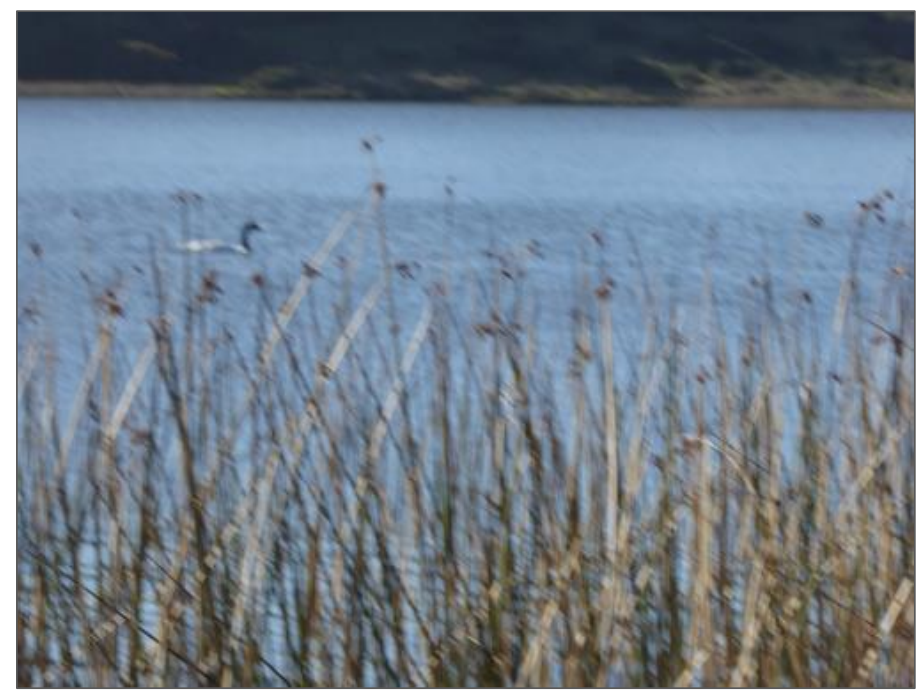

FIG 47- AL's photo [ALO3] 
The lake is an eye of the ocean, it is part of the ocean because the ocean created it with the 1960 earthquake, the biggest earthquake in the world.

[AL03] My translation.

Finally, the children's narrative was not only supported by ancestral and historical culture but was also related to dynamic cultural activity systems:

I always go to the shop to get a pie and a Coke, which is two dollars.

Our harbour goes way back to a time before I was even born. This harbour is one of my favourite places because I like to go there, because I like to ride in uncle's jet ski.

There were more references to these personal practices in the Mãori narratives than there were in the Mapuche ones, and in some of the Mapuche narratives there was a sense of cultural practices being in danger through knowledge being lost or having changed from the ancestor's generation to the current one:

...they made us think that our culture came from demons and people believed them. And now the culture is little by little being recovered.

[AK03] My translation.

'Lawen' is a medicine that attains the highest purity in the world and nature gives it to us which, thanks to some people who are still conscious to their culture, is kept alive.

[AL06] My translation.

Drawing from these examples it can be said that the self-narrative expressed by the children through their stories was strongly linked to the enactment and knowledge of their ancestral culture and in some cases to the direct experience of dynamic cultural activities.

The cultural activities mentioned in the narratives were also often mentioned in relation with particular places and territories: 


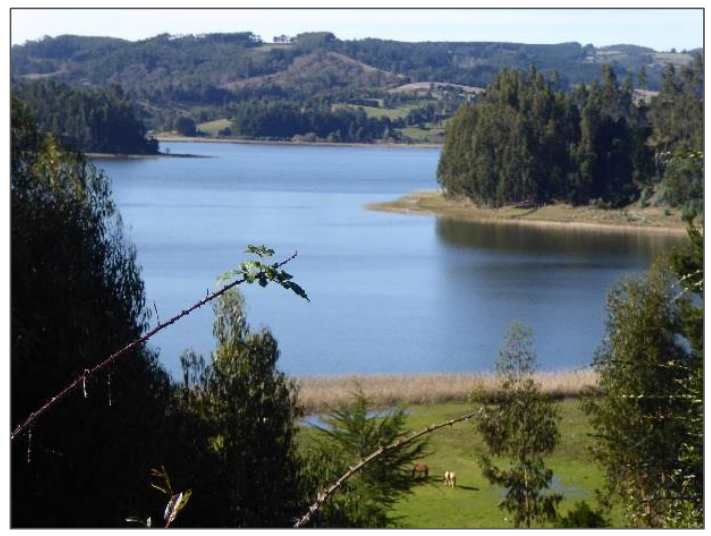

FIG 48- RO's photo [RO03]

And well, what we do in the sea is, not only go fishing, we also do prayers to our 'genechen' [guardians] and ask for things.

[RO05] My translation.

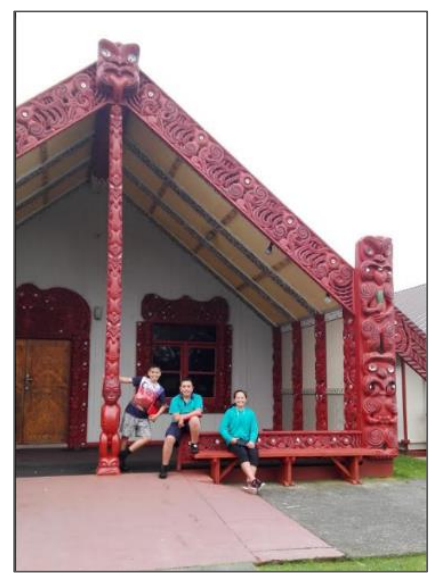

FIG 49- Photo taken by me at the marae

This place is a very important part of my culture, because this is where my ancestors were. There's carvings all along the walls and the fences and the doors.

Some narratives made a clear differentiation between the cultural experience of the territory in the time of the ancestors and the current one:

...we can already see the changes having moved from a ruka to a house. In these times there are plenty of modern things, for example: Good roads, schools, hospitals, means of transport and all kinds of communication means.

[NO03] My translation. 
And there was also a notion of the experience of the territory changing the cultural practices:

That tsunami wreaked misery and havoc, but thanks to a human sacrifice people could be saved. We don't do human sacrifices, but that time it was required.

[JU10] My translation.

The relationship between culture and territory viewed through the lens of personal and ancestral experience appeared to be grounded on historical accounts of what used to be done and on the active and embodied cultural usage of territorial spaces.

\subsection{Summary}

Following on from the strong links established in the previous chapter between selfconception, territory and culture, the analysis of K's story and others pointed to both the embodied and ancestral experiences as essential to these links. This was seen particularly through the knowledge of history of and about the territory and the enactment of cultural practices in particular places.

Once again the narratives represented these links as dynamic, where the enactment of ancestral cultural practices and knowledge of history went hand in hand with the current experiences of places. These experiences, in turn, were sometimes negotiated through cultural practices which were not available in that ancestral historical time (such as the dairy). The differences between a perceived ancestral and current time were only presented as problematic and menacing by some of the narratives, and simply described as factual by others. 


\section{Discussion and conclusions}

In the last two chapters I focused on particular narratives to show the multiple imbrications of self-conception, territory and culture within the children's narratives. In this chapter I will bring the relationships identified back to theory in order to answer my main research question: What are the relationships with and within the environment represented by Mapuche Lafkenche and Māori children when sharing their knowledge? I will draw from the CPoP framework described in the literature review to explore specifically how these relationships relate to aspects of ecological reinhabitation and cultural decolonisation. Finally I will offer alternative and broader paths of interpretation for the environmental knowledge shared by these children.

\subsection{Imbrications of Territory, Culture and Self-Conception}

In both of the narratives analysed in the preceding chapters and most of the other children's, there was a strong relationship between territory, culture and selfconception which was based on the knowledge and experience of their cultures belonging in, and with, their particular territories. This sense of interconnectedness can be understood by Valenzuela's (2014, p. 40, own translation) description of the Mapuche world view of territory "as a subject who is with him/her [the Mapuche] and forms a part of him/her at the same time". In the analysis of K's narrative, this inter-dependency was shown as being mostly based on personal and ancestral experiences and practices on and with the land.

What can thus be comprehended as a supportive cycle of relationships between these three themes is not, though, lacking conflict or dynamism. Most narratives identified changes which rippled on from one area to the next and could sometimes be perceived as menacing and requiring action. In the particular case of AL's narrative, where the changes in her territory conflicted with the survival of her culture, AL's self-conception included an active stance and response to this menace. 
As observed by Gruenewald (2003b, p. 267) "the relationships among place, identity and culture are varied and complex", which is why he advocates a critical focus on place in the educational space and develops the concept of CPoP. This theory, as previously mentioned in chapter 3 , understands a pedagogy which embraces the interconnections between classrooms, local community and environment in a critical way which allows for transformation. The two main concepts or actions that come together in this theory are ecological reinhabitation and cultural decolonisation.

\subsection{Ecological Reinhabitation and Cultural Decolonisation}

As previously explained (see chapter 3 ) ecological reinhabitation is the active inhabitation and care for a place which has been disrupted, while maintaining awareness of the ecological (human and non-human) relationships occurring with that place (Berg \& Dasmann, 2015; Gruenewald, 2003a). Cultural decolonisation, on the other hand, refers to the awareness and confrontation of dominant ideologies (Gruenewald, 2003a).

Such concepts and ideas were evident in A's narrative through her representation of the territory as a contested space which was changing with culture, but also changing culture itself. As such they can be aligned to ecological reinhabitation and cultural decolonisation in the following ways:

- There was a conscious recognition of the territory having been disrupted, in this case by Eucalyptus, but in other narratives by pollution. This acknowledgement sometimes included an understanding of the histories behind these changes and in all cases was rooted in the children's direct experience of the territory.

- There was also a conscious acknowledgement of the marginalisation of local knowledge, though only a couple of narratives related to a particular hegemonic discourse. A couple of narratives also advocated for transformative praxis geared to maintain the local knowledge and culture which was at risk. 
In K's narrative, on the other hand, there was no apparent conscious acknowledgement of disruption of environment or marginalisation of knowledge. Even though changes in territory and culture were indicated they were not presented as problematic but subsumed to the wider narrative of a supportive cycle between self-conception, territory and culture rooted in the personal and ancestral experience. Therefore it could be said that this narrative did not exemplify a CPoP as it didn't address relationships from a critical stance geared towards transformation. This interpretation would fit Freire's (1970) linear conception of Transformative Praxis which necessarily begins at a critical consciousness in order to move towards liberation through transformative action. This linear approach has been reformulated by Smith (2003, pp. 12-13) from a Māori perspective transforming it into a never-ending cycle that moves in all directions where individuals are positioned differently in relationship to conscientisation, resistance and transformative action (FIG. 50).

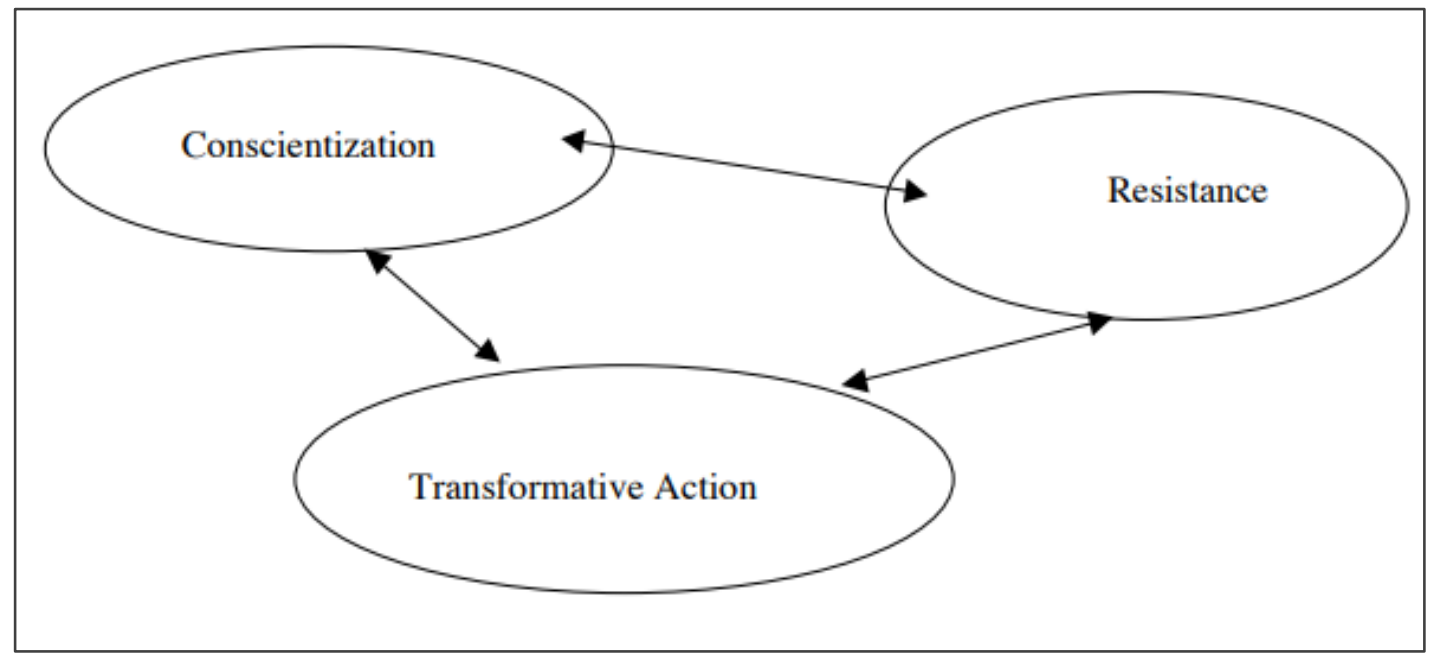

FIG 50-Smith's representation of 'transformative action' (GH Smith, 2003, p.13)

Smith concludes that "every Māori is in the struggle whether they like it or not, whether they know it or not" (p.13) and I would argue that this perspective better aligns to an analysis of K's narrative and provides further insights into the ways 
through which ecological reinhabitation and cultural decolonisation were reenacted in her story.

Working from Smith's perspective I noticed that within her narrative, changes in the environment and culture were mentioned though not recognised necessarily as disruptions. Nevertheless her and her ancestor's sustained inhabitation of place through cultural practices and embodied sensory experience are, in and of themselves, resistance and transformative action in the face of hegemonic discourses. This resistance can be exemplified by looking at K's relationship with the mountain; she called it her mountain and described its characteristics and what you can do there. This conception of the mountain relates to Māori place based notions where the maunga (mountain) represents a person's iwi (tribe), a connection which will only be understood by those who have insider knowledge of Maori tikanga (practices) and perhaps also New Zealand geography and its connections to different iwi (Penetito, 2009, p. 13). The fact that $\mathrm{K}$ drew on these notions when describing the relationships with and within her environment enacted a resistance to hegemonic discourses by addressing the spiritual and cultural history of the territory in a way which doesn't neatly align to the dominant conception of land as property and resource.

The previous analysis of K's narrative shows that there are both overt ways of enacting ecological reinhabitation and cultural decolonisation, as in A's narrative, but there are also covert ways through which these are expressed. Following this line of thought, the fact that all the narratives that were made for this project represented an interconnected and interdependent relationship between selfconception, territory and culture, can be perceived as a covert form of transformative praxis. These representations spoke about a different knowledges of the environment which don't align to binary conceptions such as nature/culture, conceptions or other representations of that which Escobar calls "the constitutive dualism of the dominant forms of modernity" (2012, p. 8). 


\subsection{Some answers}

I will now come back to my main research question and draw from the previous analysis in search for some answers.

Main question:

How do Mapuche Lafkenche and Maori Ngāti Toa children represent relationships with and within the environment in their digital stories?

From the narratives analysed it can be concluded that the children's representation

of relationships with and within the environment express a strong sense of interconnectedness between territory, culture and self-conception. The connections between these areas are multiple, the most prominent one noticed being the sense of belonging to a particular culture with an ancestral experience of interdependence and inhabitation of that particular territory. That sense of belonging was expressed through verbal cues such as possessive nouns, but also through descriptions of sensory and affective inhabitation of the territory.

The strong connections between territory, culture and self-conception seem to mostly constitute a supportive and grounding cycle, but are never expressed as stable. On the contrary, all narratives point to dynamic relationships between these elements which are subject to changes which may begin at any of the three areas and ripple onto others. These changes were presented from multiple perspectives. Some narratives expressed change as negative, menacing and requiring action, whereas others presented it as a neutral fact.

Secondary questions:

In what ways do the children's narratives enact cultural decolonisation and ecological reinhabitation?

The stories shared by the children enact cultural decolonisation and ecological reinhabitation in both overt and covert ways. Some of the narratives are overt by clearly and consciously naming an oppressor (human or non-human) and proposing ways to transform a reality which is marginalising knowledges, cultures and/or natural elements. Other narratives are covert but still showing both cultural 
decolonisation and ecological reinhabitation through their underlying sense of interconnectedness of territory, culture and self-conception. This strong connectivity represents a counter-hegemonic discourse to the dominant binary conception of culture and nature (amongst other binaries) and also advances particular ways and practices of being in the land.

\section{What are the implications of this process for the development of critical border thinking and the world's current environmental sustainability crisis?}

The concept of critical border thinking used by the MC (Anzaldúa, 1987; Escobar, 2007; Grosfoguel, 2009; Mignolo, 2012) starts from the acknowledgement that there is one dominant Western monological truth which "relates to other cultures and peoples from a position of superiority and does not acknowledge non-western cosmologies and epistemologies" (Grosfoguel, 2009, p. 25). From this starting point, it makes a call to respond to that oppressive dominant truth from the knowledges and epistemologies which sit at the border or fully outside, thus it advances an 'other' way of thinking (Escobar, 2007). This 'other' way, in turn, relates to the environmental sustainability crisis through the perception of it as a crisis of narratives and epistemologies (Mikulak, 2008), where the monological environmental truth has perpetuated a narrative of separation resulting in environmental degradation.

Following on from this perception of the environmental sustainability crisis, the present research has aimed to nurture a critical border thinking space for Mapuche and Māori children's environmental knowledges to come to the forefront and be a part of the conversation about human relationships with, and within the environment. The results of this research process can be seen in the eight Digital Stories and their analysis in the previous pages, but the process itself has implied much more than these visible outputs. It has been a process of generating and nurturing relationships, of questioning my own pre-conceptions of what knowledge -especially environmental indigenous knowledge- is, and of sharing these children's knowledges with each of the groups. 
One of the main lessons I learnt from this process is that the fostering of spaces for critical border thinking also implies fostering a research process which, in Denzin's words (2010) is rooted in "concepts of care" (p.306). This means carrying through an inquiry which prioritises the relationships built between and through the researcher, participants and territories who concur at the time and space of research. Bringing this issue to light might seem misaligned to a research question relating to the current environmental sustainability crisis and perhaps more aligned to ethics and methodology. Nevertheless- and in consideration of the knowledges shared by the children in their narratives- the relationships and interconnectedness between self, territory and culture are at the core of the 'other' ways of thinking which need to be brought from the margins to the center.

The environmental knowledges shared by the Mapuche and Māori children for this research presented a strong relationship between self, territory and culture, and this inter-conectedness, as previously analysed does not sit neatly with the compartmentalised views of Western scientific monological truth. Considering their environmental narratives as critical border thinking, my argument is that in order to continue fostering spaces for 'other' knowledges to challenge the monological truth which translates into environmental degradation, researchers and others involved in this endeavour must go beyond the "observational and privileged Western gaze" (Ginsburg, 1995, p. 74). They must embrace what Rose (1999) calls "noisy and unruly processes" (p. 177) which create an openness to change. Therefore, perhaps critical border thinking needs to go beyond thought and become an embodied and experiential practice in order to open up the environmental conversation to 'other' ways of thinking.

\subsection{Contributions to the field}

As discussed in Chapter 2, several authors identify a lack of research with indigenous children, especially from an epistemology aiming to decolonise the reproduction of hegemonic knowledges (Bartos, 2011; de Leeuw \& Greenwood, 2016; 
Holloway, 2014; Matthews \& Limb, 1999; Nairn \& Kraftl, 2016). The field of Environmental Studies is not an exception to this shortcoming, as often environmental research with children relates to utilitarian adult-centred needs tailored to improve Environmental Education of Education for Sustainability within schools (Matthews \& Limb, 1999; Sund \& Öhman, 2014; Tzou et al., 2010). The same applies to environmental research with indigenous children, which often tends to fall in reified and romanticised views of both 'childhood' and 'nature' (Bartos, 2011; Bartos, 2013; de Leeuw \& Greenwood, 2016).

The present research has aimed to address these gaps by nurturing a space for Mapuche and Maori children's environmental narratives to be shared and accessed as valuable knowledges stemming from their own cultures, territories and selfconceptions. By doing this it has aimed to address the issues of disembeddedness and marginalisation of knowledges brought about by processes of colonisation, especially in the environmental research field which works with children. Thus this research contributes to a growing field of scholars who aim to do research 'with' children in ways which allow the complexities of their relationships with, and within the environment to be expressed and explored.

Following on the steps of the aforementioned scholars, I used visual methodologies, specifically Digital Storytelling, as a means of expression and of sharing the children's environmental narratives. Environmental narratives have been identified as a compelling path to bring embedded and experiential knowledges to the surface (Robertson et al., 2000; Tzou et al., 2010). By using environmental narratives for this research from a decolonial epistemology which inherently values Mapuche and Māori children's knowledges, I contribute to the Environmental research field from a non-utilitarian perspective. This perspective holds marginalised knowledges as having equal stakes to truth as the dominant Western scientific knowledges and is a way of addressing the current environmental crisis by bringing 'other' narratives, ontologies and epistemologies into the academic environmental ecology of ideas.

These contributions also support the call to do research characterised by "connectedness, engagement and participatory consciousness" (Bishop, 1996, p. 
238), especially when working with indigenous children. The relevance of this approach may be a contribution to the field of Environmental Studies in terms of centring these relationships of care as a way of approaching research with, and within the environment. In this sense I believe much can be learnt from the narratives shared by the children during this project as they point to the interdependence of territory, culture and self-conception. This interdependence can also provide a guideline for researchers to approach their relationships with and within the environment with a 'soft' self-other differentiation (Hosking, 2011) stance.

I also hope my use of Digital Storytelling has contributed to the field of research with visual methods with children. As described by Bliss (2015), this method "enacts realities that are ever changing, made and remade, through its practice". During my research, the flexibility of Digital Storytelling was key to developing a responsive project which encouraged the children to share their embodied experiences of environment in ways that suited their availability and motivation. This research supports the evidence that Digital Storytelling is a beneficial method for the sharing of environmental narratives.

Finally, this research attempted to bring together Mapuche and Māori children through a knowledge exchange which, as pointed out earlier was only partially successful, as it ended up being quite a mediated exchange. There is currently very little in terms of academic research bringing together Mapuche and Māori and I haven't been able to find any research bringing together Mapuche and Māori and their relationships with, and within the environment. Nevertheless, there is a growing interest from several Mapuche and Māori commmunities to establish bonds of learning and collaboration and there have already been a couple of visits and exchanges such as the one I participated in during 2016. Even though the proposed goal to generate a knowledge exchange was not successful, I hope this research is also a contribution in the path of establishing networks of support and exchange between Mapuche and Māori communities. 


\subsection{Further research}

Within this research I focused my analysis on the children's environmental narratives and the ways in which they enacted cultural decolonisation and ecological reinhabitation. I specifically looked at the relationships they represented between culture, territories and self-conception and exemplified them through two particular narratives.

As mentioned when introducing the Analysis (chapter 4), the children's environmental narratives were rich in the manifold ways in which they represented relationships with, and within the environment. There are three other areas of focus which I think could have been beneficial in order to bring those relationships to the forefront.

The first one is history and perception of time. Different knowledges and ways of recounting history associated with particular places within their territories (e.g: The earthquake and how it shaped the lake in Llaguepulli or the creating of the haka by Te Rauparaha in Takapuwahia). The children's histories are not necessarily aligned to dominant or 'official' recounts of history, and the ways in which they represent the passage of time is not linear. L.T. Smith (1999) states that "to hold alternative histories is to hold alternative knowledges" (p.34). Following from this, focusing on children's histories could also be a meaningful pathway towards the decolonisation of marginalised knowledges.

The second one is sustenance and precarity. The children's narratives referred to sustenance and precarity in many ways (e.g.: When talking about the price of things in the dairy or when talking about fishing and agriculture). Further research in this area could explore the relationships between children's embodied experiences of 'taking' and 'receiving' from their environments.

And the third one is spirituality, a topic pervading all others which, in a sense, makes it harder to focus on. Some children's narratives speak quite clearly about spirits and spiritual practices. Others represent spiritual relationships with the environment through the telling of cultural practices, rituals, or by describing 
certain places and the way they felt in them (e.g.: The cemetery in Takapuwahia). Further research in this area could be a path towards further expressions of 'interconectedness' and, in particular for the Environmental studies field, for a deeper understanding of the different layers of knowledges embedded within particular environments.

The previous are some examples of areas of focus which could have been brought to the forefront through analysis. In terms of methodology and ways of doing research, it is for me clear that this project could have been more beneficial to the participants working from a participatory and co-created framework. Throughout this project there were many spaces for the children to lead the way in terms of what they wanted to share and how they wanted to do that, but this was always framed within the pre-made project that I had created. The eight participant children were mostly motivated and engaged when creating their digital stories. Nevertheless, I could clearly perceive that they would have felt comfortable leading the project into other spaces- perhaps other means of expression and different narratives- if we had more time to establish deeper connections between us. I also perceived this when communicating with their teachers and wider communities. I believe decolonising research aiming to bring marginalised knowledges to the centre should start from those margins, from the communities who are sharing their knowledges.

Finally, along the lines of what is proposed by Malone (2016) as a way of "decentring the human and attending to the complexity of child-nature relationships" (p.185), I believe there is much potential for exploring the role played by the non-human in children's relationships with, and within the environment. Research of this kind could potentially be more aligned to Mapuche and Māori ontologies in their notions of kinship to the non-human through lineage, and to children's sensory and affective experience within the environment. 


\section{Reference List}

Allen, R. L. (2004). Whiteness and critical pedagogy. Educational philosophy and theory, 36(2), 121-136.

Anzaldúa, G. (1987). Borderlands: la frontera (Vol. 3): Aunt Lute San Francisco.

Aylwin, J. (2006). Mapuche Lead the Fight for Recognition of Indigenous Rights in Chile. Retrieved from https://www.worldpoliticsreview.com/trendlines/19841/mapuche-lead-the-fight-for-recognition-of-indigenous-rights-in-chile

Barnhardt, R., \& Kawagley, A. O. (2005). Indigenous knowledge systems and Alaska Native ways of knowing. Anthropology \& education quarterly, 36(1), 8-23.

Bartos, A. E. (2011). Remembering, Sensing and Caring for their Worlds: Children's Environmental Politics in a Rural New Zealand Town. University of Washington.

Bartos, A. E. (2013). Children sensing place. Emotion, Space and Society, 9, 89-98. doi:10.1016/j.emospa.2013.02.008

Bateson, M. C. (2015). Composing a Life. On Being. Retrieved from https://onbeing.org/programs/mary-catherine-bateson-composing-a-life/

Belich, J. (2013). The New Zealand wars and the Victorian interpretation of racial conflict: Auckland University Press.

Bengoa, J. (2000). Historia del pueblo mapuche:(siglo XIX y XX) (Vol. 7): Lom Ediciones.

Berg, P., \& Dasmann, R. F. (2015). Reinhabiting California. In E. Q. Cheryll Glotfelty (Ed.), The Biosphere and the Bioregion: Essential Writings of Peter Berg (pp. 35-38). New York: Routledge.

Berkes, F. (2010). Shifting perspectives on resource management: resilience and the reconceptualization of 'natural resources' and 'management'. Mast, 9(1), 13-40.

Bishop, R. (1996). Addressing issues of self-determination and legitimation in Kaupapa Maori research. Research perspectives in Maori education, 143-160.

Bishop, R. (2005). Freeing Ourselves from Neo-colonial Domination in Research: A Kaupapa Mäori Approach to Creating Knowledge. In N. K. Denzin \& Y. S. Lincoln (Eds.), The Sage handbook of qualitative research (pp. 109-138). California: SAGE Publications, Inc.

Bishop, R., Berryman, M., Cavanagh, T., \& Teddy, L. (2009). Te kotahitanga: Addressing educational disparities facing Māori students in New Zealand. Teaching and Teacher Education, 25(5), 734-742.

Blaschke, P. M., Trustrum, N. A., \& DeRose, R. C. (1992). Ecosystem processes and sustainable land use in New Zealand steeplands. Agriculture, ecosystems \& environment, 41(2), 153-178.

Bliss, E. (2015). Performative Methodologies: Geographies of Emotion and Affect in Digital Storytelling Workshops. University of Waikato.

Bliss, E., \& Fisher, J. (2014). The journey to a good life: Exploring personal and organisational transformation through digital storytelling Ethnographic worldviews (pp. 93-107): Springer.

Bowers, C. A. (2001). Educating for eco-justice and community: University of Georgia Press.

Chakraborty, K. (2009). 'The good Muslim girl': conducting qualitative participatory research to understand the lives of young Muslim women in the bustees of Kolkata. Children's Geographies, 7(4), 421-434. doi:10.1080/14733280903234485

Chawla, L. (1988). Children's concern for the natural environment. Children's Environments Quarterly, 13-20.

Chihuailaf, E. (1999). Recado confidencial a los chilenos. Santiago, Chile: Lom Ediciones. 
Collette, J., \& O'Malley, P. (1974). Urban migration and selective acculturation: The case of the Maori. Human Organization, 33(2), 147-154.

Correa, M., \& Mella, E. (2010). Las razones del illkun/enojo. Memoria, despojo y criminalización el en territorio mapuche, Observatorio Derechos de los Pueblos Indígenas, Santiago de Chile, Editorial LOM.

Creswell, J. W. (2013). Research design: Qualitative, quantitative, and mixed methods approaches: Sage publications.

Cruz, A. C. (2017). Alfabetos para escribir y para luchar. Consideraciones sociopolíticas en torno a la falta de estandarización de la escritura en mapudungun. CUHSO CulturaHombre-Sociedad, 27(2), 215-228.

de Leeuw, S., \& Greenwood, M. (2016). Geographies of Indigenous Children and Youth: A Critical Review Grounded in Spaces of the Colonial Nation State. 47-65. doi:10.1007/978-981-287-044-5_22

Deetz, S. (2010). Politically attentive relational constructionism (PARC). Distinctive qualities in communication research, 32-52.

Deleuze, G. (1987). A thousand plateaus capitalism and schizophrenia In F. I. Guattari (Ed.). Minneapolis: University of Minnesota Press.

Denzin, N. K. (2010). Grounded and indigenous theories and the politics of pragmatism. Sociological Inquiry, 80(2), 296-312.

Denzin, N. K., \& Lincoln, Y. S. (2008). Strategies of qualitative inquiry (Vol. 2): Sage.

Escobar, A. (2007). Worlds and Knowledges Otherwise. Cultural Studies, 21(2), 179-210. doi:10.1080/09502380601162506

Escobar, A. (2012). Cultura y diferencia: la ontología política del campo de Cultura y Desarrollo. Wale'keru. Revista de investigación en cultura y desarrollo, 2, 7'16.

Escobar, A., Álvarez, S., \& Dagnino, E. (2001). Introducción. Lo cultural y lo político en los movimientos sociales latinoamericanos. Política cultural y cultura política. Una nueva mirada sobre los movimientos sociales latinoamericanos, 17-48.

Fajardo Garrido, V. T. (2013). El desarrollo del Turismo Mapuche y sus influencias en la construcción de la Identidad Mapuche Lafkenche en la comunidad Llaguepulli del Lago Budi, La Araucanía. Universidad Católica de Temuco, Temuco, Chile.

Fetzel, T., Gradwohl, M., \& Erb, K.-H. (2014). Conversion, intensification, and abandonment: A human appropriation of net primary production approach to analyze historic land-use dynamics in New Zealand 1860-2005. Ecological economics, 97, 201-208.

Flores Chávez, J., \& Azócar Avendaño, A. (2006). Fotografía de capuchinos y anglicanos a principios del siglo XX: la escuela como instrumento de cristianización y chilenización. Memoria americana(14), 75-87.

Foucault, M. (1991). Discipline and punishment: The birht of a prison. London: Penguin. Freeman, M., \& Mathison, S. (2009). Researching children's experiences: Guilford Press. Freire, P. (1970). Pedagogy of the Oppressed, trans. Myra Bergman Ramos. New York: Continuum, 65-80.

Gallegos, C. (2007). Paradigms on Indigenous Language Revitalisation: the Case of Te Reo Maori in Aotearoa New Zealand and Mapudungun in Chile. In W. Murray (Ed.): Victoria University of Wellington.

Gergen, K. J. (2009). Realities and relationships: Soundings in social construction: Harvard university press.

Gibbs, M. (2001). Toward a strategy for undertaking cross-cultural collaborative research. Society \& Natural Resources, 14(8), 673-687.

Ginsburg, F. (1995). The Parallax Effect: The Impact of Aboriginal Media on Ethnographic Film. Visual Anthropology Review, 11(2), 64-76. doi:10.1525/var.1995.11.2.64

Godoy, I. S. (2009). Territorialización en ámbitos rurales Lafkenche de una educación emancipadora plurinacional. Boletín de Geografía(30), 11-20. 
Grosfoguel, R. (2007). The epistemic decolonial turn: Beyond political-economy paradigms 1. Cultural Studies, 21(2-3), 211-223. doi:10.1080/09502380601162514

Grosfoguel, R. (2009). A decolonial approach to political-economy: Transmodernity, border thinking and global coloniality. Kult, 6, 10-38.

Gruenewald, D. A. (2003a). The best of both worlds: A critical pedagogy of place. Educational Researcher, 32(4), 3-12.

Gruenewald, D. A. (2003b). Foundations of Place: A Multidisciplinary Framework for PlaceConscious Education. American Educational Research Journal, 40(3), 619-654. doi:10.3102/00028312040003619

Gruenewald, D. A. (2008). The best of both worlds: A critical pedagogy of place. Environmental Education Research, 14(3), 308-324.

Haraway, D. (2013). Simians, cyborgs, and women: The reinvention of nature: Routledge.

Hill, M. (1997). Participatory research with children. Child \& family social work, 2(3), 171183.

Holloway, S. L. (2014). Changing children's geographies. Children's Geographies, 12(4), 377392. doi:10.1080/14733285.2014.930414

Holloway, S. L., \& Valentine, G. (2000). Spatiality and the New Social Studies of Childhood. Sociology, 34(4), 763-783.

Hosking, D. M. (2011). Telling Tales of Relations: Appreciating Relational Constructionism. Organization Studies, 32(1), 47-65. doi:10.1177/0170840610394296

Hull, G. A., \& Katz, M.-L. (2006). Crafting an Agentive Self: Case Studies of Digital Storytelling. Research in the Teaching of English, 41(1), 43-81.

Hull, G. A., \& Nelson, M. E. (2005). Locating the Semiotic Power of Multimodality. Written Communication, 22(2), 224-261. doi:10.1177/0741088304274170

Hussein, M. E., Hirst, S., Salyers, V., \& Osuji, J. (2014). Using grounded theory as a method of inquiry: Advantages and disadvantages. The Qualitative Report, 19(27), 1-15.

INE, C.-. (2002). Hojas Informativas Estadísticas Sociales Pueblos Indígenas en Chile-Censo 2002 Santiago, Chile: Gobierno de Chile Retrieved from

http://historico.ine.cl/canales/chile estadistico/estadisticas sociales culturales/et nias/pdf/info etniascenso2002.pdf.

Johnson, J. T., Louis, R. P., \& Kliskey, A. (2014). Weaving indigenous and sustainability sciences: diversifying our methods. National Science Foundation, Arlington, 1-116.

Ka'ai-Mahuta, R. (2011). The impact of colonisation on te reo Māori: A critical review of the State education system. Te Kaharoa, 4(1). doi:10.24135/tekaharoa.v4i1.117

Kahn, P. H., \& Keller, S. R. (2002). Children and nature: Psychological, sociocultural, and evolutionary investigations: MIT press.

Kincheloe, J., \& Steinberg, S. (2008). Indigenous Knowledges in Education: Complexities, Dangers, and Profound Benefits. In N. K. D. Y. S. L. L. T. Smith (Ed.), Handbook of Critical and Indigenous Methodologies: SAGE Publications, Inc.

King, M. (2003). Penguin History of New Zealand: Penguin UK.

Kingi, T. (2008). Maori landownership and land management in New Zealand. Making land work, 2, 129-151.

Kullman, K. (2012). Experiments with moving children and digital cameras. Children's Geographies, 10(1), 1-16.

Ladson-Billings, G. (1997). I know why this doesn't feel empowering: A critical race analysis of critical pedagogy. Mentoring the mentor: A critical dialogue with Paulo Freire, $60,127-141$.

Lee, J., \& Abbott, R. (2009). Physical activity and rural young people's sense of place. doi:10.1080/14733280902798894

Leff, E. (2003). La ecología política en América Latina: un campo en construcción. Sociedade e Estado, 18(1-2), 17-40. 
Leiva Sepúlveda, J., \& Miranda Sandoval, M. (2015). Libros didácticos para el Ámbito del Saber IXOFIJ MOGEN, en la Escuela KOM PU LOF ÑI KIMELTUWE (Lugar de enseñanza de todas las comunidades), Lago Budi, IX Región. Boletín de Geografía(35), 43-59.

Leonardo, Z. (2002). The souls of white folk: Critical pedagogy, whiteness studies, and globalization discourse. Race ethnicity and education, 5(1), 29-50.

Lewis, A., \& Lindsay, G. (1999). Researching children's perspectives: McGraw-Hill Education (UK).

Louv, R. (2005). Last child in the woods: Saving our kids from nature deficit disorder. North Carolina: Algonquin Books.

Macfarlane, A. (2015). Restlessness, resoluteness and reason: Looking back at 50 years of Māori education. New Zealand Journal of Educational Studies, 50(2), 177-193.

Macfarlane, A., Webber, M., McRae, H., \& Cookson-Cox, C. (2014). Ka Awatea: An iwi case study of Māori students' success: Te Rū Rangahau, University of Canterbury.

Mackinlay, E., \& Barney, K. (2014). Unknown and unknowing possibilities: Transformative learning, social justice, and decolonising pedagogy in Indigenous Australian studies. Journal of Transformative Education, 12(1), 54-73.

Maldonado-Torres, N. G. E. (2011). Thinking through the Decolonial Turn: Post-continental Interventions in Theory, Philosophy, and Critique-An Introduction.

Transmodernity: Journal of Peripheral Cultural Production of the Luso-Hispanic World, 1(2).

Malone, K. (2016). Posthumanist Approaches to Theorizing Children's Human-Nature Relations. In K. N. K. Tracey Skelton (Ed.), Space, Place, and Environment (pp. 185206). Singapore: Springer.

Marimán, P., Caniuqueo, S., Millalén, J., \& Levil, R. (2006). i Escucha, winka! Cuatro ensayos de Historia Nacional Mapuche y un epílogo sobre el futuro. Santiago de Chile: Ediciones LOM.

Mason, J. (2002). Qualitative researching (2nd ed.. ed.). London: SAGE.

Matthews, H., \& Limb, M. (1999). Defining an agenda for the geography of children: review and prospect. Progress in Human Geography, 23(1), 61-90. doi:10.1191/030913299670961492

Maurial, M. (1999). Indigenous knowledge and schooling: A continuum between conflict and dialogue: Routledge New York, NY.

McRae, H. S. (2014). Ngāti Whakaue Iho Ake - An Iwi Science Education Exploration. In W. Penetito \& D. Anderson (Eds.): Victoria University of Wellington.

Meadows, D. (2003). Digital storytelling: Research-based practice in new media. Visual Communication, 2(2), 189-193.

Mignolo, W. (2012). Local histories/global designs: Coloniality, subaltern knowledges, and border thinking: Princeton University Press.

Mikulak, M. (2008). The Rhizomatics of Domination: From Darwin to Biotechnology. In B. Herzongerath (Ed.), An (Un)Likely Alliance: Thinking Environment(s) with Deleuze/Guattari: Cambridge Scholars Publishing.

Ministerio de Educación. (2012). Bases Curriculares Educación Básica. Gobierno de Chile Retrieved from http://www.curriculumenlineamineduc.cl/605/articles22394 programa.pdf.

Ministry for Culture and Heritage. (May, 2017). Maori land loss, 1860-2000. Retrieved from https://nzhistory.govt.nz/media/interactive/maori-land-1860-2000

Ministry of Education. (2007a). The New Zealand Curriculum. Learning Media Limited.

Ministry of Education. (2007b). Translation of Te Marautanga o Aotearoa: He tauira hei korerorero. 
Ministry of Education. (2017). School Rolls. Ministry of Education (New Zealand) Retrieved from https://www.educationcounts.govt.nz/statistics/schooling/studentnumbers $/ 6028$.

Morra, S. (2014, 3/14/2014). 8 Steps To Great Digital Storytelling. Retrieved from https://samanthamorra.com/2013/06/05/edudemic-article-on-digital-storytelling/

Morrow, V. (1999). Reflections on research with children. Time to listen to children: Personal and professional communication, 203.

Morrow, V., \& Richards, M. (1996). The ethics of social research with children: an overview. Children \& society, 10(2), 90-105.

Moses, J., \& Knutsen, T. (2012). Ways of knowing: Competing methodologies in social and political research: Palgrave Macmillan.

Murakami, K. (2008). Re-imagining the future: Young people's construction of identities through digital storytelling. Beyond current horizons, 1-14.

Myers, M. D. (2013). Qualitative research in business and management: Sage.

Nairn, K., \& Kraftl, P. (2016). Introduction to Children and Young People, Space, Place, and Environment. 1-24. doi:10.1007/978-981-287-044-5_33

New Zealand Government. (2012). Deed of Settlement between the Crown and Ngati Toa Rangatira. Retrieved from https://www.govt.nz/treaty-settlementdocuments/ngati-toa-rangatira/ngati-toa-rangatira-deed-of-settlement-summary7-dec-2012/.

Palacios, J. (2012). Traditional storytelling in the digital era. Fourth World Journal, 11(2), 41.

Pearce, W. B. (1995). A sailing guide for social constructionists. Social approaches to communication, 88-113.

Peña-Cortés, F., Escalona-Ulloa, M., Rebolledo, G., Pincheira-Ulbrich, J., \& Torres-Álvarez, O. (2009). Efecto del cambio en el uso del suelo en la economía local: una perspectiva histórica en el borde costero de La Araucanía, Sur de Chile. Efecto de los cambios globales sobre la salud humana y la seguridad alimentaria, 184-197.

Penetito, W. (2009). Place-based education: Catering for curriculum, culture and community. New Zealand Annual Review of Education, 18(2008), 5-29.

Pink, S. (2013). Doing visual ethnography: Sage.

Pinto Contreras, R. (2013). Construyendo currículum emergente en Llaguepulli. REXE. Revista de Estudios y Experiencias en Educación, 12(24).

Puga, I. (2011). Escuela y estratificación social en Chile:¿ cuál es el rol de la municipalización y la educación particular subvencionada en la reproducción de la desigualdad social? Estudios pedagógicos (Valdivia), 37(2), 213-232.

Punch, S. (2002). Research with children: The same or different from research with adults? Childhood, 9(3), 321-341.

Quilaqueo, D., Quintriqueo, S., Torres, H., \& Muñoz, G. (2014). Saberes Educativos Mapuche: Aportes epistémicos para un enfoque de educación intercultural. Chungara, Revista de Antropología Chilena, 46(2), 271-283. doi:http://dx.doi.org/10.4067/S0717-73562014000200008

Quintriqueo, S., \& Torres, H. (2013). Construcción de Conocimiento Mapuche y su relación con el Conocimiento Escolar. Estudios pedagógicos (Valdivia), 39(1), 199-216.

Deed of Settlement of Historical Claims, (2012).

Richards, P. (2010). Of Indians and terrorists: how the state and local elites construct the Mapuche in neoliberal multicultural Chile. Journal of Latin American Studies, 42(1), 59-90.

Robertson, M., Nichols, P., Horwitz, P., Bradby, K., \& MacKintosh, D. (2000). Environmental Narratives and the Need for Multiple Perspectives to Restore Degraded Landscapes in Australia. Ecosystem Health, 6(2), 119-133. doi:10.1046/j.1526-

0992.2000.00013.x 
Rodríguez, A., \& Winchester, L. (2001). Santiago de Chile: Metropolización, globalización, desigualdad. EURE (Santiago), 27(80), 121-139.

Rojas-Maturana, M., \& Peña-Cortés, F. (2015). Saberes ambientales lafkenche en escuelas de la costa de La Araucanía (Chile)\}. Revista Latinoamericana de Ciencias Sociales, Niñez y Juventud, 13(2).

Rosas, M. (2013). Llaguepulli y la Resistencia Mapuche Dentro Del Espacio Del Indio Permitido. Columbia University, Independent Study Project (ISP) Collection. (Paper 1621).

Rose, D. B. (1999). Indigenous ecologies and an ethic of connection. In N. Low (Ed.), Global ethics and environment. London: Routledge.

Rose, G. (1997). Situating knowledges: positionality, reflexivities and other tactics. Progress in Human Geography, 21(3), 305-320. doi:10.1191/030913297673302122

Rose, G. (2001). Visual methodologies : an introduction to the interpretation of visual materials London: Sage.

Ryan, K. W. (2011). The new wave of childhood studies: Breaking the grip of bio-social dualism? Childhood, 19(4), 439-452. doi:10.1177/0907568211427612

Sabatini, F., \& Wormald, G. (2004). Santiago de Chile bajo la nueva economía, 1980-2000: crecimiento, modernización y oportunidades de integración social. The Center for Migration and Development, Working Paper Series, Princeton University, CMD Working Paper.

Smith, G. A. (2002). Place-based education: Learning to be where we are. Phi delta kappan, 83(8), 584-594.

Smith, G. A. (2010). Critiquing place-based education. Retrieved from http://clearingmagazine.org/archives/2108

Smith, G. H. (1992). Research issues related to Maori education. The issue of research and Maori, 1-9.

Smith, G. H. (2000). Maori education: Revolution and transformative action. Canadian Journal of Native Education, 24(1), 57.

Smith, G. H. (2003). Kaupapa Maori Theory: Theorizing indigenous transformations of education and schooling. Paper presented at the 'Kaupapa Maori Symposium', NZARE / AARE Joint Conference, Auckland, New Zealand.

Smith, L. T. (1999). Decolonizing methodologies: Research and indigenous peoples: Zed Books Ltd.

Smith, L. T. (2007). On tricky ground. The landscape of qualitative research, 1, 85-113.

Sobel, D. (1996). Beyond ecophobiañ Reclaiming the heart in nature education: Orion Society.

Stanley, B., \& Sieber, J. E. (1992). Social research on children and adolescents (Vol. 133): Sage.

Sund, L., \& Öhman, J. (2014). On the need to repoliticise environmental and sustainability education: Rethinking the postpolitical consensus. Environmental Education Research, 20(5), 639-659.

Temm, P. B. (1990). The Waitangi Tribunal: the conscience of the nation: Random Century.

Timutimu, N., Simon, J., \& Matthews, K. M. (1998). Historical research as a bicultural project: seeking new perspectives on the New Zealand Native Schools system. History of Education, 27(2), 109-124.

Tuck, E., \& Yang, K. W. (2012). Decolonization is not a metaphor. Decolonization: Indigeneity, education \& society, 1(1).

Tzou, C., Scalone, G., \& Bell, P. (2010). The Role of Environmental Narratives and Social Positioning in How Place Gets Constructed for and by Youth. Equity \& Excellence in Education, 43(1), 105-119. doi:10.1080/10665680903489338 
Valenzuela, M. F. (2014). Educación mapuce con mirada geográfica y territorial. Boletín de Geografía(34), 37-44.

van der Haar, D., \& Hosking, D. M. (2004). Evaluating Appreciative Inquiry: A Relational Constructionist Perspective. Human Relations, 57(8), 1017-1036. doi:10.1177/0018726704045839

Victoria University of Wellington, V. (2017). Imagining Decolonised Cities- The Brief. Retrieved from http://www.idcities.co.nz/resources/The\%20Brief.pdf

Walker, R. (1990). Ka whawhai tonu matou: Penguin Books.

Walsh, C. (2012). "Other" knowledges, "Other" critiques: Reflections on the politics and practices of philosophy and decoloniality in the "Other" America. Transmodernity: Journal of Peripheral Cultural Production of the Luso-Hispanic World, 1(3).

Walsh, C. (2014). Pedagogical Notes from the Decolonial Cracks Decolonial Gesture, 11(1). Retrieved from http://hemisphericinstitute.org website: http://hemisphericinstitute.org/hemi/fr/emisferica-111-d

Wang, C., \& Burris, M. A. (1997). Photovoice: Concept, Methodology, and Use for Participatory Needs Assessment. Health Education \& Behavior, 24(3), 369-387. doi:10.1177/109019819702400309

Webb, A., \& Radcliffe, S. (2013). Mapuche Demands during Educational Reform, the Penguin Revolution and the Chilean Winter of Discontent. Studies in Ethnicity and Nationalism, 13(3), 319-341.

Williamson, G., Pérez, I., Modesto, F., Coilla, G., \& Raín, N. (2012). Infancia y adolescencia mapuche en relatos de la Araucanía. Contextos educativos: Revista de educación(15), 135-152.

Wittgenstein, L. (1953). Philosophical investigation. Basil Blakwell: Oxford.

Wood, B. (2011). Citizenship in our place : exploring New Zealand young people's everyday, place-based perspectives on participation in society. Thesis (Ph.D.)--Victoria University of Wellington, 2011. 
Appendices

\section{Appendix 1: Information and consent sheets in English}

For parents/guardians and students:

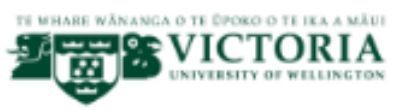

\section{Environmental narratives in the encounter of Maori and Mapuche primary school children}

Dear Parent/Guardian,

My name is Katia Guiloff, I'm a Master's student in Environmental Studies at Victoria University of Wellington. I'm undertaking a research project leading to a thesis. Your child's has been invited to be involved; I would be grateful if you would agree for your child to participate in this project.

\section{What is this research about?}

The main goal of the project is to create a space for dialogue and reflection between a group of Mapuche Lafkenche children and a group of Māori children from Porirua. It aims to:

- Generate a stronger connection to the environment from their cultural identity.

- Generate support networks and empathy between two groups that share some similarities in terms of history and perspectives.

- Give space for the children's voices and thoughts on environmental issues to be heard.

\section{What would it involve for your child?}

I will facilitate two workshops in which the children will learn about the other group of children (culture, history, geography), learn how to make a Digital Story videos and reflect on their own role as Kaitiaki in the well-being of their environment.

\section{Where will the videos go? How can I find out about the findings?}

The videos will be shared with you and your children, the other group of children, their teacher, their parents/guardians, me and my supervisors (Drs. Sara Kindon and Hiria McRae). I will protect them with a password and we will upload them to a private site in order to share them with the other group.

I might use stills from the videos in order to illustrate points of my writing in the thesis, scholarly articles and/or conference presentations. These stills will not show any faces or contexts which allow people to identify your children. All writing will be kept confidential and your child and their class will not be identified.

The thesis will be submitted for marking to the University and deposited in the University Library. You are most welcome to a summary of the findings and a copy of any publication stemming from this research. 


\section{What else do Ineed to know?}

This research has been approved by Victoria University of Wellington Human Ethics Committee, approval number 0000024326 . If you have any ethical concerns about this research you should contact Prof. Susan Corbett, Convener of the Committee (telephone: +64 44635480 ; E-mail: susan.corbett@vuw.ac.nz_

You have the right to withdraw your child's contribution to the research up until $15 / 11 / 17$, with no questions asked. If you choose to withdraw your child's contribution I will ensure that what your child says and/or creates will not be written down or used in the research.

\section{What next?}

If you consent to your child's participation in this research, please let me know by returning the attached consent form to me. If you have any questions or would like to recive further information about the project, please do not hesitate to contact me by email katia.guiloff@vuwac.nz, or my supervisor Sara Kindon, at the School of Geography, Environment and Earth Sciences at Victoria University by phone, 463 6194, or email sara.kindon@vuw.acnz.

Your child's involvement in this research would be greatly valued.

Thanks for your participation and contribution.

Ngã mihi mahana ki a koe/kōrua mō te tautoko i te kaupapa nei.

Katia Guiloff

C0103, Cotton Building, Kelburn Campus,

Victoria University of Wellington, katia.guiloff@vuw.ac.nz,

Supervisors:

Dr Sara Kindon, Associate Professor, School of Geography, Environment and Earth Sciences sara.kindon@vuw.ac.nz

Dr Hiria McRae, Senior Lecturer, Te Kura Maori, hiria.mcrae@vuw.ac.nz 


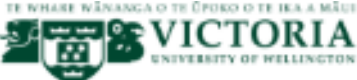

\section{Environmental narratives in the encounter of Maori and Mapuche primary school children}

$\varnothing$

We'd like to participate in an exchange of envir onmental knowled ge with a group of Mapuche Lafkenche children.

I/we have been given understandable information about the exchange and have had the opportunity to ask questions and receive satisfying answers.

I/we understand that the videos produced will only be shared with Katia, her supervisors, the other group of children, their family and teachers.

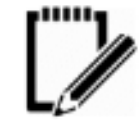

The notes taken by Katia during the workshops may be included in her report, but the children's identities will remain confidential.

I/we understand that I/we may withdraw myself/us from this project any time before the 15 th of November, 2017 without having to give reasons or without penalty of any sort.

\section{Name of student:}

Name of parent/guardian:

Date:

Email:

(If you would like a summary of the findings and any other publications stemming from this research)

Signed:

Facilitator: Katia Guiloff, katia.guiloff@vuwac.nz Supervisors: Dr Sara Kindon, sara.kindon@vuwaac.nz - Dr Hiria McRae, hiria.mcrae@vuwaacnz

If you have any ethical questions or conoerns about this study, contact Prof. Susan Corbett, Convener of the Victoria University of Wellington Human Ethics Committee (telephone: +64 4463 5480; E-mail: susan corbett@vuw.ac.nz 
For teacher/facilitator:

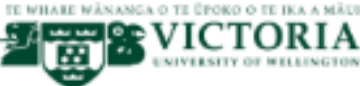

\section{Research Project Title: \\ Environmental narratives in the encounter of Maori and Mapuche primary school children}

\author{
Researcher: \\ Ms Katia Guiloff, Master's in Environmental Studies \\ Supervisors: \\ Dr Sara Kindon, Associate Professor, School of Geography, Environment and Earth Sciences \\ Dr Hiria McRae, Senior Lecturer, Te Kura Maori
}

\section{RESEARCH INFORMATION SHEET: Teachers}

Hi there,

My name is Katia Guiloff, I'm a Master's student in Environmental Studies at Victoria University of Wellington. I'm currently s doing my thesis project in the area of Indigenous Environmental Education, specifically looking at Māori and Mapuche school children's environmental narratives.

The main goal of the project is to create a space for dialogue and reflection between a group of Mapuche Lafkenche children and a group of Mãori children from Te Whanganui Iwi aiming to:

- Generate a stronger connection to the environment from their cultural identity.

- Generate support networks and empathy between two cultures that share some similarities in terms of history and perspectives.

- Give space for the children's voices and thoughts on environmental issues to be heard within their communities and within the wider environmental narratives.

\section{What is involved with the research?}

During this year I will be holding 4-5 workshops in Whanganui and 4-5 in Llaguepulli, in the South of Chile (or Wallmapu, which is the Mapuche name for this territory). During these workshops we will learn to work with 'Digital Storytelling', a form of digital media which allows participants to tell a story using images, videos, voice and/or music. Through these means the children will get the chance to work in groups and tell the other group a bit about themselves and the role they play in the well-being of their Awa. The other group will get to do the same and finally they can send videos to each other in response.

In order to get the images for their stories, children might need to walk around their neighbourhood and take pictures, talk to people and/or use images they already have. In the workshops we will discuss how to do this in a safe, respectful and fun way.

If you choose to take part in the research, it would mean you are $\mathrm{OK}$ with me recording what is said during the workshops. Only I will have access to these recordings and I will not use your name, or your student's or your school's in any of the writing I do about it.

The digital stories the children create will only be shared with their group and the Mapuche group, but, at the end of the project we can all talk together and the participants can decide if they'd like to share this with other people and in what ways. 
I am happy to answer any questions you might have about this research.

If you would like to take part in this project please sign the form below and return it to me.

\section{$\underline{\text { Privacy and confidentiality }}$}

I won't share your real name with anyone else. Instead you can choose, or if you want, I will give you a 'code' name to disguise your identity. You will get a chance to check what I have collected and analysed and have an opportunity to give me some more ideas about the research at this stage. You can choose to pull out of the research at any time up until the end of November 2017 by emailing me at

or calling me at

The information from this research will be used to write up reports that can be read by university students, lecturers and presented at conferences. I will take care that the workshop recordings can't be accessed by other people.

Please feel free to contact me if you have any questions or ideas that you'd like to talk about.

Thanks for your participation and contribution,

Katia Guiloff 


\section{Consent to participation in research: Teachers}

Title of research:

Environmental narratives in the encounter of Maori and Mapuche primary school

children

Researcher:

Ms Katia Guiloff, Master's in Environmental Studies

I agree to participate in this research.

I have been given and understand the information about this research project. I have had an opportunity to ask questions and have them answered to my satisfaction.

I understand that any information I provide will be kept confidential to the researcher, and that no opinions will be attributed to me in any way that will identify me. I understand that my real name will not be used and I will have an opportunity choose a 'code name' or have one allocated to me by the researcher.

I understand that I may withdraw myself (or any information I have provided) from this project by the end of November, 2018 without having to give reasons or without penalty of any sort.

I am happy for Katia to record our conversations during the workshops.

I would like my tape recordings electronically wiped / returned/ (circle one) at the conclusion of the research.

I would like to receive feedback on the findings of this research, yes/ no (circle one).

Name:

Date:

Signed :

Please feel free to contact me with any questions that you may have regarding the research at 


\section{Appendix 2: Information and consent sheets in Spanish}

For parent/guardian and students:

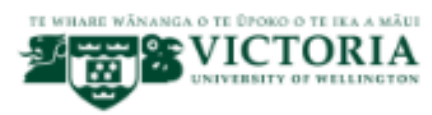

\section{Título del provecto de investigación: Narrativas medioambientales de niños del Lof Llaguepulli}

Investigadora:

Katia Guiloff, Máster en Estudios Medioamb ientales, katia.guiloff@vuw.ac.nz

Supervisoras:

Dr Sara Kindon, Associate Professor, Escuela de Geografia, Medioambiente y Ciencias de la

Tierra, sara.kindon@vuw.ac.nz

Dr Hiria McRae, Senior Lecturer, Te Kura Maori (Departamento de Edu cación Ma orí),

hiria.mcrae@vuwac.nz

HOJA DE INFORMACIÓN ACERCA DEL ESTUDIO: Estudiantes/Apoderados

Hola,

Me llamo Katia Guiloff y estoy cursando un Magíster en Estudios Medioambientales en la Universidad de Victoria en Wellington, Nueva Zelanda. Estoy llevando a cabo una investigación de tesis en el área de educación medioambiental indígena, específicamente investigando las narrativas medioambientales de niños Mapuche Lafkenche del Lof Llaguepulli.

El propósito de este proyecto es generar un espacio de reflexión y diálogo para los niños, para reflexionar acerca de sus relaciones con y dentro del medio ambiente en miras a:

- Fortalecer los lazos con el medioambiente desde su identidad cultural/territorial.

- Generar redes de apoyo y empatía con otras culturas compartiendo perspectivas..

- Crear un espacio para que las voces y pensamiento de estos niños acerca de asuntos medioambientales sean escuchadas dentro de su comunidad y dentro de los discursos globales acerca del medioambiente.

Si así lo deseas, puedes participar en este proyecto lo cual significa explorar tu comunidad y alrededores y conversar con tus amigos/as y familia para crear una historia (con fotos y narración oral) en la cual cuentas un poco acerca del rol que tú juegas en el bienestar del agua en tu comunidad.

\section{¿Qué involucra esta investigación?}

Durante este año estaré haciend o 3-4 talleres en Llaguepulli. En estos talleres aprenderemos a trabajar con 'Narrativas Digitales', una forma de narración digital que permite contar una historia utilizando imágenes, videos, voz y/o música.

Para obtener imágenes y desarrollar tu historia quizás tendrás que caminar un poco por tu comunidad y alrededores sacando fotos, conversando con gente $\mathrm{y} / \mathrm{o}$ utilizando imágenes que ya tengas disponibles. En los talleres conversaremos acrca de cómo hacer estas cosas de una manera segura, respetuosa y entretenid a. 
Las historias digitales que sean creadas en los talleres sólo serán compartidas con tu grupo y, si así lo desean, con otro grupo de niños Maorí en Aotearoa/Nueva Zelanda, pero al final del proyecto podemos conversar en conjunto y ustedes pueden decidir si les gustaría compartirlas con otras personas y de qué forma y bajo qué condiciones.

Estoy disponible para responder a cualquier duda que puedas tener acerca de este proyecto o cualquier idea que quisieras compartir al respecto.

Si te gustaría participar por favor lee y firma el formulario adjunto y me lo entregas. También es necesario que $t u / s$ apoderado/a/s incluyan su firma.

\section{Privacidad y confidencialidad}

No compartiré detalles sobre tu nombre con nadie más al escribir sobre este proyecto. Al final del proyecto tendrás la oportunidad de revisar la información que yo haya colectado y analizado y también me podrás hacer comentarios. Puedes decidir salir del proyecto en cualquier momento hasta el final de Noviembre del 2017 sin necesidad de dar explicaciones, contactándome a mi email: katia.guiloff@vuw.ac.nz o enviándome un texto o llamando al:

La información obtenida de esta investigación será utilizada para escribir informes que pueden ser leídos por estudiantes, profesores y presentados en conferencias. Pero a las grabaciones de los talleres sólo tendré acceso yo.

Esta investigación ha sido evaluada y aprobada por el Comité de Ética Humana de la Universidad de Victoria en Wellington.

Por favor ponte en contacto conmigo si tienes cualquier pregunta o ideas que quisieras conversar.

De antemano muchas gracias por tu participación y contribución,

\section{Katia Guiloff}

Datos de contacto: Katia Guiloff, katia.guiloff@vuwac.nz,

Si tienes preguntas o comentarios acerca de la ética de este proyecto, puedes contactar a la Profesora Susan Corbett, Convener of the Victoria University of Wellington Human Ethics Committee

(fono: +64 4463 5480; E-mail: susan.corbett@vuwaac.nz), 


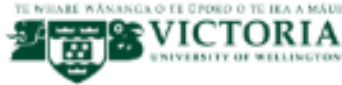

\section{Intercambio de conocimientos medioambientales entre niños Mapuche Lafkenche y Maorí}

\footnotetext{
$\varnothing$

Quisiera participar en este intercambio de conocimientos medioambientales con un grupo de niños Maorí.

랔

Me han dado información comprensible sobre el intercambio y he tenido la oportunidad de hacer preguntas y recibir respuestas satisfactorias.

Entiendo que los videos serán compartidos sólo con Katia, sus profesoras, el otro grupo de niños, su familia y profesor/es.

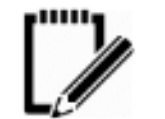

Los apuntes que escriba Katia durante los talleres pueden ser incluídos en su informe.

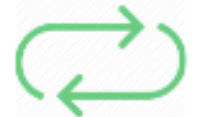

Entien do que el intercambio durará hasta el 15 de noviembre de este añoy si quiero hacer algún cambio me puedo comunicar con Katia.
}

Nombre estudiante:

Doy mi consentimiento para que mi hijo/a o quien está bajo mi cargo, participe en este intercambio.

\section{Firma (apoderado):}

Fecha:

Email u otro medio de contacto:

(Si desea recibir comentarios sobre los resultados de la investigación)

Facilitadora: Katia Guiloff, katia.guiloff@vuwac.nz Profesoras: Dr Sara Kindon, sarakindon@vuw.ac.nz - Dr Hiria McRae, hiria.mcrae@vuw.ac.nz 
For teacher/facilitator:

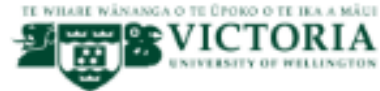

\section{Intercambio de conocimientos medioambientales entre niños Mapuche Lafkenche y Maorí}

\section{¿De qué se trata el intercambio?}

La meta principal es generar un espacio de diálogo y reflexión entre un grupo de niños Mapuche Lafkenche y un grupos de niños Māori de la Iwi (tribu) de Wanganui en miras a:

- Fortalecer los lazos con el medioambiente desde su identidad cultural/territorial.

- Generar redes de apoyo y empatía entre dos culturas que comparten algunas similitudes en su historia y perspectivas.

- Crear un espacio para que las voces y pensamiento de estos niños acerca de asuntos medioambientales sean escuchadas.

\section{¿Qué vamos a hacer?}

Durante el intercambio vamos a hacer 2-3 talleres con los niños en los que ellos crearán Narrativas Digitales contándole a los niños Maorí acerca de cuál es su rol en el bienestar del medioambiente, en especial del Lafken.

Durante estos talleres los niños:

- Aprenderán sobre el grupo de niños Maorí (cultura, historia, geografia).

- Aprenderán cómo hacer una Historia Digital.

- Crearán videos cortos y los enviarán al otro grupo.

- Recibirán los videos del otro grupo.

- Tendrán la oprotunidad de tener un último diálogo a través de Skype.

\section{¿Qué pasa después?}

Los videos serán compartidos solamente con los niños participantes, sus familias, sus profesores. conmigo y con mis supervisoras (Dras. Sara Kindon y Hiria McRae). Los guardaré en mi computadora y en un disco duro protegidos con una clave y también los subiremos a una página web privada protegidos por una contraseña para compartirlos con las personas involucradas.

Es posible que use imágenes de los videos para mostrar en mi tesis, artículos publicados $\mathrm{y} / 0$ presentaciones en conferencias, pero éstas no incluirán rostros ni fondos que puedan identificar a los niños ni sus cursos. La tesis será entregada a la Universidad de Victoria y depositada en su Biblioteca.

\section{¿Qué más necesito saber?}

Si tienes preguntas o quisieras recibir más información no dudes en ponerte en contacto conmigo a través de mi correo electrónico katia.guiloff@vuw.ac.nz, o con mi supervisora Sara Kindon, en Victoria University por telèfono, (+64 4)463 6194, o email sara.kindon@vuw:ac.nz.

De antemano muchas gracias por tu apoyo y contribución. Chageltumai.

\section{Katia Guiloff}

Supervisoras: Dr Sara Kindon,sara.kindon@vuw.ac.nz -Dr Hiria McRae, hiria.mcrae@vuw.ac.nz

Si tiene preguntas o comentarios acerca de la ética de este proyecto, puede contactar a la Profesora Susan Corbett (fono: +64 4463 5480; E-maili susan.corbett@vuw.ac.nz, proyecto \#0000024326), 


\section{Intercambio de conocimientos medioambientales entre niños Mapuche Lafkenche y Maorí}

\section{Formulario de consentimiento}

- Me han dado información comprensible sobre el intercambio y he tenido la oportunid ad de hacer preguntas y recibir respuestas satisfactorias.

- Comprendo que los videos y opiniones serán compartidos sólo con Katia, sus profesoras, el otrogrupo de niños, su familia y profesor/es.

- Entiendo que el intercambio durará hasta el 15 de noviembre de este año y si quiero hacer algún ca mbio me puedo comunicar con Katia.

- Quisiera recibir un resumen de los resulta dos de esta investigación y artículos que puedan ser publicados en relación a ella.

Nombre:

Fecha:

Email:

(Si desea recibir comentarios sobre los resultados de la investigación)

\section{Firma:}


For principal:

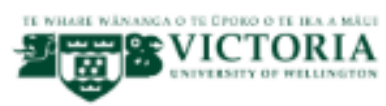

\section{Intercambio de conocimientos medioambientales entre niños Mapuche Lafkenche y Maorí}

\section{¿De qué se trata el intercambio?}

La meta principal es generar un espacio de diálogo y reflexión entre un grupo de niños Mapuche Lafkenche y un grupos de niños Māori de la Iwi (tribu) de Wanganui en miras a:

- Fortalecer los lazos con el medioambiente desde su identidad cultural/territorial.

- Generar redes de apoyo y empatía entre dos culturas que comparten algunas similitudes en su historia y perspectivas.

- Crear un espacio para que las voces y pensamiento de estos niños acerca de asuntos medioambientales sean escuchadas.

\section{¿Qué vamos a hacer?}

Durante el intercambio vamos a hacer 2-3 talleres con los niños en los que ellos crearán Narrativas Digitales contándole a los niños Maorí acerca de cuál es su rol en el bienestar del medioambiente, en especial del Lafken.

Durante estos talleres los niños:

- Aprenderán sobre el grupo de niños Maorí (cultura, historia, geografia).

- Aprenderán cómo hacer una Historia Digital.

- Crearán videos cortos y los enviarán al otro grupo.

- Recibirán los videos del otro grupo.

- Tendrán la oprotunidad de tener un último diálogo a través de Skype.

\section{¿Qué pasa después?}

Los videos serán compartidos solamente con los niños participantes, sus familias, sus profesores, conmigo y con mis supervisoras (Dras. Sara Kindon y Hiria McRae). Los guardaré en mi computadora y en un disco duro protegidos con una clave y también los subiremos a una página web privada protegidos por una contraseña para compartirlos con las personas involucradas.

Es posible que use imágenes de los videos para mostrar en mi tesis, artículos publicados $\mathrm{y} / 0$ presentaciones en conferencias, pero éstas no incluirán rostros ni fondos que puedan identificar a los niños ni sus cursos. La tesis será entregada a la Universidad de Victoria y depositada en su Biblioteca.

\section{¿Qué más necesito saber?}

Si tienes preguntas o quisieras recibir más información no dudes en ponerte en contacto conmigo a través de mi correo electrónico katia.guiloff@vuw.ac.nz, o con mi supervisora Sara Kindon, en Victoria University por telèfono, (+64 4)463 6194, o email sara.kindon@vuw.ac.nz.

De antemano muchas gracias por tu apoyo y contribución. Chageltumai.

Katia Guiloff

Supervisoras: Dr Sara Kindon,sara.kindon@vuw.ac.nz - Dr Hiria McRae, hiria.mcrae@vuw.ac.nz

Si tienes preguntas o comentarios acerca de la ética de este proyecto, puede contactar a la Profesora Susan Corbett (fono: +644463548 ; E-mail: susan.corbett (ivuw.ac.nz, proyecto $¥ 0000024326$ ). 


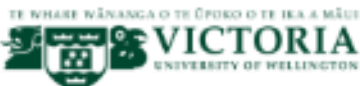

\section{Intercambio de conocimientos medioambientales entre niños Mapuche Lafkenche y Maorí}

\section{Formulario de consentimiento}

- Me han dado informa ción comprensible sobre el intercambio y he tenido la oportunid ad de hacer preguntas y recibir respuestas satisfactorias.

- Compren do que los videos y opiniones serán compartidos sólo con Katia, sus profesoras, el otro grupo de niños, su familia y profesor/es.

- Entiendo que el intercambio durará hasta el 15 de noviembre de este año y si quiero hacer algún cambio me puedo comunicar con Katia.

- Quisiera recibir un resumen de los resulta dos de esta investigación y artículos que puedan ser publicados en rela ción a ella.

Nombre:

Fecha:

Email:

(Si desea recibir comentarios sobre los resultados de la investigación)

Firma:

Facilitadora: Katia Guiloff, katia.guiloff@vuwiac.nz Profesoras; Dr Sara Kindon, sara.kindon@vuwaac.nz - Dr Hiria McRae, hiria.mcrae@vuwac.nz Si tienes preguntas o comentarios acerca de la ética de este proyecto, puedes contactar a la Profesora Susan Corbett, Convener of the Victoria University of Wellington Human Ethics Committee (fono: +64 4463 5480; E-mail: susan.corbett@vuw.ac.nz). 


\title{
Appendix 3: Memorandum from Human Ethics Committee
}

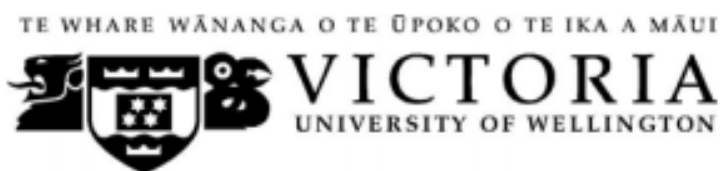

\section{MEMORANDUM}

\author{
Phone $\quad 0-4-4635480$ \\ Email susan.corbett@vuw.ac.nz
}

\begin{tabular}{|c|c|}
\hline TO & Katia Guiloff Titiun \\
\hline COPY TO & A/Prof Sara Kindon, Hiria McRae \\
\hline FROM & AProf Susan Corbett, Convener, Human Ethics Committee \\
\hline DATE & 30 March 2017 \\
\hline PAGES & 1 \\
\hline SUBJECT & $\begin{array}{l}\text { Ethics Approval: } 24326 \\
\text { Environmental narratives in the encounter of Maori and Mapuche } \\
\text { primary school children }\end{array}$ \\
\hline
\end{tabular}

Thank you for your application for ethical approval, which has now been considered by the Standing Committee of the Human Ethics Committee.

Your application has been approved from the above date and this approval continues until 20 February 2018. If your data collection is not completed by this date you should apply to the Human Ethics Committee for an extension to this approval.

Best wishes with the research.

Kind regards

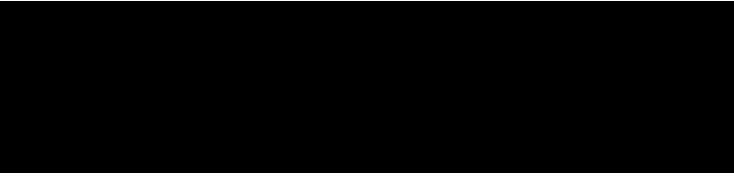

\section{Susan Corbett}

Convener, Victoria University Human Ethics Committee 
Appendix 4: Power points used for presentations

English version, presented to children in Takapuwahiua:

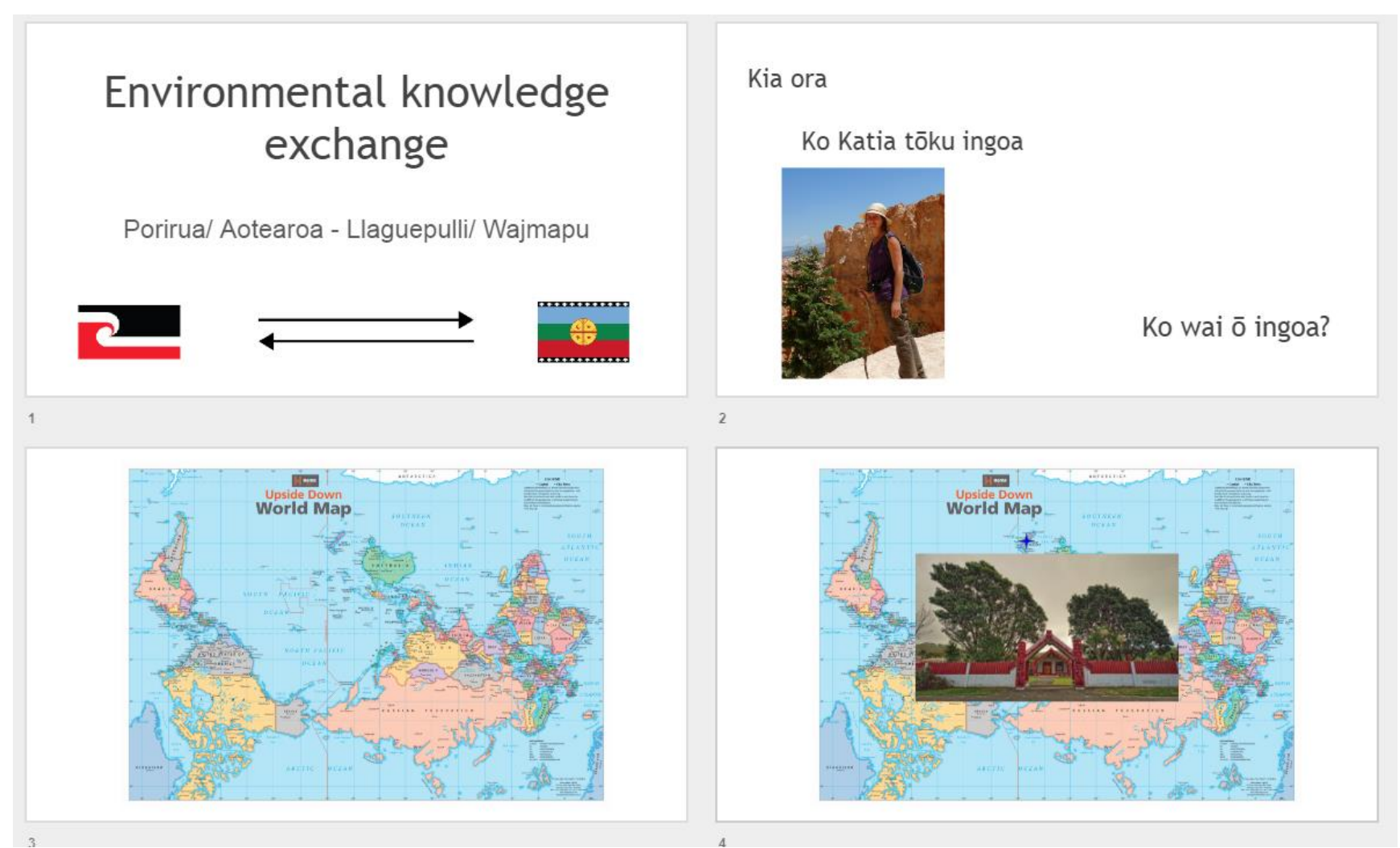



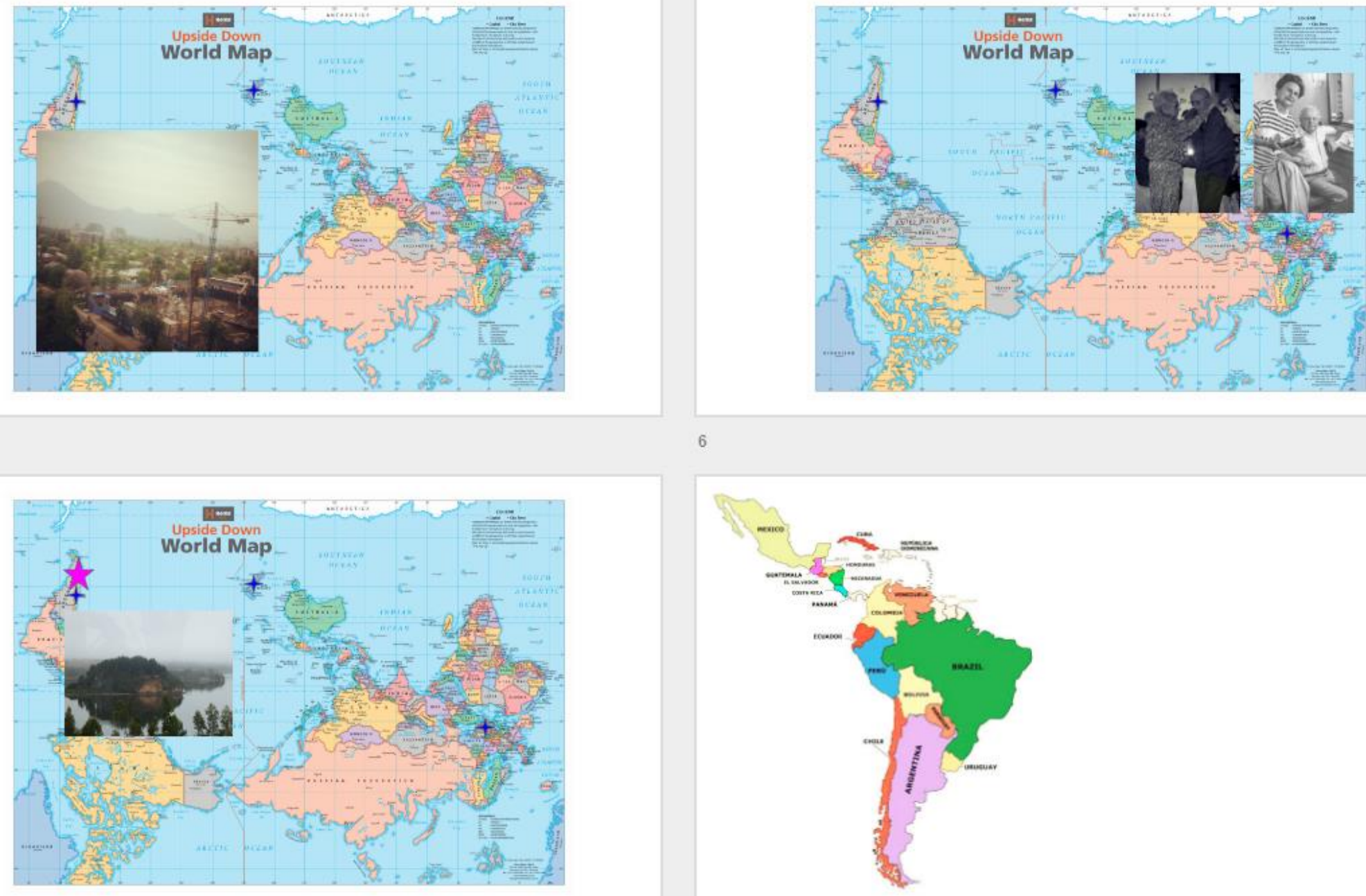

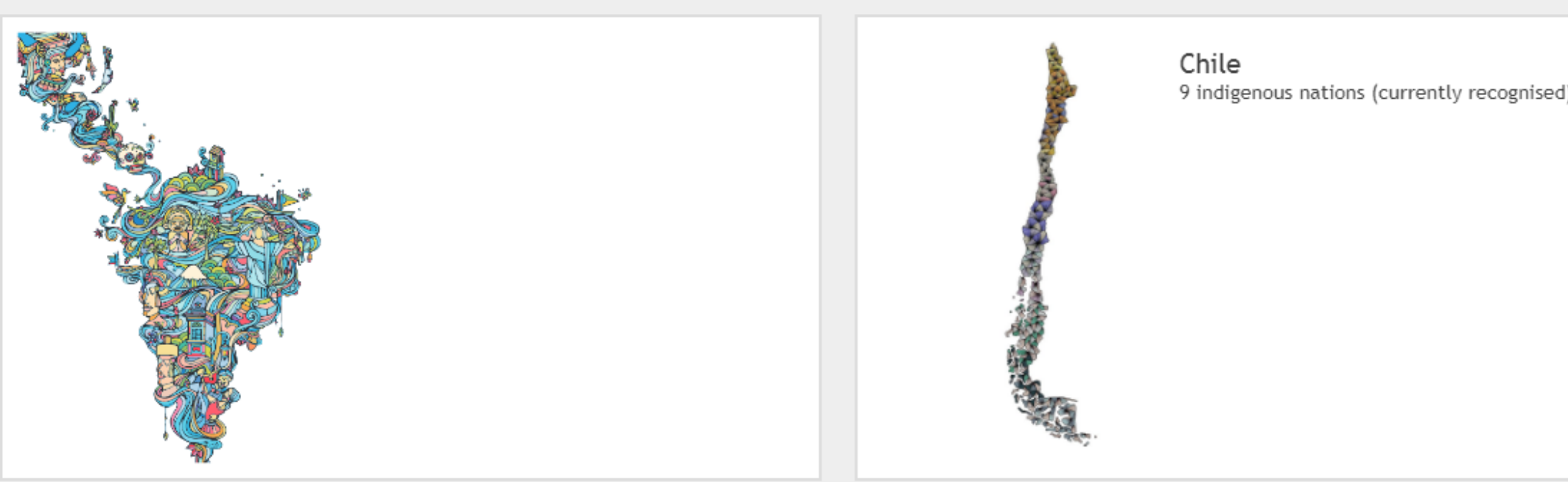

Chile
9 indigenous nations (currently recognised)

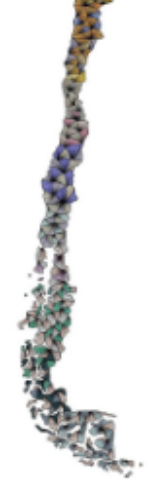

10
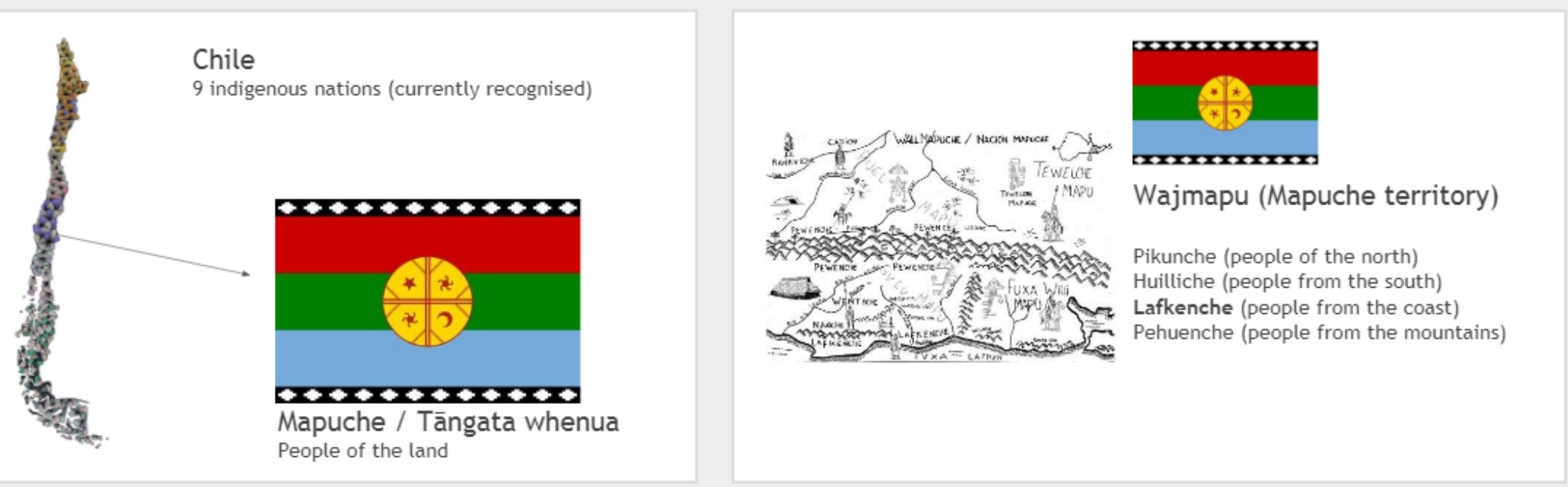


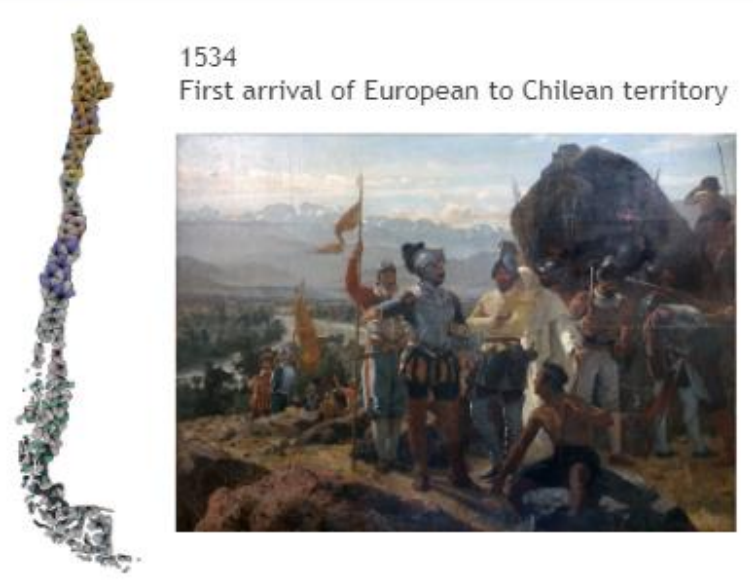

13

Up to 1990 s

Mapuche territory reduced to $6.8 \%$

- Loss of Mapuzugun (Mapuche language)

Education managed by missionaries and teaching European non-Mapuche content
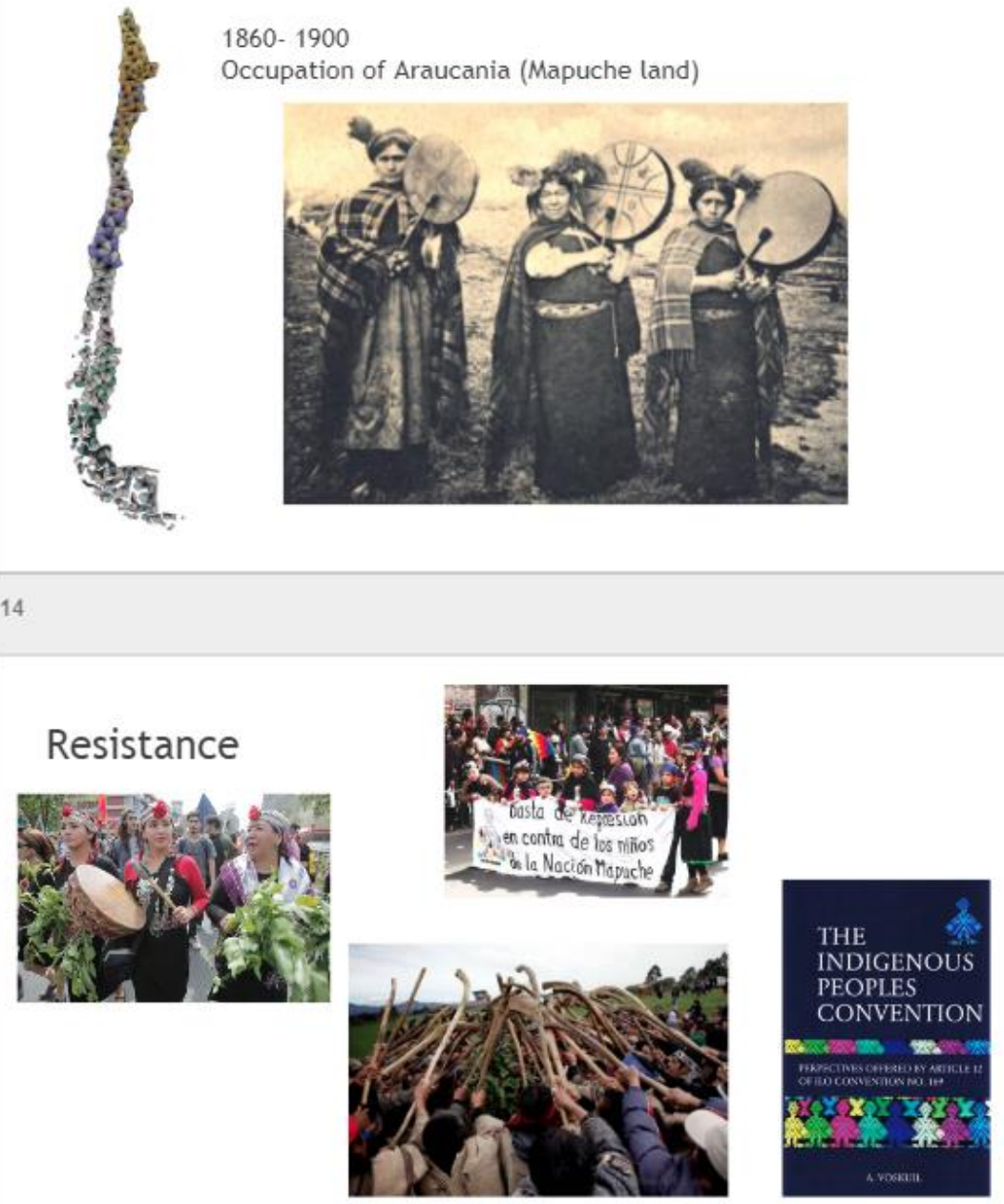

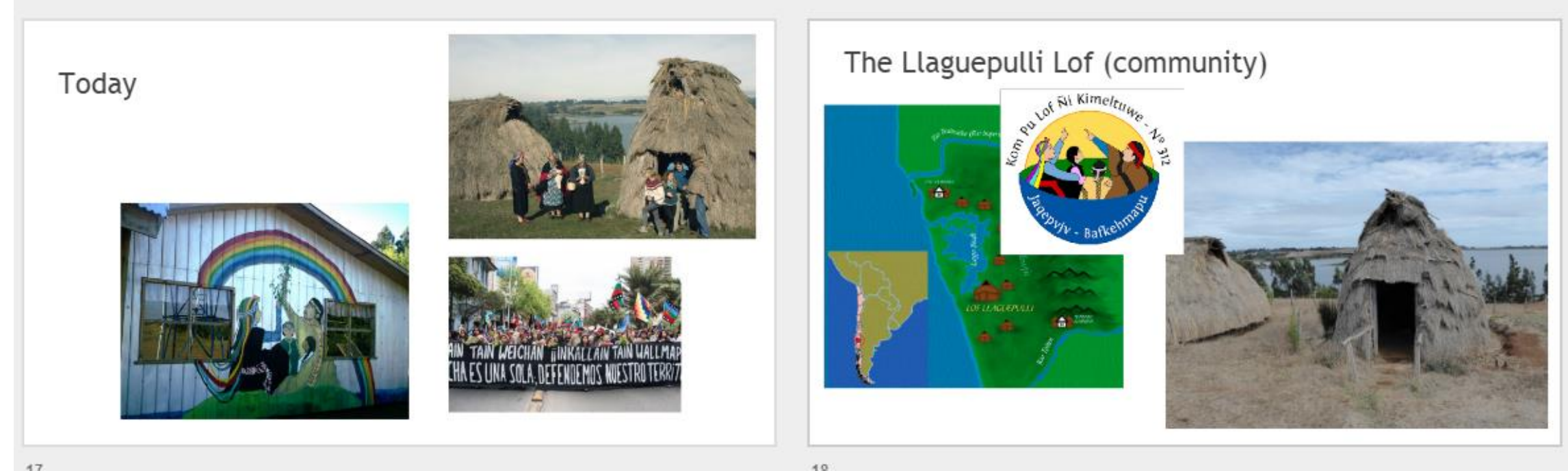

17

18
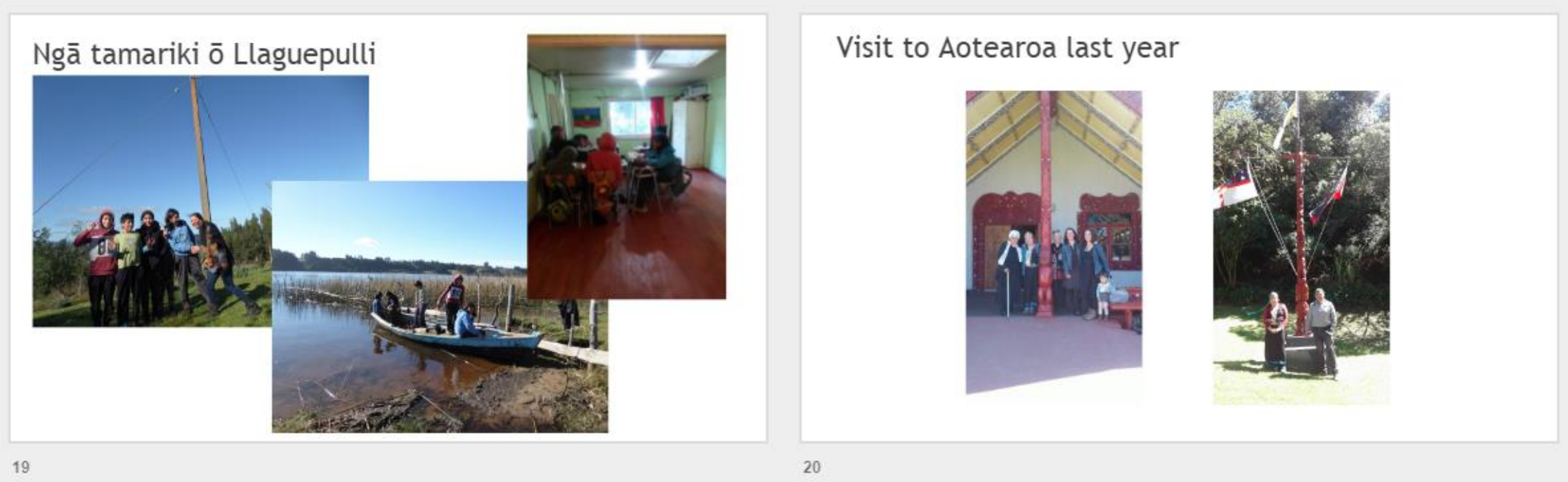


\section{Sharing knowledge}

- A space to reflect about your relationship with the environment.

- A space to get to know and create networks with Mapuche kids

A space for your own thought about these issues to be heard.

21

Some Mapuche environmental concepts:

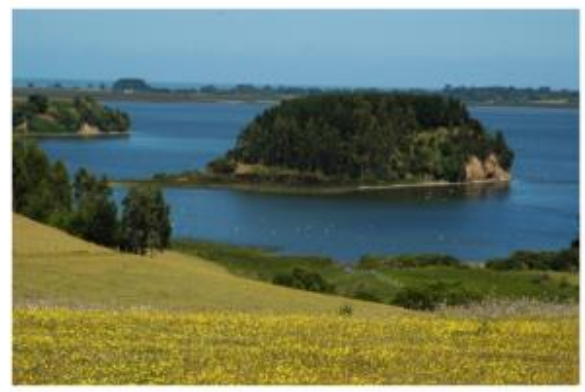

Gen : Spirits (of places)
How will we do it

1. Watch videos the Mapuche tamariki made about their place.

2. Create a digital narrative about your place.

3. Share those videos with the Mapuche tamariki.

22

Some Mapuche environmental concepts:

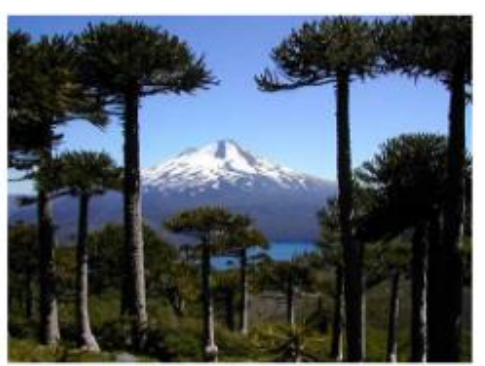

Ixofil Mogen : Many lives 


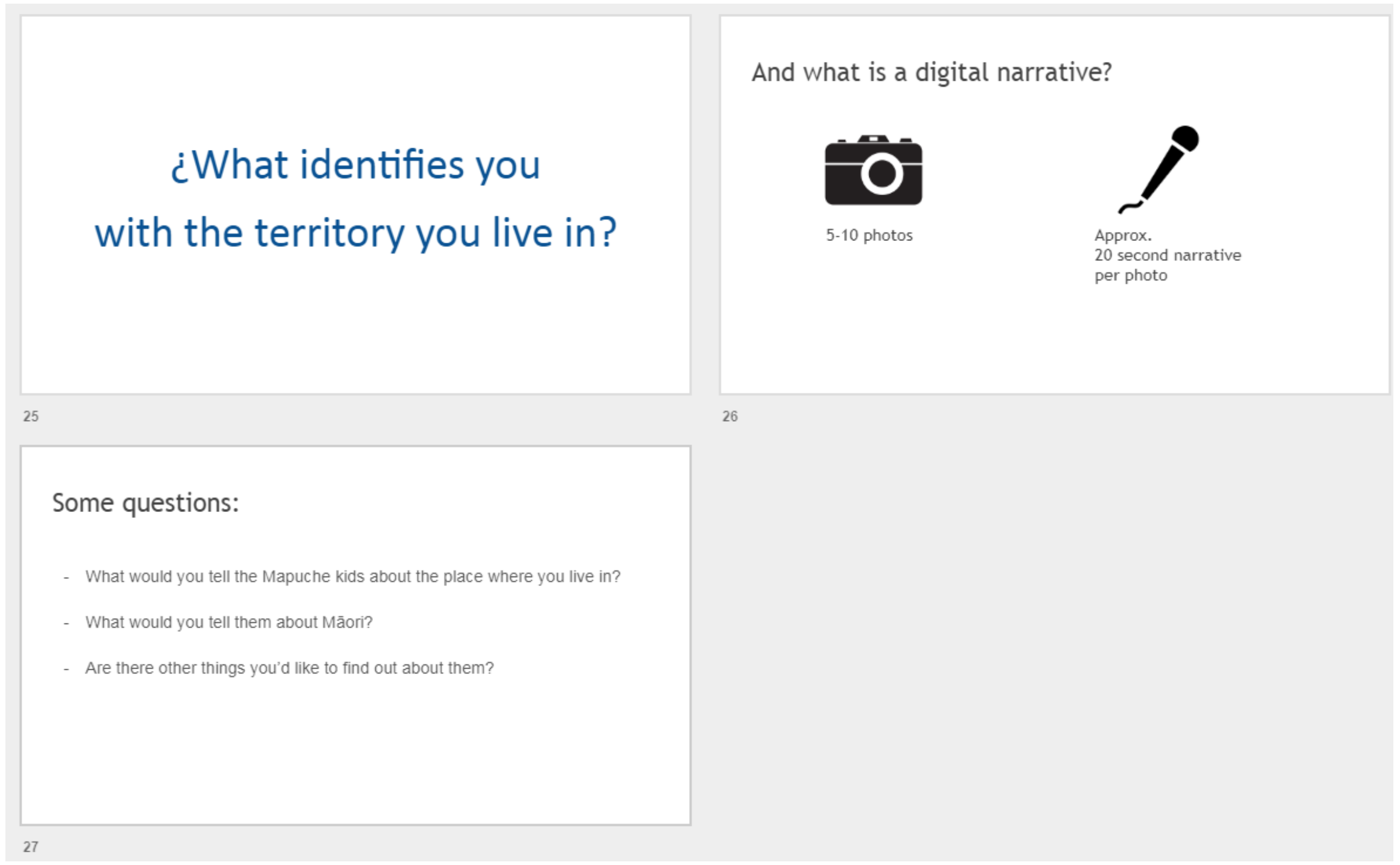


Spanish version, presented to children in Llaguepulli:

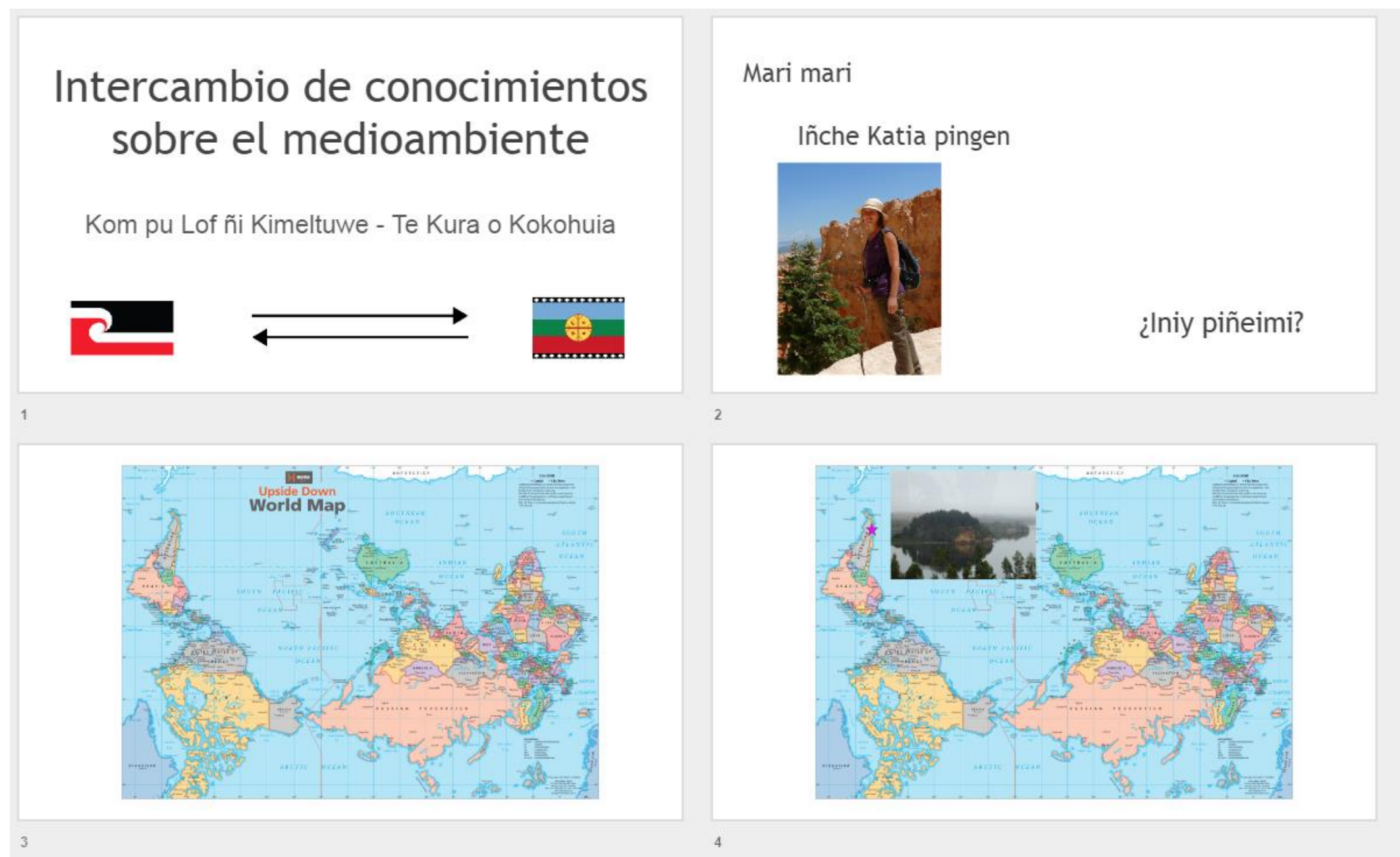




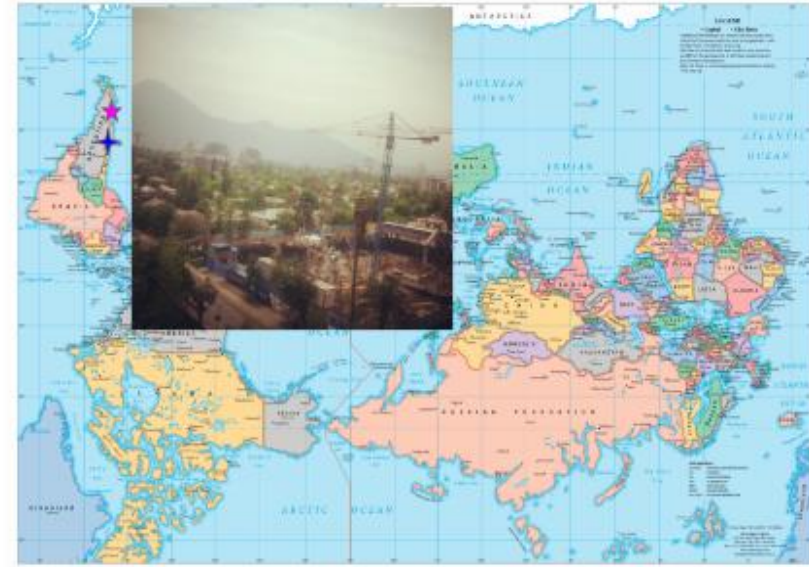

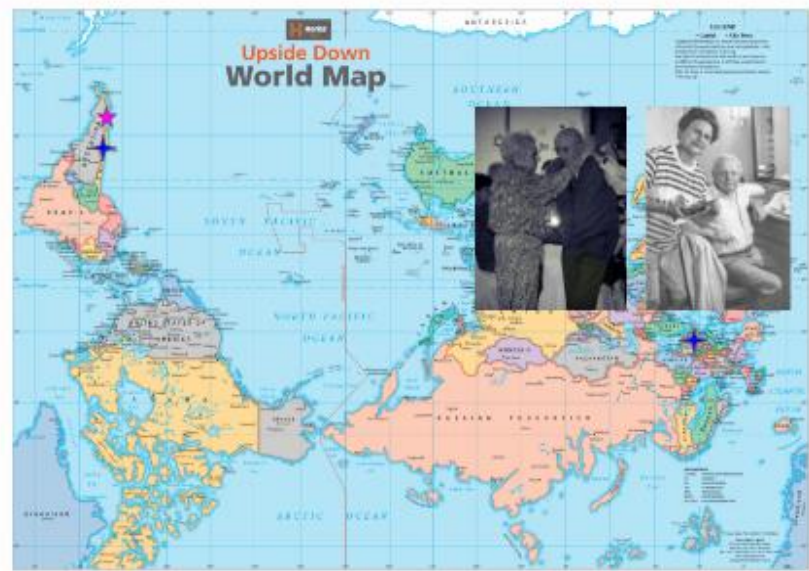

6

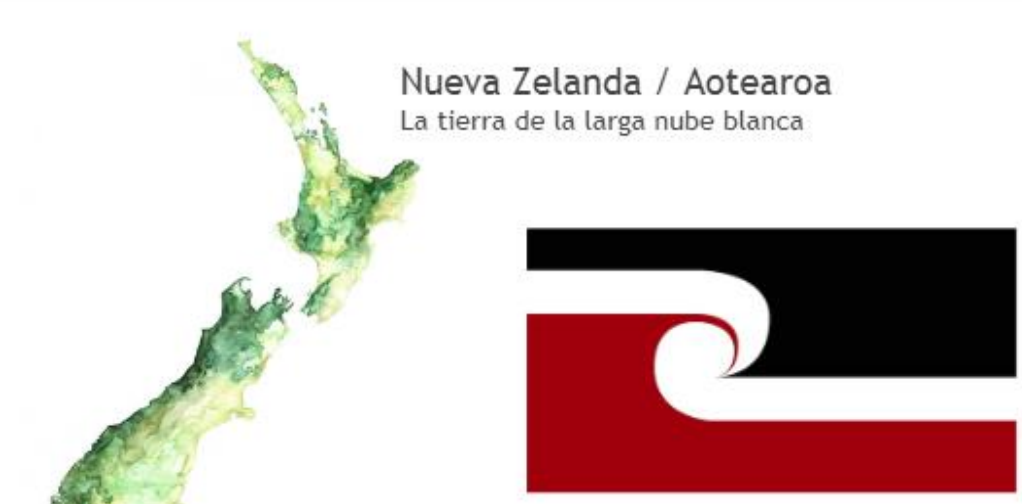

Māori / Tāngata whenua La gente de la tierra 


\section{1) (3es sing and $x$} Año 1200
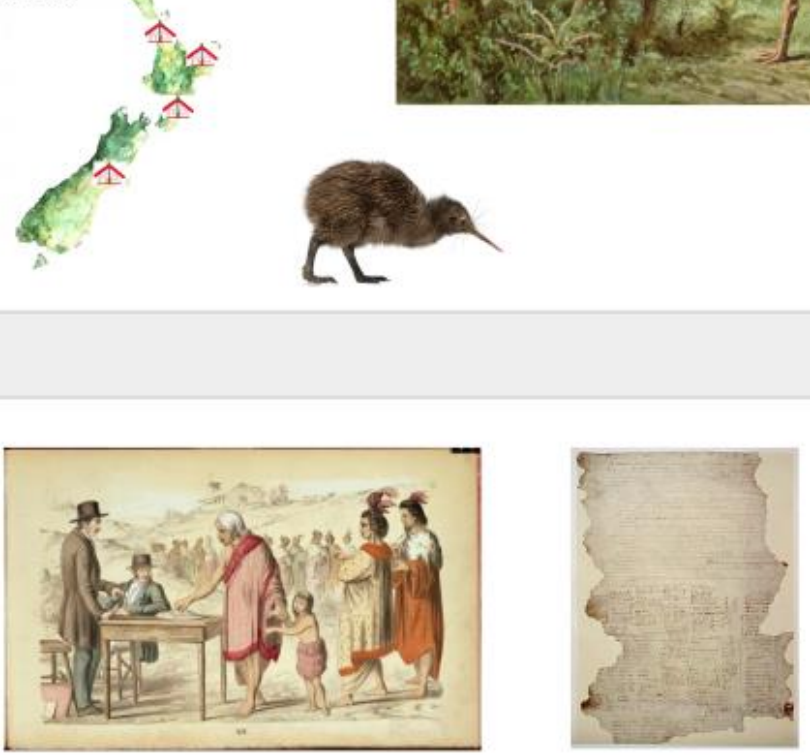

1840: Tratado de Waitangi
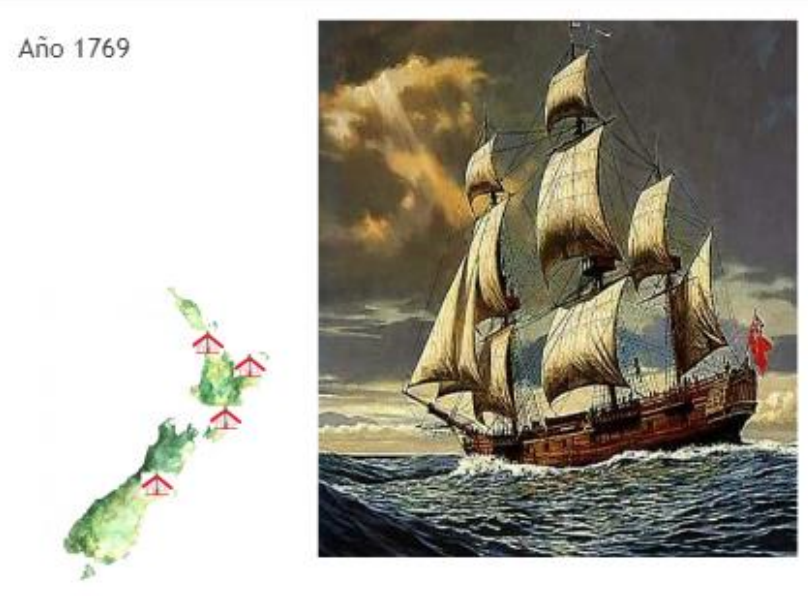

10

\section{Hasta 1960}

- Confiscación de tierras (1.6 millones de hectáreas)

- Pérdida de la lengua Te Reo Maori

- Escuelas y universidades manejadas por misioneros e ingleses
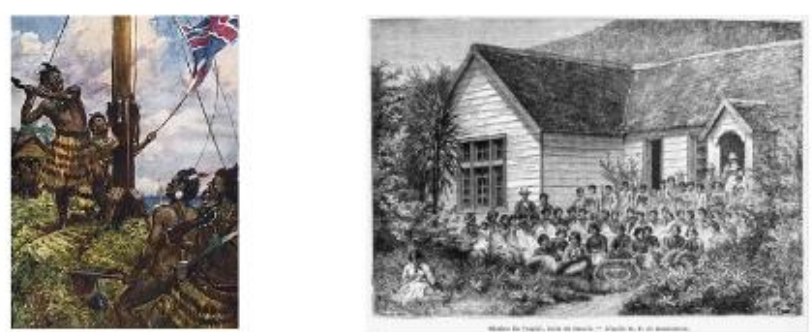
1970s: Proceso de revitalización
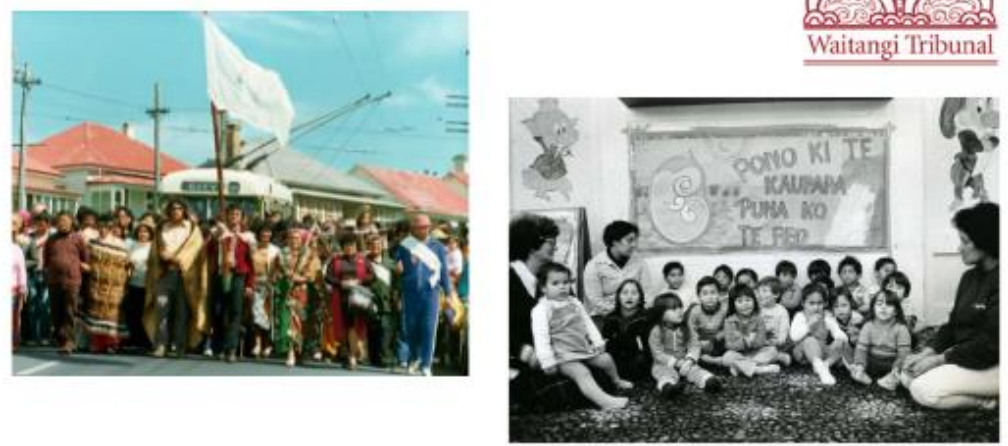

13

El Iwi de Whanganui
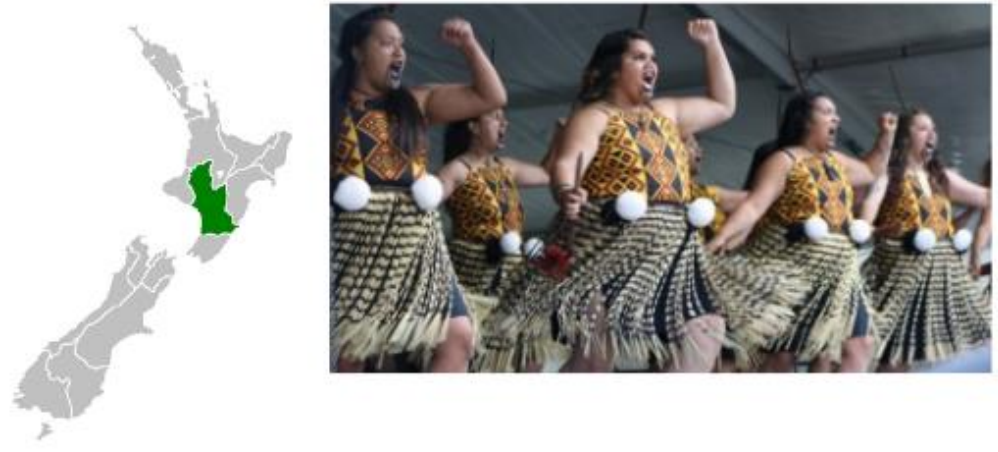

Derechos de la tierra hoy: El río Whanganui

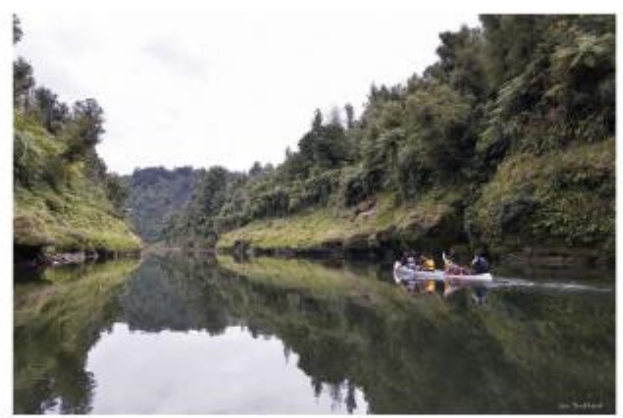

Derechos legales de ser humano - El río es un ancestro
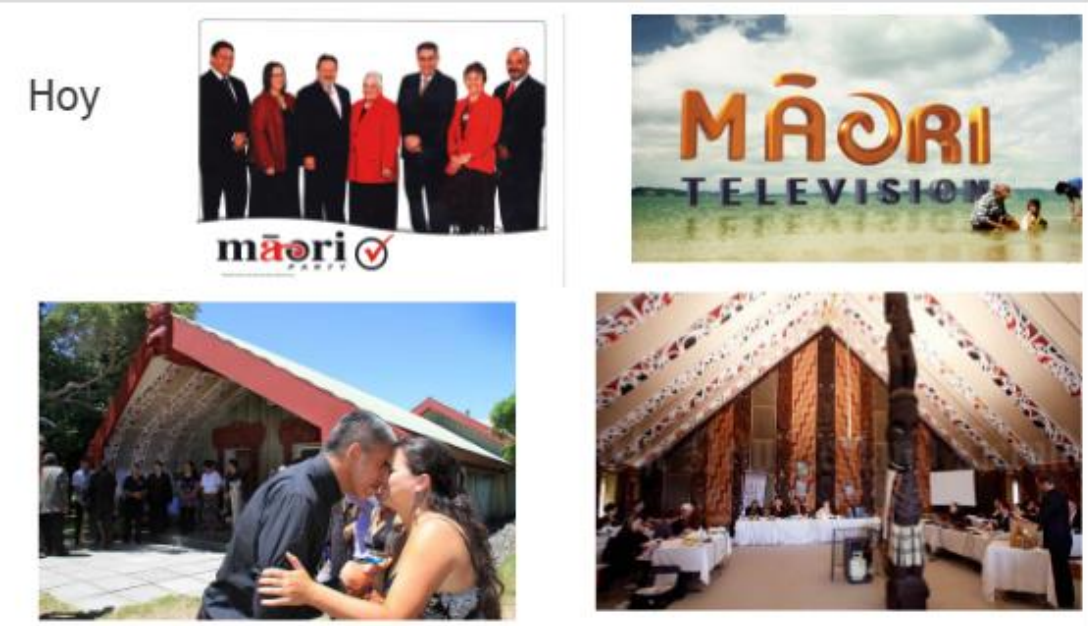


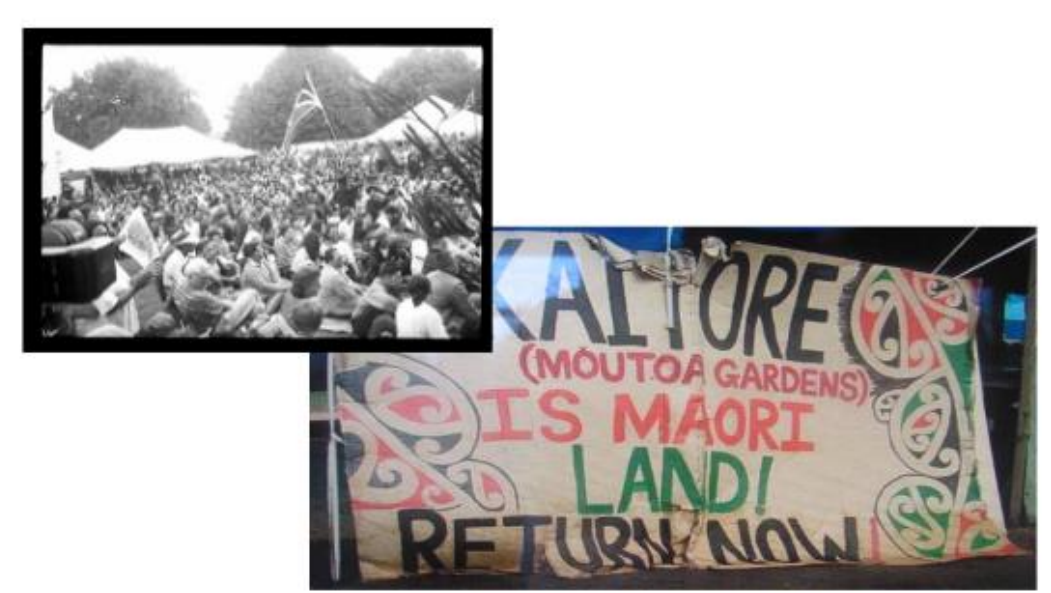

17

\section{Compartiendo conocimientos}

Un espacio para reflexionar acerca de tu relación con el medioambiente, específicamente con el agua.

- Un espacio para conocer y crear lazos con niños Maorí

Un espacio para dar a escuchar sus visiones sobre el medioambiente.
2016

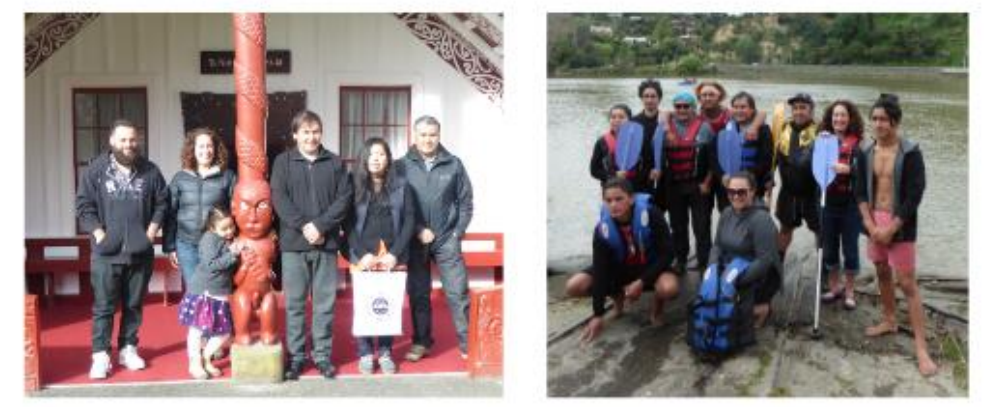

18

Algunos conceptos medioambientales Māori:

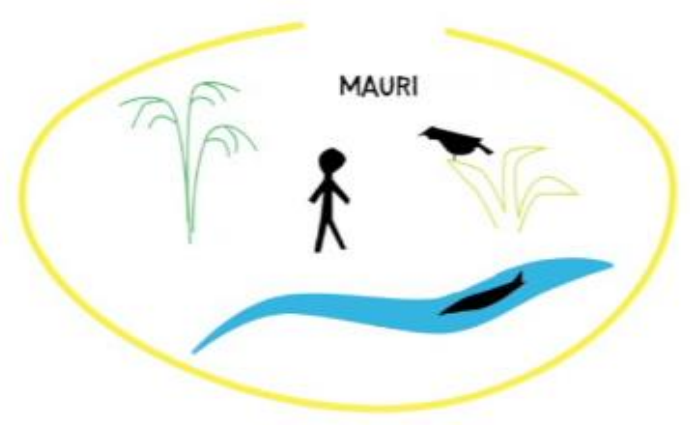


Algunos conceptos medioambientales Māori:

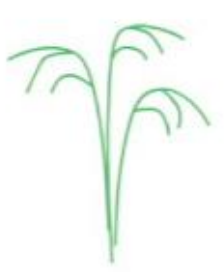

\section{KAITIAKITANGA}
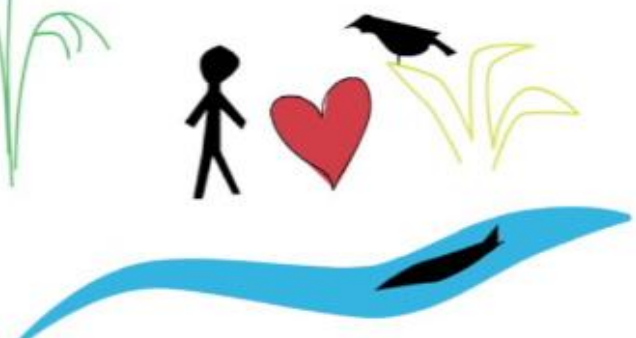

¿Qué te identifica a ti como territorio?
Ko au te awa, ko te awa ko au

Yo soy el río, el río soy yo

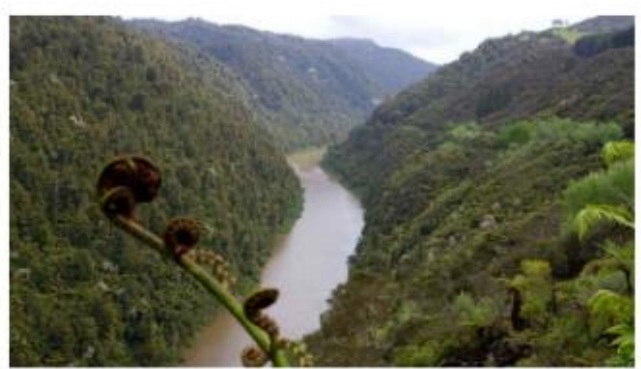

22

¿Cómo lo hacemos?

1

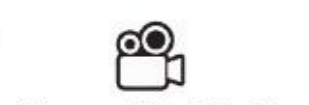

Crear una Historia Digital

2

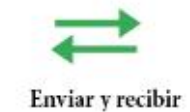

3

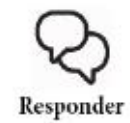


¿Y qué es una Historia Digital?

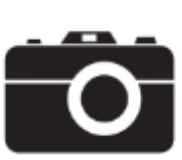

Aprox.

10 fotos

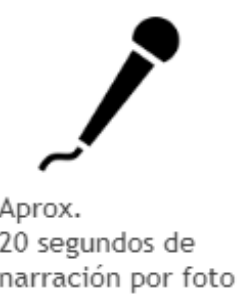

\section{Algunas preguntas:}

- ¿Qué significa para ti y tu comunidad que esté bien?

- ¿Cómo se relaciona este bienestar con tu vida y la de tu comunidad?

- ¿Se relaciona esto con algunos conceptos/prácticas de tu cultura? 
